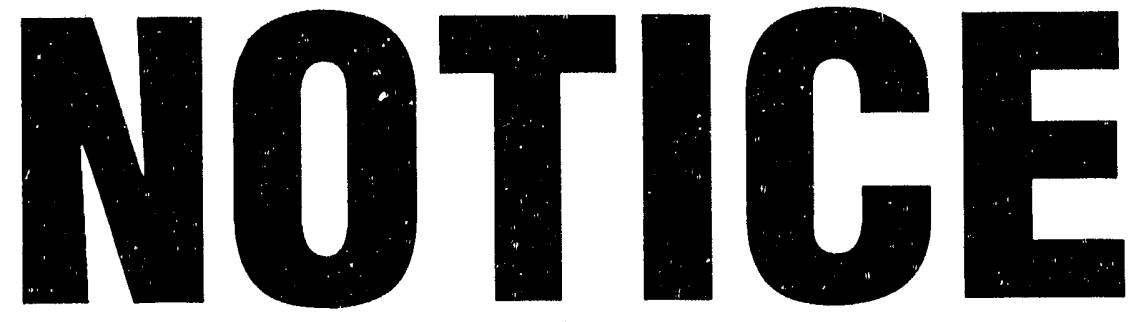

CERTAIN DATA

GONTAINED INTHIS
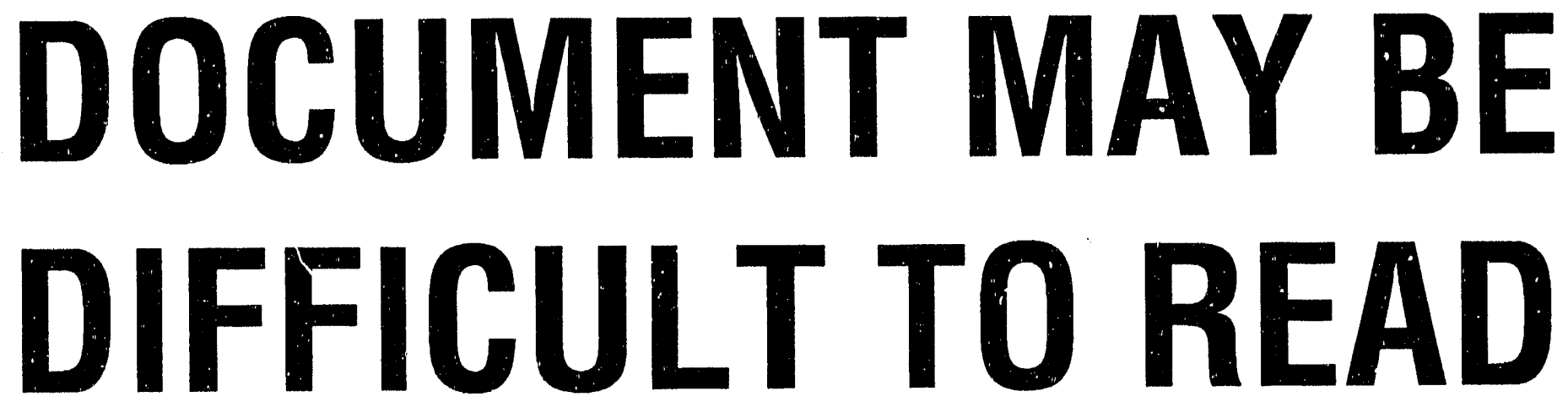

IN MICROFICHE

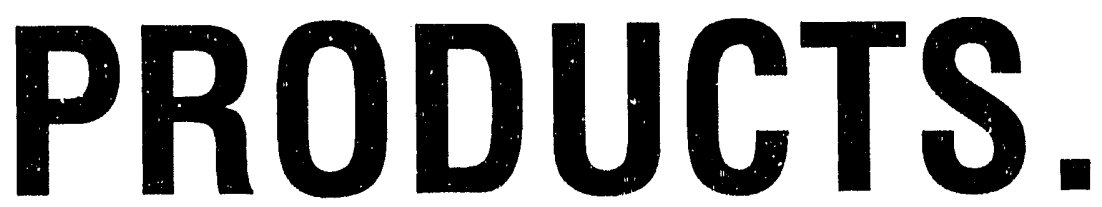


CR-90-1182

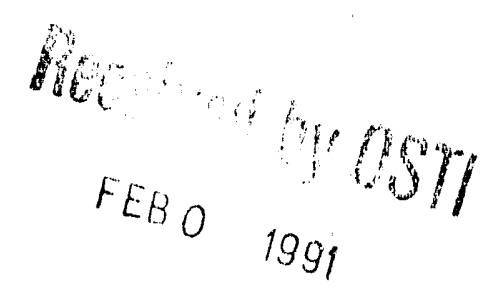

\title{
Impulse Gage Development for the 100-200 Ktap Range
}

Final Report

\author{
by \\ Patrick C. Rose \\ Walter J. Naumann \\ July 31, 1990 \\ Prepared for \\ Lawrence Livermore National Laboratory \\ Livermore, California 94550 \\ Attention: Dr. M. Gerassimenko
}

Contract No. 6659605

ADVANCED TECHNOLOGIES DIVISION

G E N E R A L

RESEA R C H Torporation

P.O. BOX 6770, SANTA BARBARA, CALIFORNIA 93160.6770 
IMST IMMTR

Work performed under the anspices of the l ... Department of lenerg! by lan rence lisermore Nattonal I aboralor) under contract number $11-7405-5.16-48$.

Ihin document was prepared as all account of work spmosored by an age'te? of the I nited states fovermment. Veiflere the I nited States (ioneroment nor the I niscrsity af Califorriba thor all! of their emplonees. make's all! warrant?. eyprese or implied, or asemenes ams legal liability or responvibilits for the accuracy. completencess. or usefulness of alls information. apparalus. product, or process disclosed, or represents that in use would not infringe prisatels owned rights. Reference herein (1) alls specific commerciatl products, process, or sersice by trade name, trademark, manufaleturer. or otherwine, denes not mecessarils constitute ar impls ite endorsement. recommendation, or fatoriong by the I nited

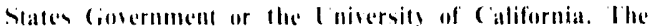

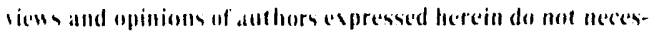
sarily state or reflect these of the I nited states fiosermment or the I niscreis of ( allifornia, and shall not be used lor adertising or product endursement purposes. 


\section{ACKNOWLEDGEMENTS}

The authors wish to thank J. Everson for his competent operation of the GRC gas gun and $N$. Hughes for preparing the final report. 
Special effects underground test (UGT) material response and source diagnostics data require impulse gages that can be used in the 50-150 ktap range and have equilibrated from electrical and mechanical noise sources within $0.001 \mathrm{~s}$. Such gages were designed, analyzed, and tested under this program. One- and two-dimensional stress propagation calculations were performed and predictions were developed for deformation of the gage specimen cup. These predictions were conservative when compared to gas gun test results. The response of the gage will equilibrate within 58 to its final value within $300 \mu s e c$. The impulse delivered to the gages for these tests exceeded 250 ktap. The code and experimental results provides a basis for confidence in the operability of the gage in an actual UGT environment. 
ACKNOWLEDGEMENTS

A

B

C
LISTING OF TFT INPUT FILE THAT MODELED GAS GUN TESTS . . . . . . . . . . . . . . . . A-1 IMPULSE GAGE ENGINEERING DRAWINGS . . . . . . . B-1 MATERIAL CERTIFICATIONS . . . . . . . . . $\mathrm{C}-1$ 
2-1 Carbon break-rod impulse gage for the 100 ktap 
(Continued)

Photograph of assembled impulse gage . . . . . . . 22

Photograph of gas gun impactor (tungsten carbide)

Oscilloscope photograph of LVT coil with impedance test with 100:1 attenuator installed (compare to

3-26 Predicted and measured deformation for $1 / 16$ inch specimen cup wall . . . . . . . . . . . . . 4 43 
2-1 AUTODYN prediction of specimen cup bulge, $1 / 4$ inch wall . . . . . . . . . . . . . . 14

2-2 AUTODYN prediction of specimen cup bulge, $1 / 8$ inch vall . . . . . . . . . . . . . . . . 14 AUTODYN prediction of specimen cup bulge, $1 / 16$ inch wall . . . . . . . . . . . . . . 14 IVT coil electrical calibration (into $1 \mathrm{M} \Omega$ ) . . . . 24

$3-2$ PSPICE simulation inputs for the case of no impedance matching circuit . . . . . . . . . 26

$3-3$ PSPICE simulation inputs for the 100:1 attenuating circuit . . . . . . . . . . . . . . . 31 summary of gas gun tests... . . . . . . . . 36 


\section{SECTION 1}

\section{BACKGROUND}

The testing of special effects nuclear devices requires irstruments to record high stresses and impulses. This report presents work performed for Lawrence Livermore National Laboratory (I,LNL) on the seventh, eighth, and ninth amendments to subcontract 6659605, UGT Instrumentation Development. The LLNL Technical Monitor was Dr. Michel Gerassimenko. General Research Corporation (GRC) has been working with LLNL for the past $\mathbf{s i x}$ years on developing stress and impulse measurement techniques for this application (Refs. 1-3).

The task objectives were co design and test impulse gages suitable for use in special effects UGT experiments. The contract Technical scope of Work (sow) specified:

1. Perform design of gage capable of measuring high impulse (30-150 ktaps) in the available time interval of $1 \mathrm{msec}$.

2. Perform aboveground tests (AGTs) to demonstrate gage operation and survival in the impulse range of interest for scaled stress environments.

3. Perform AGTs to demonstrate readout of the gage in the requisite time interval.

4. Perform calculations to demonstrate the ability to predict the gage failure threshold.

Design of the gage was guided by GRC's experience in several past UGTs. The GRC light gas gun was used for most of the gage test"s. Several one- and two-dimensional computer codes were used to calculate gage response in the gas gun tests and in the UGT environment. 
The remainder of this report describes the gage design and supporting calculations (Section 2) and gage testing (Section 3 ). 


\title{
SECTION 2
}

\section{DESIGN AND CALCULATIONS}

\author{
This section describes the gage design and calculations which are \\ compared to test results.
}

\subsection{INTRODUCTION}

Several impulse gage designs were considered. The first of these is the GRC designed Carbon Break-Rod (CBR) gage which has been used in the 100 ktap range in past UGTs (Refs. 4-8). This gage is shown in Figure 2-1. CBR gages have returned data successfully in past Horizontal Line-Of-site (HLOS) tests. The break- rod design was deenied unacceptable for the present application due to the fragility of the breakrods (it was felt that lowering the gage from the surface to the Vertical Iine-of-Site (VLOS) test environment might damage the breakrods prior to the test). Difficulties were also anticipated in finding a suitable insulator which would withstand the high stresses and prevent shorting of the broken rods.

A Time-Resolved Impulse (TRI) gage has been designed by GRC for use in HLOS tests, as shoinn in Figure 2-2 (Ref. 9). This gage was designed to fill the gap between the longest duration stress gages

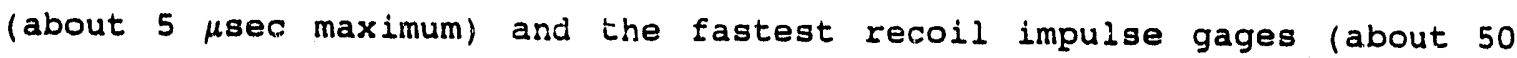
$\mu$ sec minimum). Several TRI gage designs have been fielded in tests from DIABLO HAWK to the recent MINEFAL QUARRY. The TRI gage is unacceptable for the current application because the moving coil and connections, suitable only for lower impulses, would fail at high impulses. Fortunately the fast response of the TRI gage is not required.

The Linear Velocity Transducer (LVT) impulse gage has been used by GRC for HLOS and VLOS tests (Refs. 1, 10, and 11). The MISSION CYBER design is shown in Figure 2-3. This gage was designed for small $11 / 2$ inch diameter) exposure areas. The tube shown at the front of the gage 


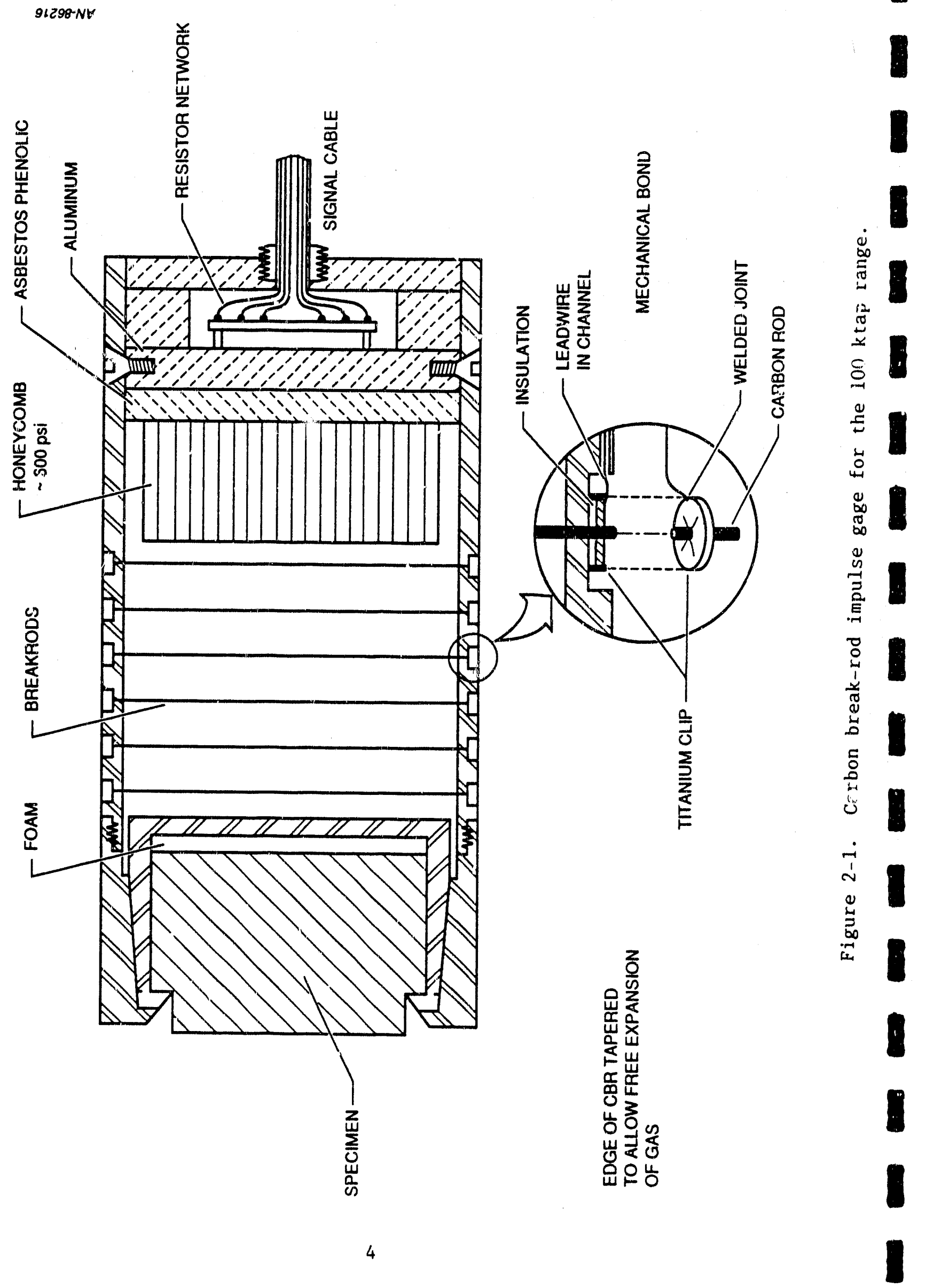




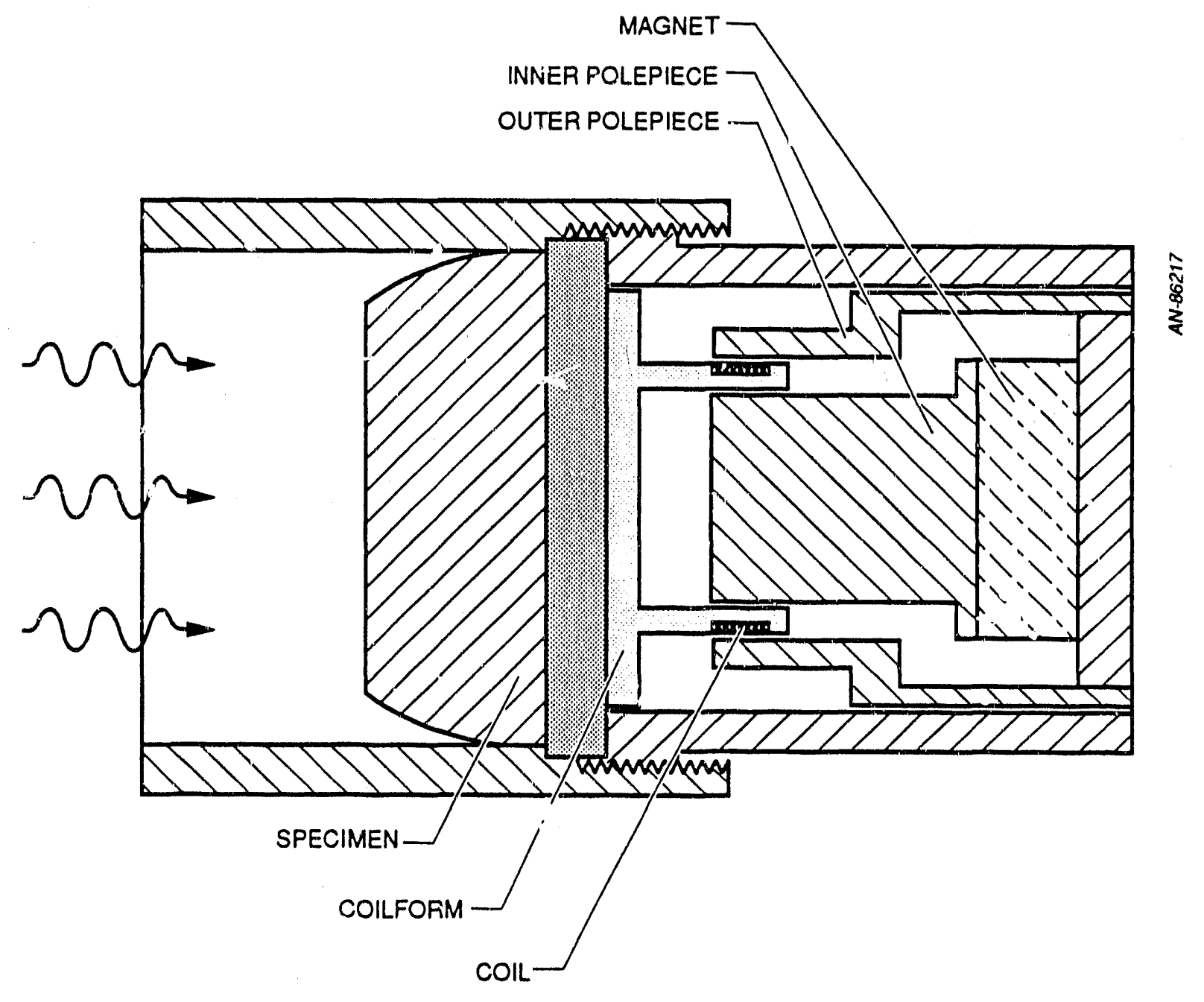

Figure 2-2. Time-resolved impulse (TRI) gage for impulse resolved to 10-15 $\mathrm{\mu sec}$. 

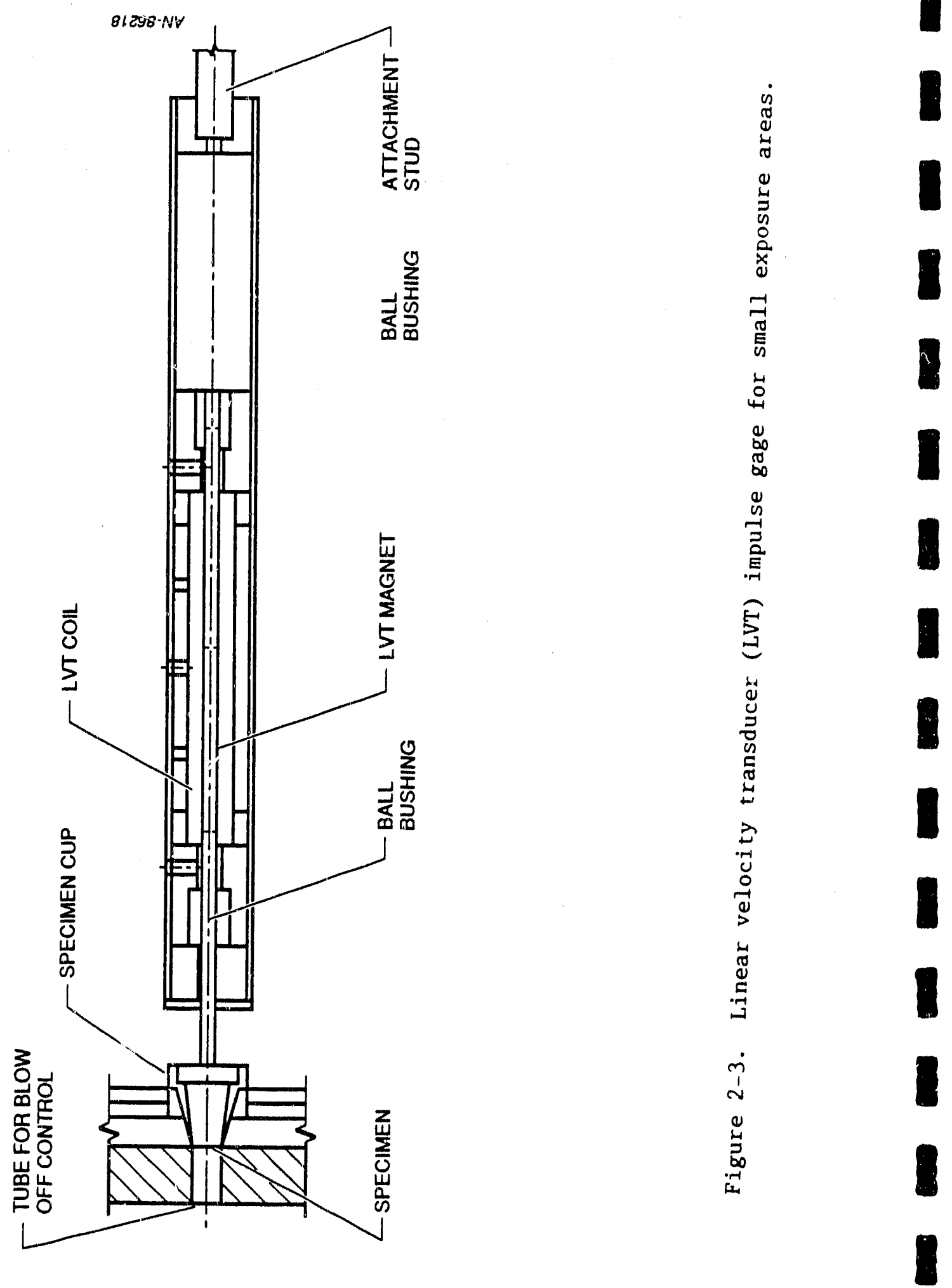
was designed to collimate blowoff material, thus simulating a one-dimensional response. These gages returned data successfully in MISSION CYBER. These tests were intended to verify the performance of the small area impulse gages for future use in a VLOS environment. This experiment showed that for the conditions of the test, drag from the tube can enhance coupling to compensate for losses in coupling due to threedimensional expansion and condensation on the tube walls.

However this compensation could not be verified for the special environments of interest so this design was rejected in favor of larger exposure areas without tubes. The LVT itself, with a different specimen geometry is known by analysis and test (Refs. 9 and 11) to be capable of measuring the required velocities within the allowed one millisecond and was selected as appropriate for the subject gage.

A Make Wire Gage (MWG) design (Ref. 12) frequently used by GRC was unsuitable because its sliding contacts would not operate reliably within the one millisecond time allowed.

\subsection{GAGE DESIGN.}

The proposed design for the present work is shown in Figure 2-4. This gage uses two independent means of recording the velocity of the moving mass.

First, a conventional LVT is housed at the back of the gage. The LVT magnet is housed in a stainless steel shaft which is attached to the back of the specimen cup, as shown in Figure 2-4.

The second means of readout is a new simple technique consisting of four spring-loaded pins which protrude through the Delrin "Switch Block". Each pin has a unique length. As the specimen cup travels backward (or up in a vLOS environnent) it strikes each pin and lifts the pin off its contact, opening an electrical circuit. This design is 

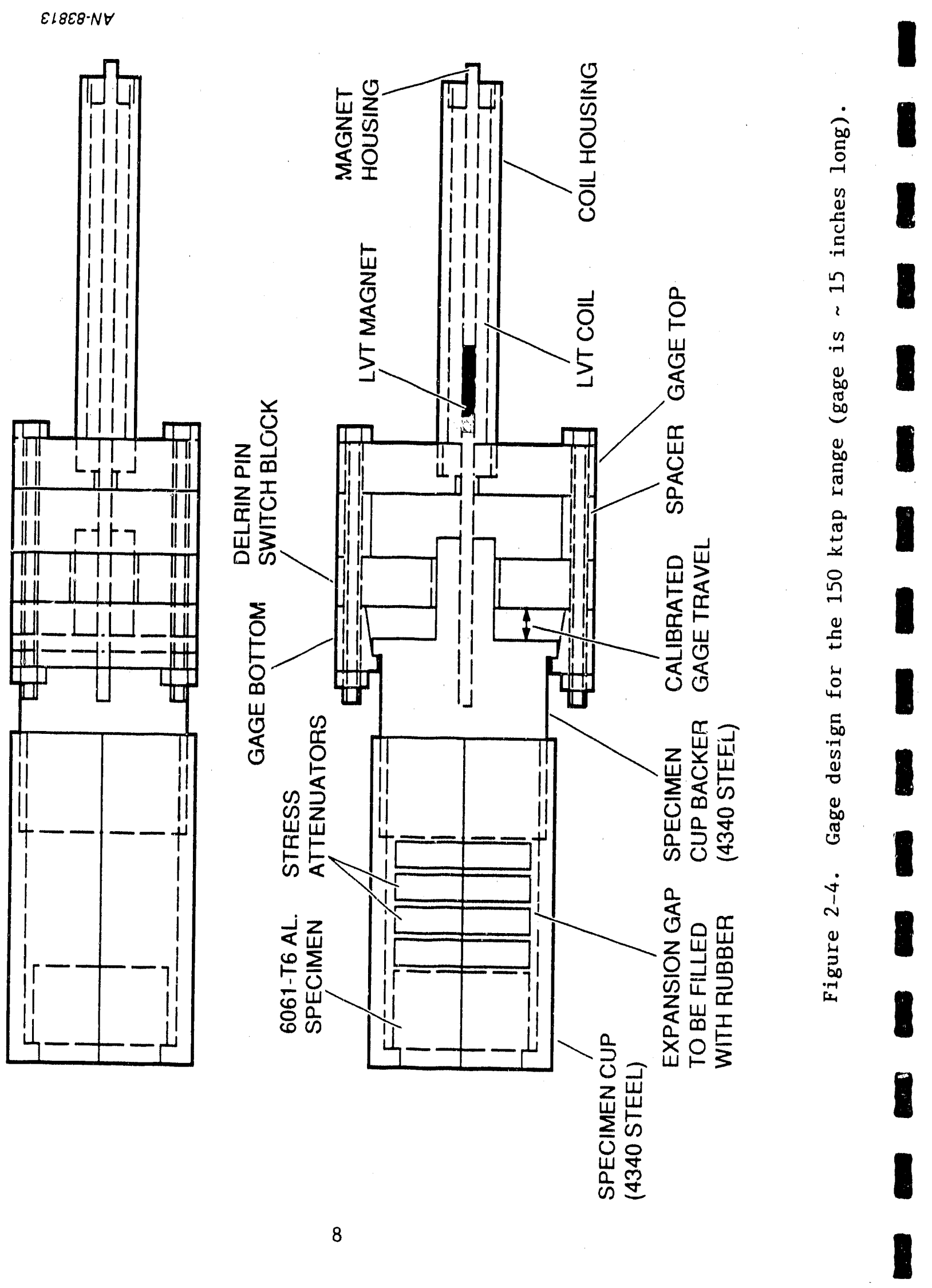
shown in Figure 2-5. The circuit is closed at zero-time since an open circuit at zero-time would experience greater radiation induced noise.

A concern when designing a gage for the present environment is the response of the specimen/specimen cup to the impulse and stress generated by the source. Is is important that the part of the specimen that is not blown off the front surface be retained in the specimen cup, and that all remaining rarts are constrained to move together during the recording time.

The front surface stresses zxpected in the VLOS environment of interest are much higher than the stresses obtainable in gas guns (Ref. 13). While tho stress versus time resulting from the vLos environment of interest cannot be simulated in available simulators, the impulse can be simulated. The initial stresses need not be simulated to verify operation of the gage because of the attenuation of the stresses as they propagate through the gage. As the stress propagates its magnitude decreases and the duration increases to conserve momentum. Initially, the stress and internal energy are such that the specimen material is vaporized, melted or spalled and therefore removed from the gage moving mass. This is part of the impulse generation process and not part of the gage response process. It is completed before impulse is measured and therefore does not need to be simulated to assess response time and integrity of the gage.

However, the stress as the wave travels from the specimen into the gage cup and components is important. The gage components can be allowed to yield but must not fail so that no parts are lost or loose which could result in errors. These stresses at potential failure locations must be simulated to validate gage operation.

The gas gun tests are based on the fact that the stresses from the LOS environment attenuate rapidly and soon cannot be distinguished from 

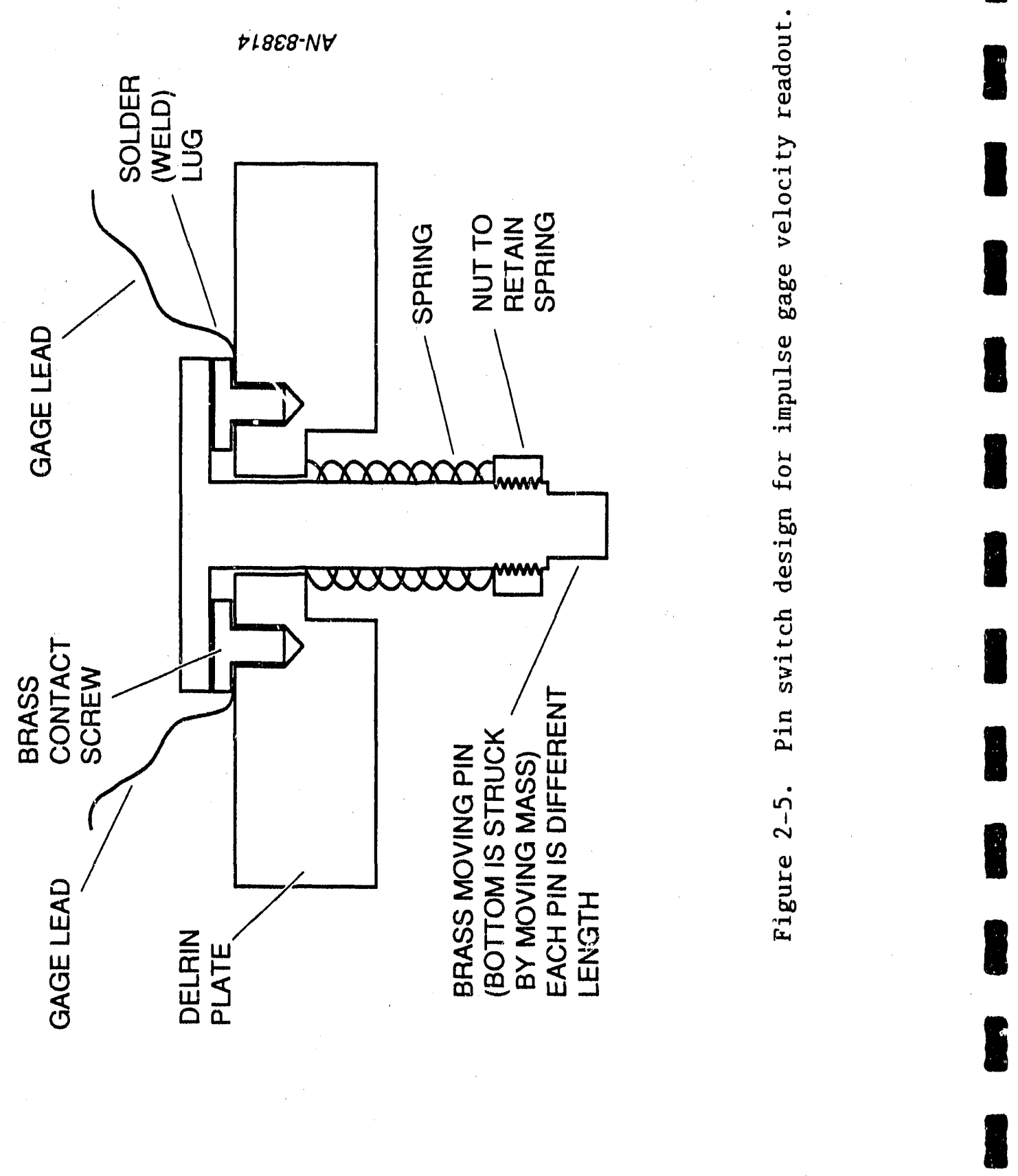
the wave resulting from a lower stress but equal impulse wave resulting from a gas gun impact.

Since the expected stresses over the area of the specimen cup could not be reproduced in an aboveground simulator, it was decided to conduct a series of calculations that would assess the ability of hydrodynamic methods to predict specimen cup response in the GRC 3 inch light gas gun. If the code could predict stress effects in the gas gun, and the same code predicted gage survival in the VLOs environment, then some basis for confidence in the code would exist. This of course assumes that the code and its material models are valid enough in the regime of stress produced by the vLOS source to accurately predict the stresses in the potential gage failure regions. Since, as discussed above, the gage stresses are not sensitive to front surface conditions this assumption is likely valid.

To predict specimen cup response in the GRC gas gun, the onedimensional hydrodynamic code TFT (Ref. 14) was used. TFT was used to calculate the stress generated at the front surface of the specimen due to the impact of a tungsten carbide flyer. The two-dimensional hydrodynamic code AUTODYN (Ref. 15) was used to propagate the stress from the front surface to the rear of the specimen cup. AUTODYN has been used to successfully predict the results of armor/anti-armor studies (Ref. 16) involving 4340 steel, the alloy used in the subject gage.

AUTODYN was also used to predict performance of the specimen cup in the UGT VLOS environment. The HYPUF code (Refs. 17 and 18) was used to provide initial front surface stress-time histories which were input to AUTODYN. The code predicted survival of a specimen cup with a $1 / 4$ inch thick wall.

Figure 2-6 shows the UGT prediction for a generic, hypothetical source at a depth of $5.6 \mathrm{~cm}$ into aluminum. Also plotted is the front 

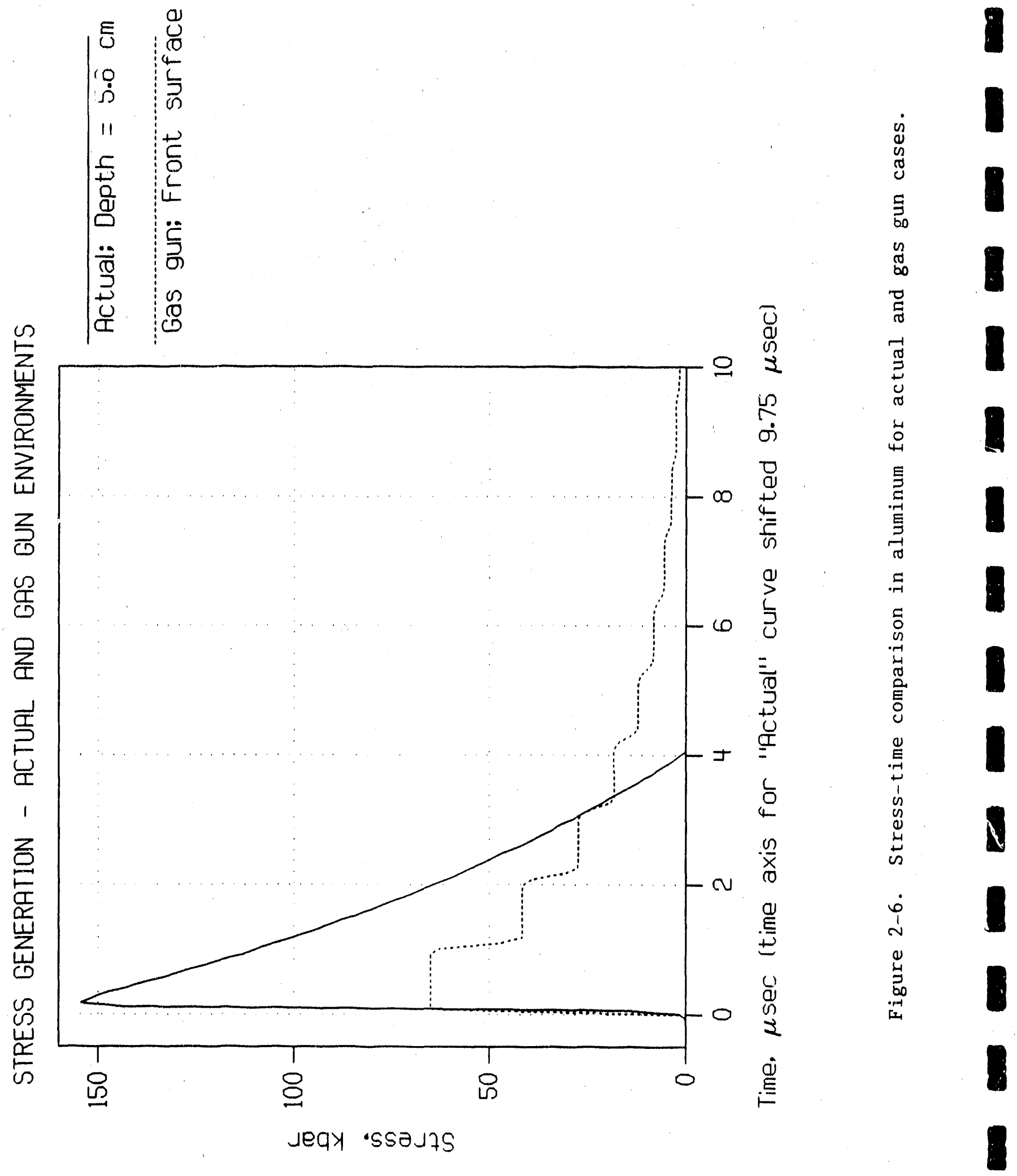
surface sêress generated by a 0.112 inch thick tungsten carbide flyer plate. Both cases generated an impulse of 200 ktap. This is the closest simulation achievable with the GRC gas gun and agreement will improve as the waves propagate into the gage. It is evident that near the front of the specimen cup the gas gun can generate stresses significantly over the yield strength of 4340 steel (10 kbar or 145,000 psi) and therefore can exercise potential failure mechanisms.

The TFT input file used to generate the "Gas Gun" curve of Figure 2-6 is listed in Appendix $A$.

The amount of deformation as a function of location as predicted by AUTODYN was tabulated and compared with the gas g'un test results. The thickness of the specimen cup was varied from $1 / 4$ inch to $1 / 16$ inch, both in the code predictions and the tests. This was done to provide correlation between code and experiment over a range of deformations. The tungsten carbide flyer was sized to impact only the Aluminum-1100F specimen and not the surrounding steel (alloy 4340-NT) specimen cup. Tables 2-1 through 2-3 contain the AUTODYN predictions of specimen cup bulge which are plotted in Figure 2-7 and with results in section 3 of this report.

Figure 2-8 is the AUTODYN prediction of the hypothetical UGT response. It shows the specimen cup intact well beyond the read time of the gage. 
Table 2-1. AUTODYN prediction of specimen cup bulge, $1 / 4$ inch wall.

\begin{tabular}{|c|c|}
\hline $\begin{array}{c}\text { Location from front } \\
\text { of cup, inches }\end{array}$ & $\begin{array}{c}\text { sideways displacement } \\
\text { of cup wall, inches }\end{array}$ \\
\hline 0.003 & 0.090 \\
0.243 & 0.072 \\
0.420 & 0.072 \\
1.493 & 0.031 \\
2.005 & 0.014 \\
2.404 & 0.005 \\
\hline
\end{tabular}

Table 2-2. AUTODYN prediction of specimen cup bulge, $1 / 8$ inch wall.

\begin{tabular}{|c|c|}
\hline $\begin{array}{c}\text { Location from front } \\
\text { of cup, inches }\end{array}$ & $\begin{array}{c}\text { Sideways displacement } \\
\text { of cup wall, inches }\end{array}$ \\
\hline 0.007 & 0.139 \\
0.240 & 0.118 \\
0.456 & 0.128 \\
1.711 & 0.024 \\
2.693 & 0.003 \\
\hline
\end{tabular}

Table 2-3. AUTODYN prediction of specimen cup bulge, $1 / 16$ inch wall.

\begin{tabular}{|c|c|}
\hline $\begin{array}{c}\text { Location from front } \\
\text { of cup, inches }\end{array}$ & $\begin{array}{c}\text { sideways displacement } \\
\text { of cup wall, inches }\end{array}$ \\
\hline 0.207 & 0.139 \\
0.447 & 0.189 \\
0.670 & 0.160 \\
0.776 & 0.145 \\
1.557 & 0.045 \\
2.660 & 0.005 \\
\hline
\end{tabular}




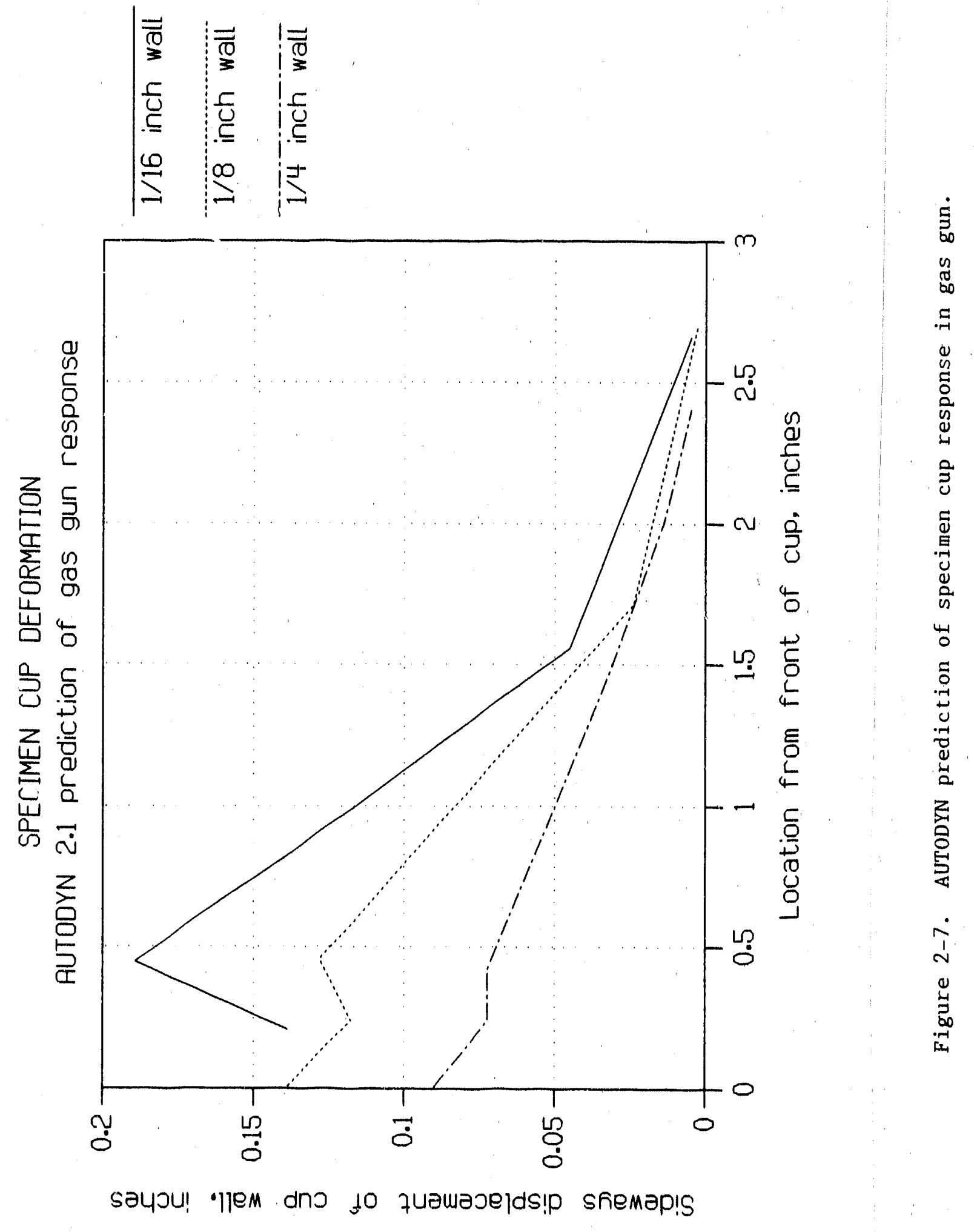


CYCLE 730

TIME 2.333E +01

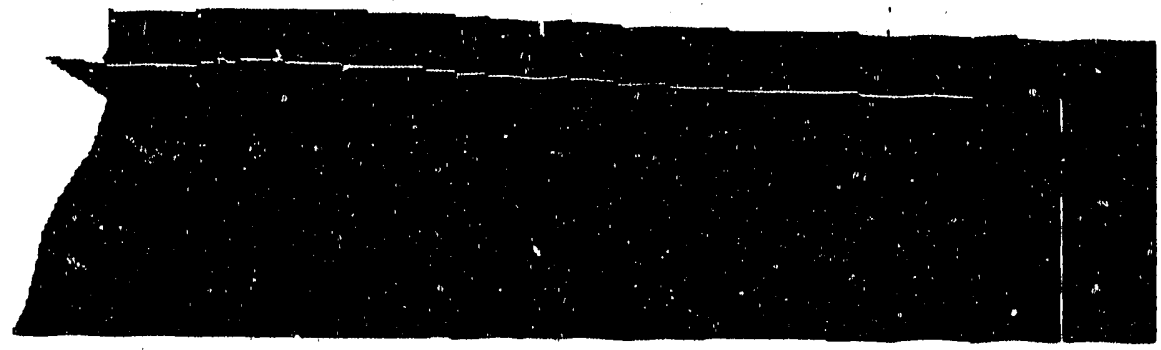

CYCLE 730

TIME 2.333E +01

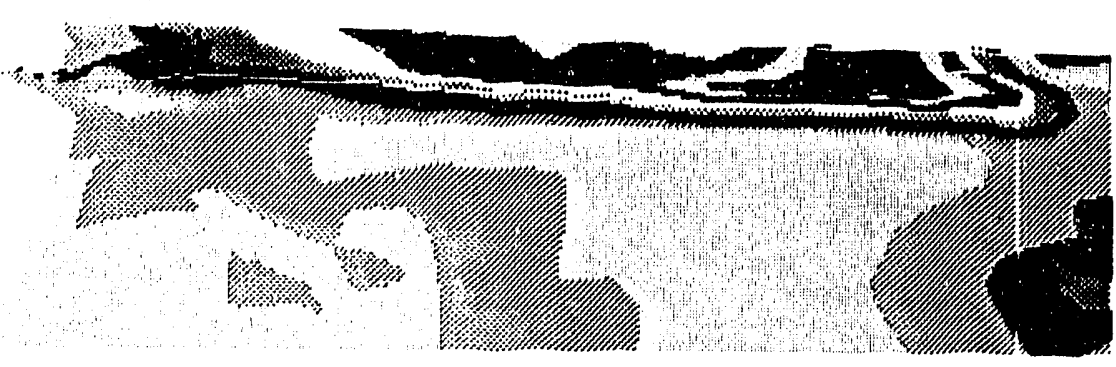

MATERIAL STATUS

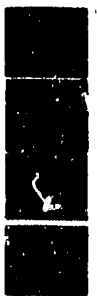

HYDAO

ELASTIC

PLASTIC

FAILED

\section{STRESS}

(MBAR)

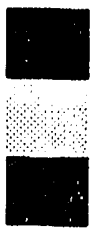

$7.20 E-03$

$6.00 E-03$

4.80E-03

$3.60 E-13$

$2.40 E-03$

$1.20 E-03$

$0.00 E+00$

$-1.20 E-03$

$-2.40 E-03$

$-3.60 E-03$

Figure 2-8. Material status and stress for the hypothetical UG' case at $23.33 \mathrm{msec}$. 


\section{SECTION 3}

TESTING

The gage shown in Figure 2-4 was fabricated from the drawings contained in Appendix B. The impactor and sabot used in the gas gun tests are shown in drawings 98750-2-3 through 98750-2-6. Photographs of gage parts and the assembled gage are shown in Figures 3-1 through 3-10. Photographs of the gas gun impactor and sabot are shown in Figures 3-11 and $3-12$.

To assure reproducibility of the test results it was necessary to control the materials used in fabricating the specimens (aluminum 1100F) and the specimen cups (4340 steel) except as noted in section 3.4 . Appendix $C$ contains certifications for these materials. The alumirium was analyzed to verify the 1100 alloy; the report of the test laboratory is included in Appendix C. The 4340 steel was specified in terms of MIL-S-5000E to be supplied in condition E-3. This specification is also included in Appendix $C$.

\subsection{IVI COIL CALIBRATION.}

Prior to assembly of the gages, the LVT coils were calibrated in terms of electrical output at a given magnet velocity. The LVT coils used for these gages were Trans-Tek (Ref. 19) model 0111-0000 with magnet model M000-0000. These were undersized magnets for the 0111-0000 coils and were enclosed in a stainless steel tube (see Figure 3-7). The magnets were enclosed to provide a strong and straight attachment of the magnet to the specimen cup. The results of the LVT coil calibrations are given in Table 3-1. It has been shown that up to magnet velocities of $3000 \mathrm{~cm} / \mathrm{sec}$, LVT coil output is linear with magnet velocity (Reference 11 page 30). The calibrations reported here uscd magnet velocities of approximately $100 \mathrm{~cm} / \mathrm{sec}$ and gage velocity during use is on the order of $1000 \mathrm{~cm} / \mathrm{sec}$. Coil number 24940-3-1 was purchased from a different lot than the other coils, which may explain its reduced sensitivity. 


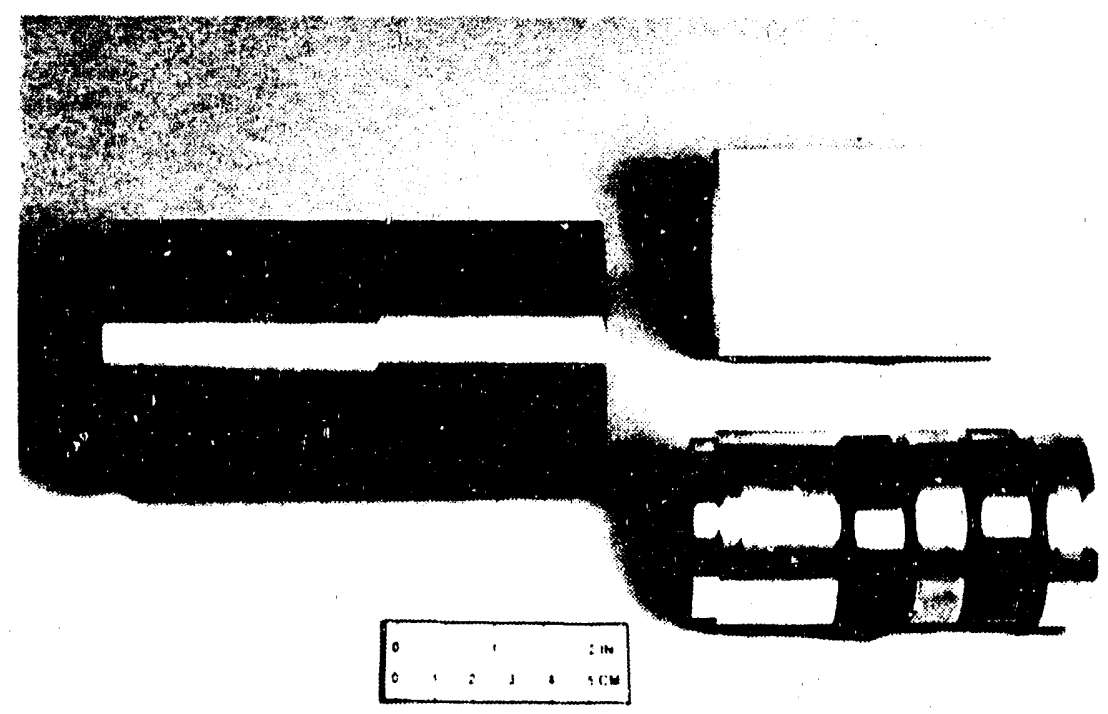

Figure 3-1. Photograph of impulse gage specimen cup showing specimen backers and teflon expansion ring.

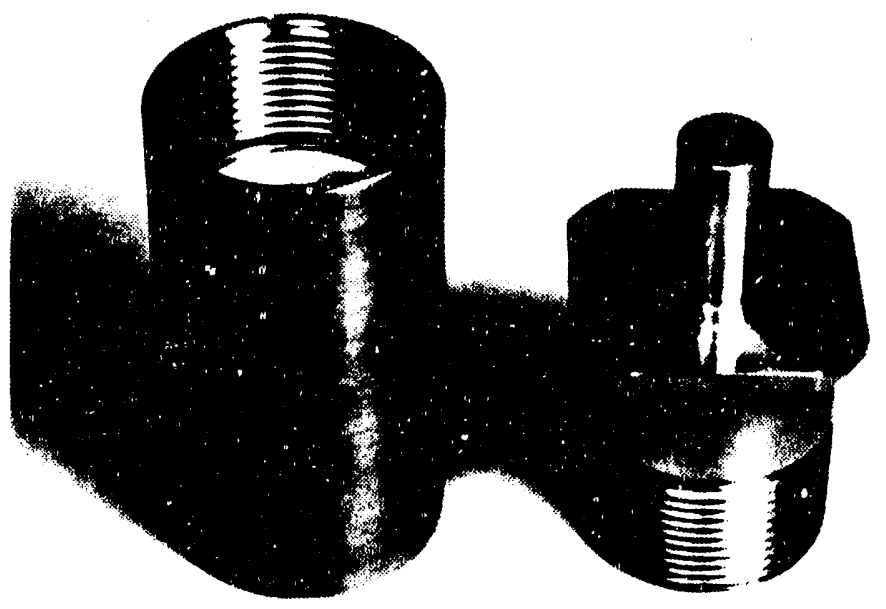

Figure 3-2. Photograph of impulse gage specimen cup showing pieces in cup and cup backer. 


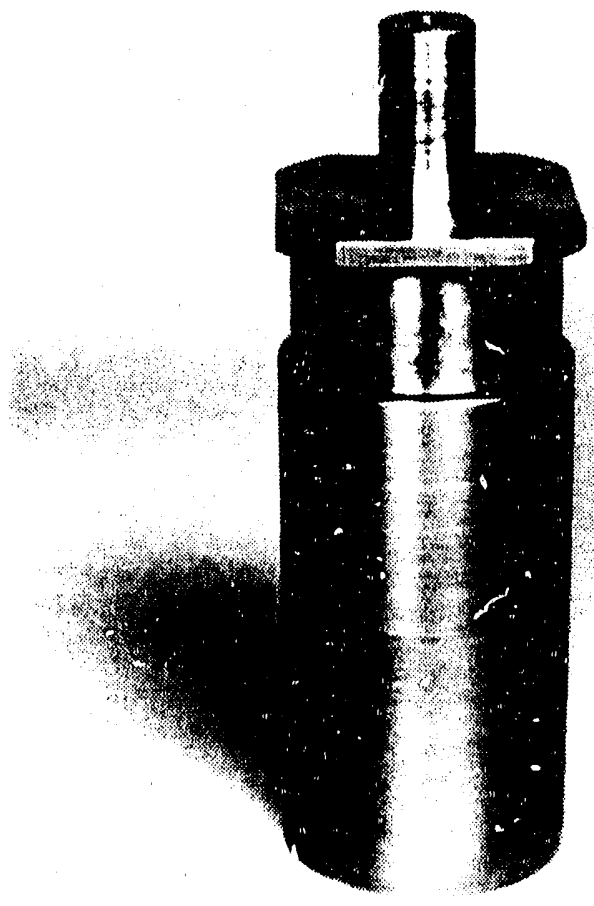

Figure 3-3. Photograph impulse gage specimen cup and backer.

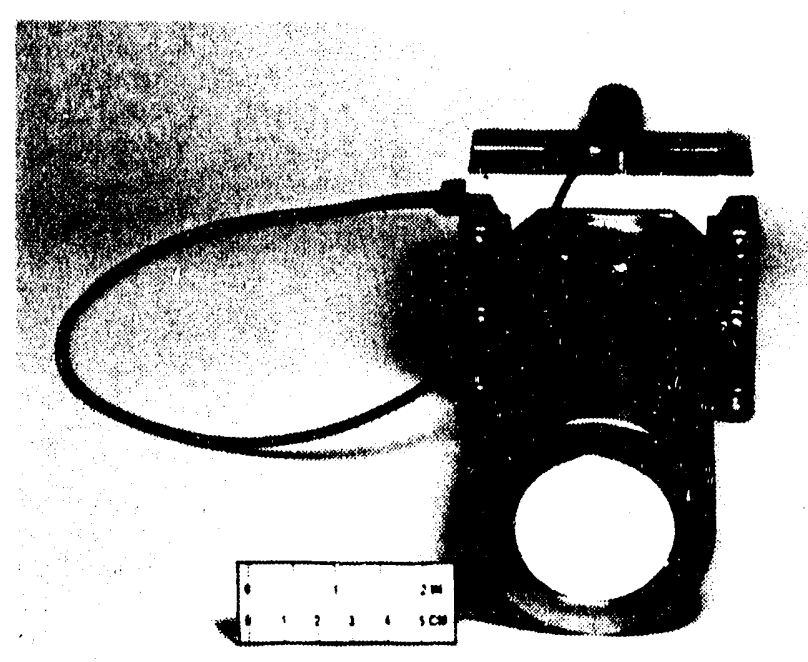

Figure 3-4. Photograph of the front of impulse gage, showing aluminum specimen and surrounding specimen cup. 


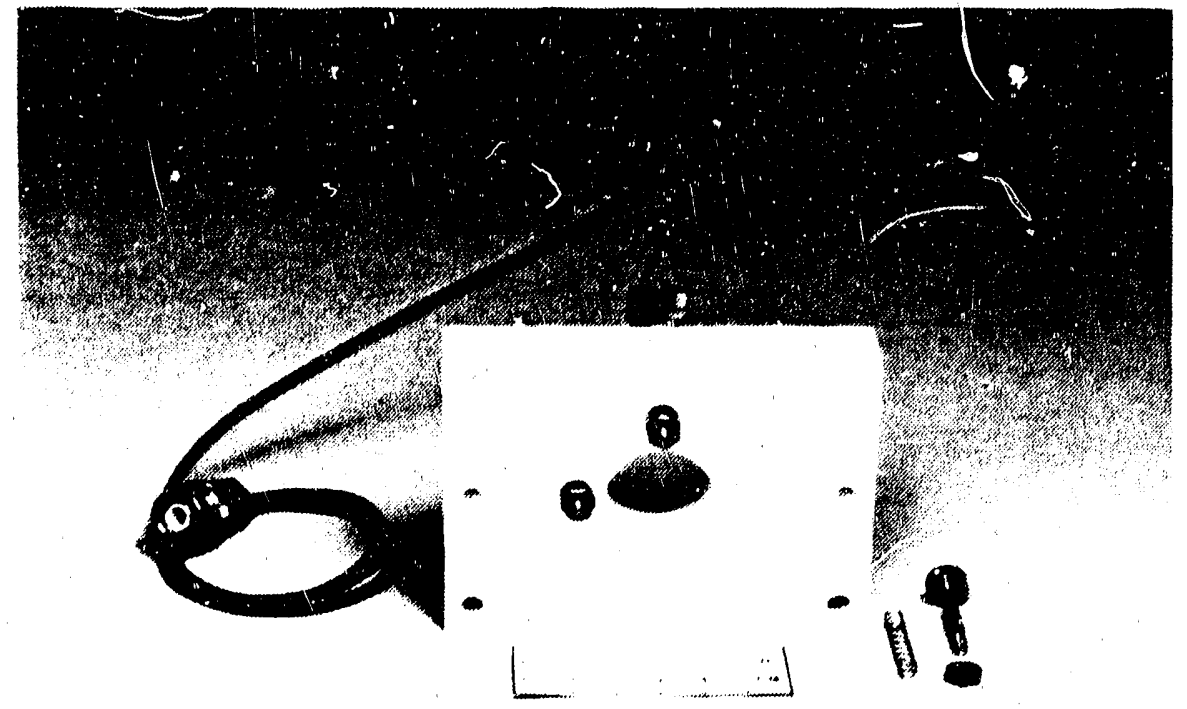

Figure 3-5. Photograph of bottom of pin switch block with disassembled pin and spring.

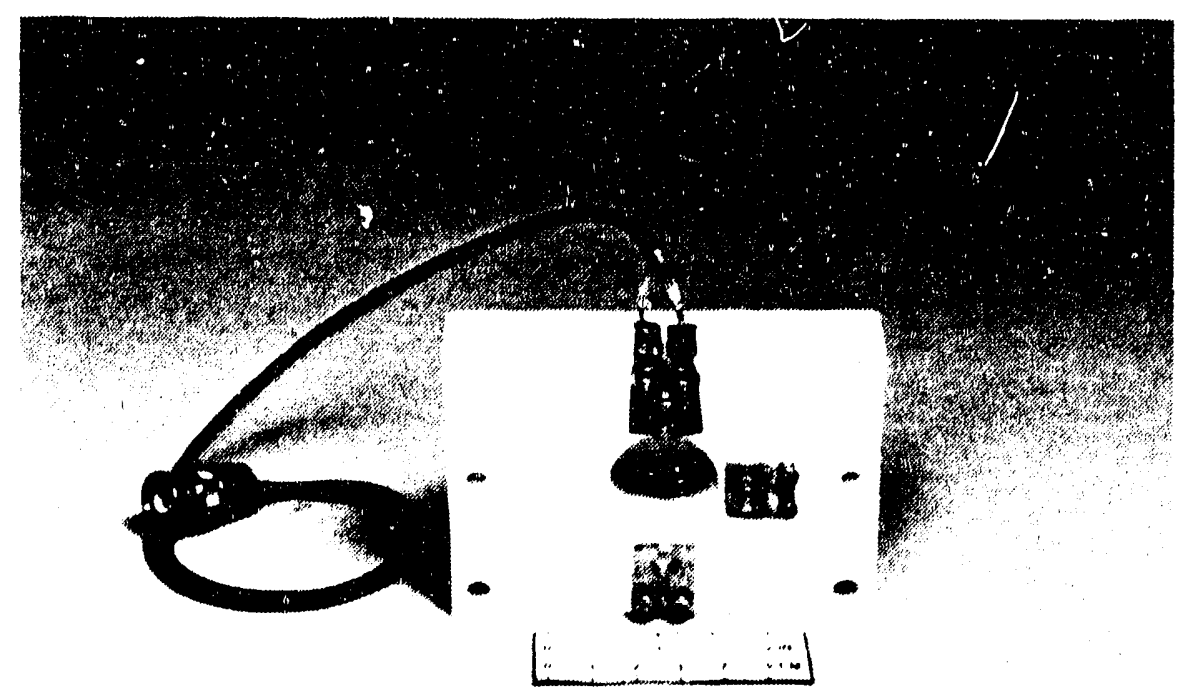

Figure 3-6. Photograph of top of pin switch block showing contacts used for switch readout. 


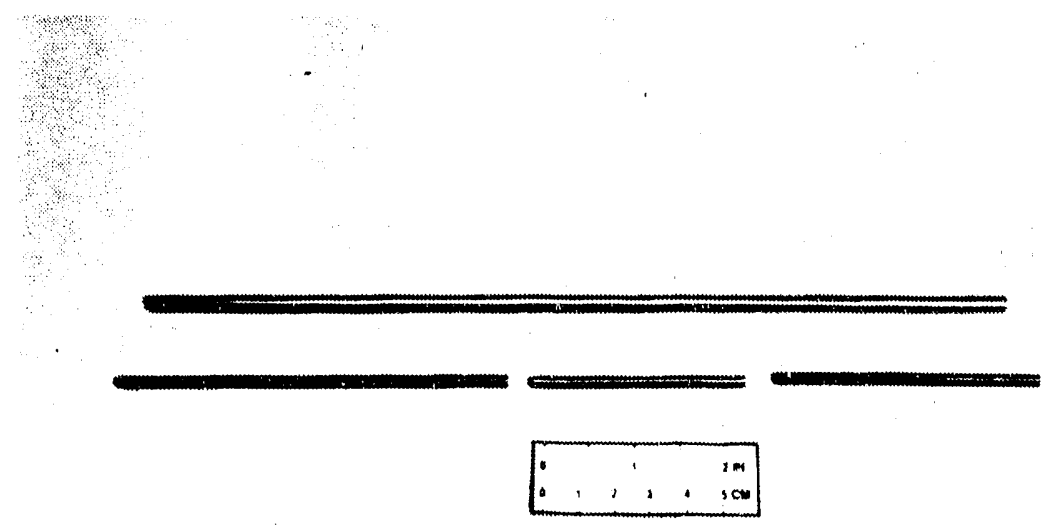

Figure 3-7. Photograph of LVT magnet, stainless steel spacers, and magnet enclosure tube.

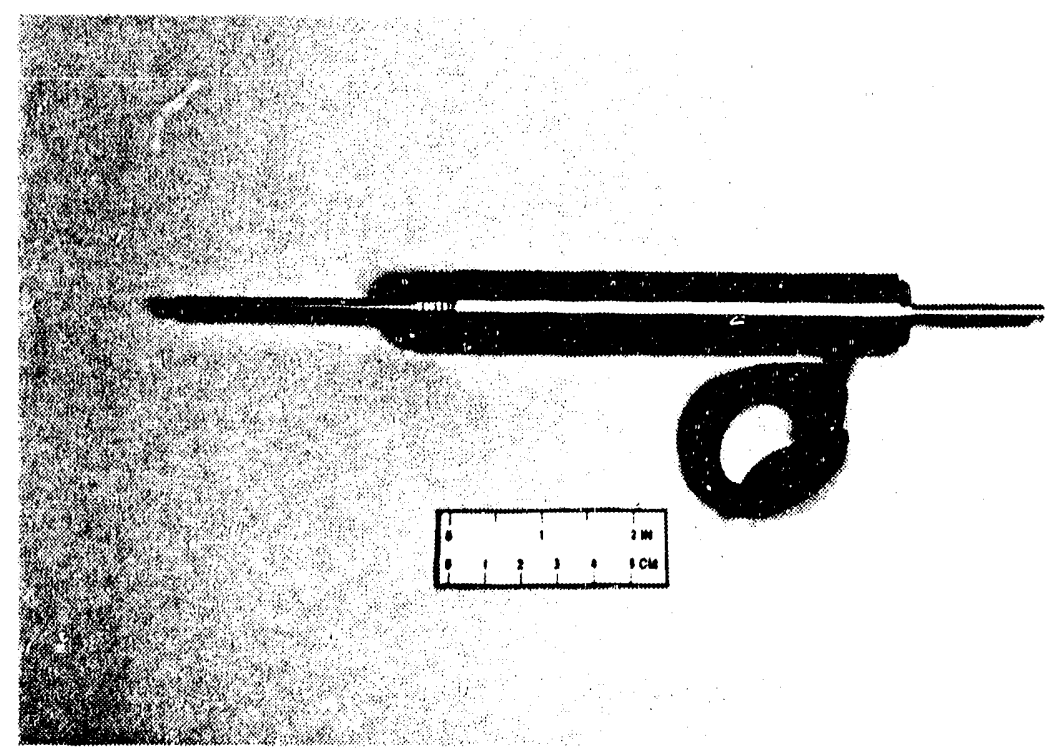

Figure 3-8. Photograph of magnet assembly in LVT coil. 


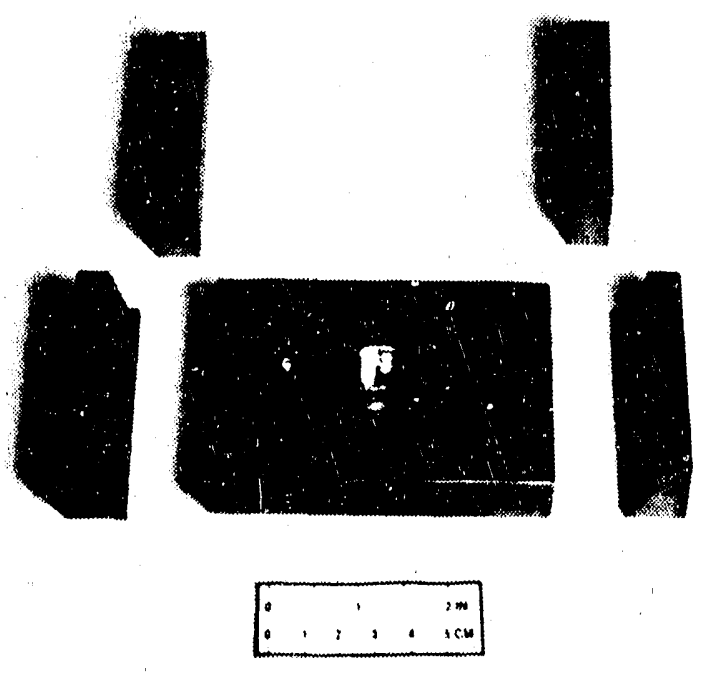

Figure 3-9. Photograph of gage upper block (holds the LVT coil).

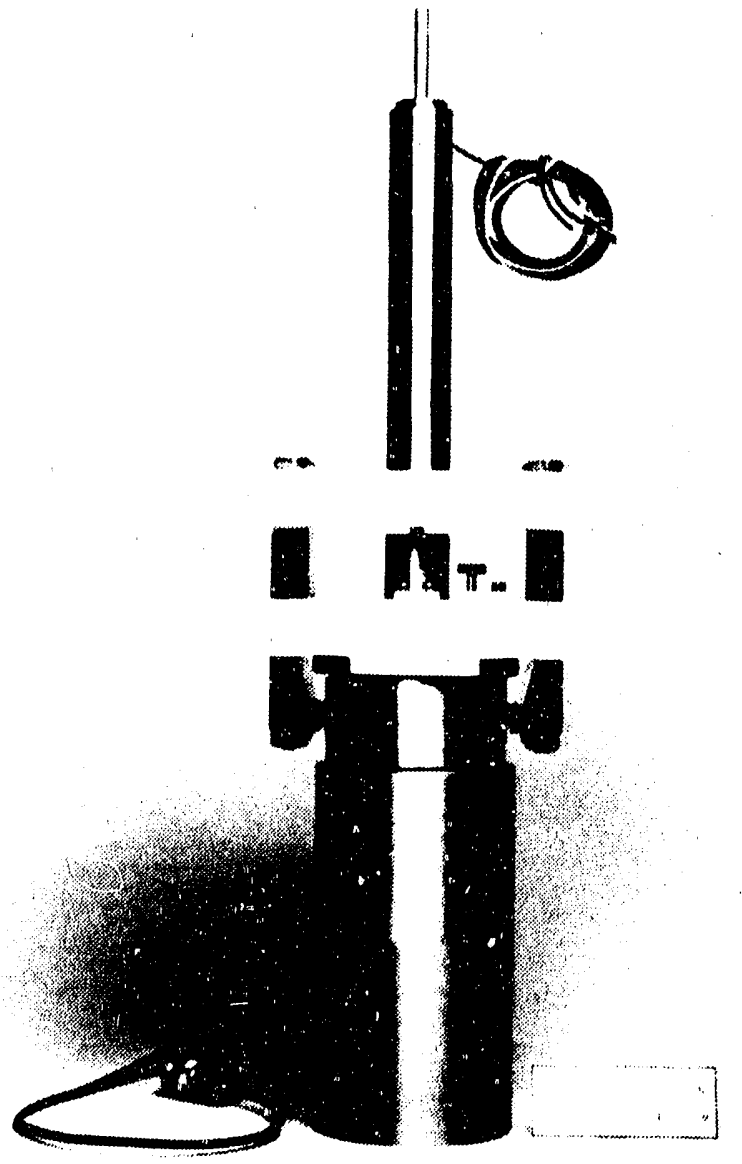

Figure 3-10. Photograph of assembled impulse gage. 


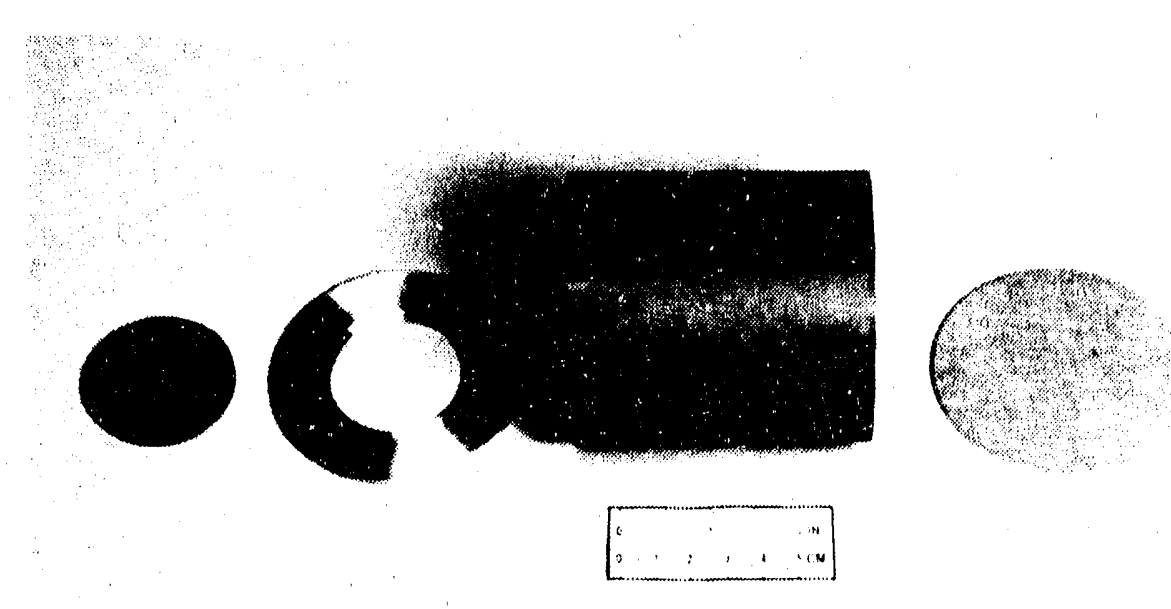
Figure 3-11. Photograph of gas gun impactor (tungsten carbide) and
sabot components.

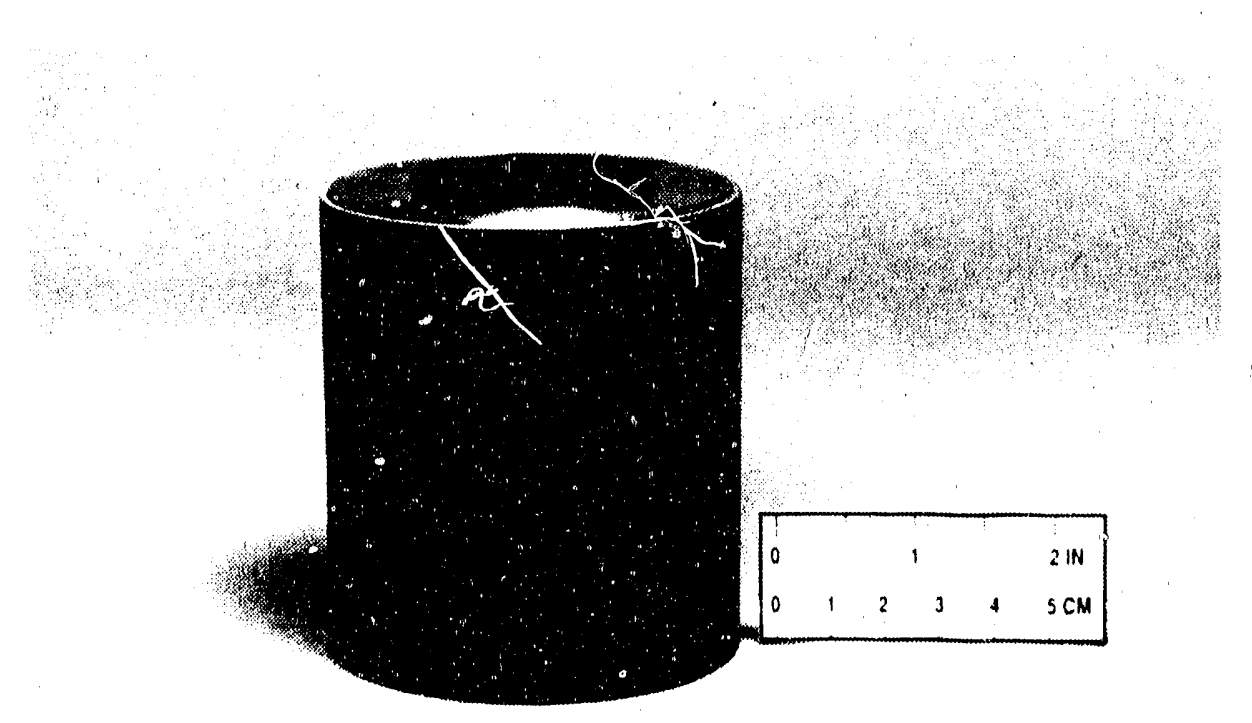

Figure 3-12. Photograph of assembled sabot. 
1able 3-1. LVT coil electrical calibration (into $1 \mathrm{M} \Omega$ ).

\begin{tabular}{|c|c|}
\hline LVT Coil \# & Calibration $(\mathrm{mV} / \mathrm{cm} / \mathrm{sec})$ \\
\hline $24940-3-1$ & 46 \\
$30557-3-1$ & 101 \\
$30557-3-2$ & 109 \\
$30557-3-3$ & 91 \\
$30557-3-4$ & 89 \\
\hline
\end{tabular}

\subsection{MECHANICAI RESPONSE TEST.}

Following assembly of the ga, os a test was performed to measure the mechanical response time of the gage. Gage \#1 was held with the front of the gage pointed down, as it would be for a UGT VLOS test. The specimen was struck with a low velocity impactor which triggered a recording oscilloscope. The outpul of the LVT (wil was recorded on the oscilloscope. A representative trace is shown in Figure $3-13$. The trace shows that the LVT coil has equilibrated to within \pm 58 in about $400 \mu s e c$, which was deemed an acceptable mechanical response. The ringing was due in part to electrical effects as shown in the following section of this report.

\subsection{LUI COIL OUTPUT ATTENUATION.}

Electrical isolation of the LVT coil from the cable is necessary to achieve a fast response without ringing. This is achieved with an attenuator. Attenuation was also required by the range of the recorders.

The anticipated velocity of the impulse gage moving mass during the gas gun tests was $600 \mathrm{~cm} / \mathrm{sec}$. Using this magnet velocity and the LVT calibrations of Table 3-1 the expected LVT electrical output would be 60 volts. This signal is too large for either oscilloscopes or the transient recorders used in the gas gun laboratory, so the LVT output required attenuation. 


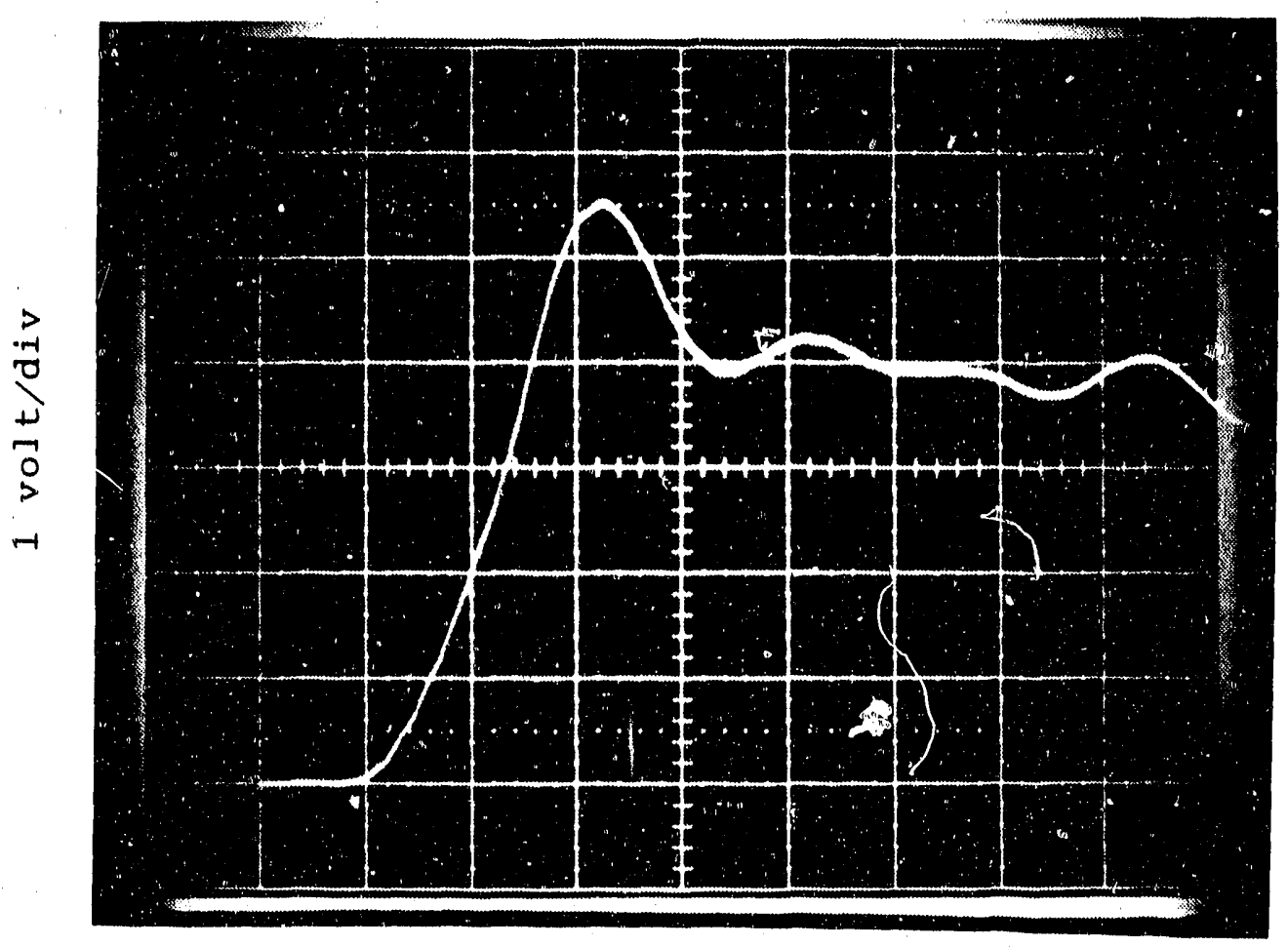

$0.1 \mathrm{msec} / \mathrm{div}$

Figure 3-13. 0scilloscope photograph of LVT coil output, mechanical response test. 
The PSPICE (Ref. 20) code was used to model the LVT coil and the capacitance of the RG-8/U cable which connected the coil to the recorders. The cable capacitance was $830 \mathrm{pF}$. The impedance of the LVT coll was $13 \mathrm{k} \Omega$. Trans-Tek documentation specified a coil inductance of 1.6 Henrys.

A PSPICE simulation of the above coil and cable connecter to a 1 Mn load is shown in Figure 3-14. The ringing of the coil is evident. This simulation was verified by injecting a signal into the LVT and recording the LVT output. The oscilloscope photograph is shown in Figure 3-15.

A 100:1 attenuator was added to the LVT coil circuit and the above modeling and test were repealed. The attenuator was an $86 \mathrm{k} \Omega$ resistor in series with the coil output followed by a $1 \mathrm{k} \Omega$ resistor across the coil output. The corresponding PSPICE prediction and bench test are shown in Figures $3-16$ and $3-17$. The small overshoot in Figure 3-17 is attributed to shunt capacitance in the LVT coil which was not modeled. The output has been attenuated by a factor of 100 which enables the use of the Lecroy transient recorders for the gas gun tests. The coil has also been isolated from the cable capacitance to eliminate the ringing seen in Figures 3-14 and 3-15. The PSPICE input files used to produce these simulations are shown in Tables $3-2$ and 3-3.

Table 3-2. PSPICE simulation inputs for the case of no impedance matching circuit.

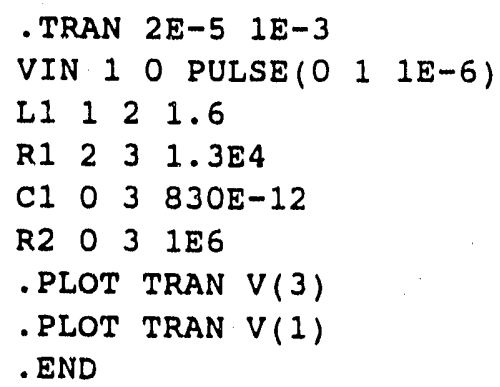




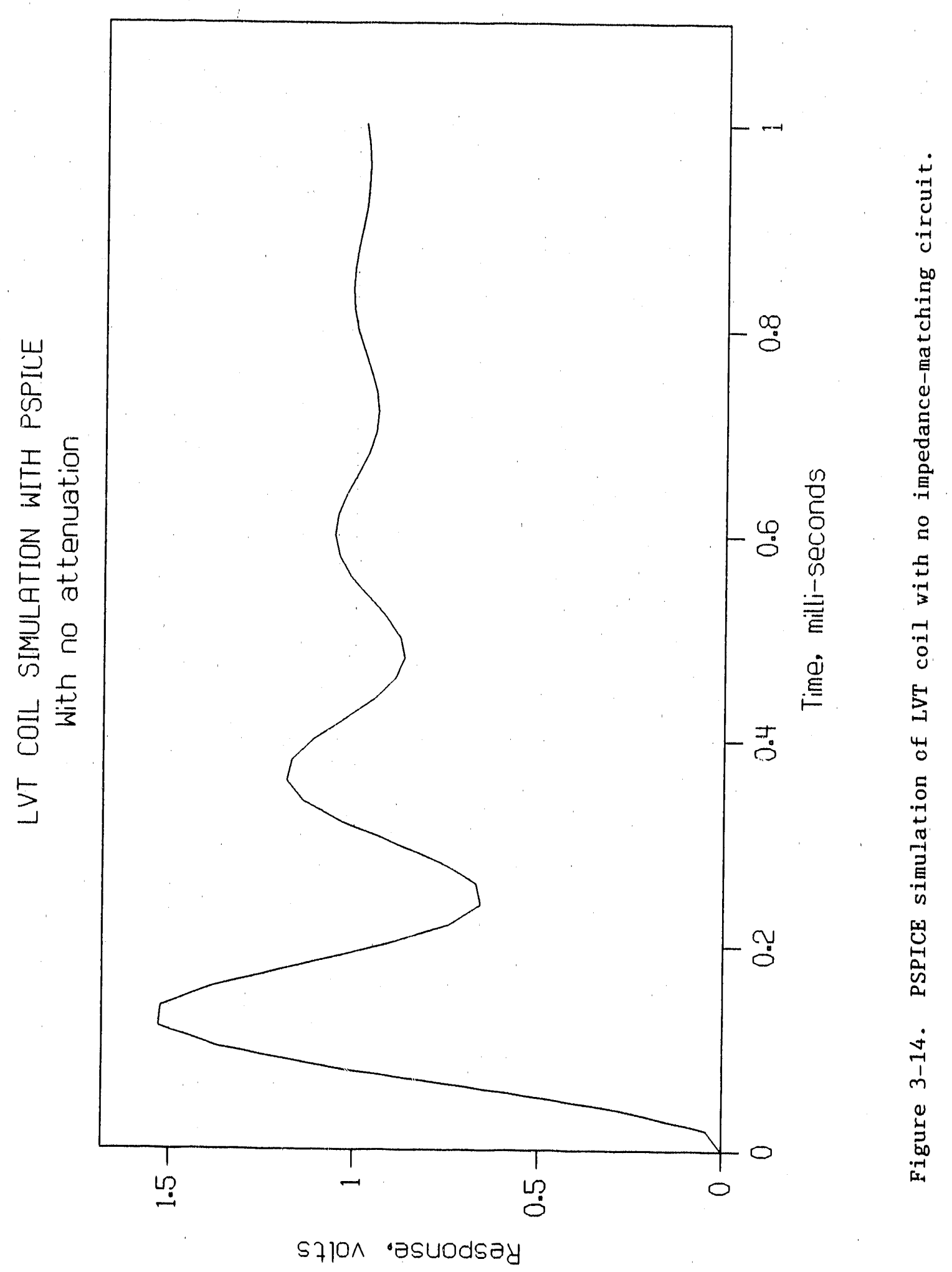




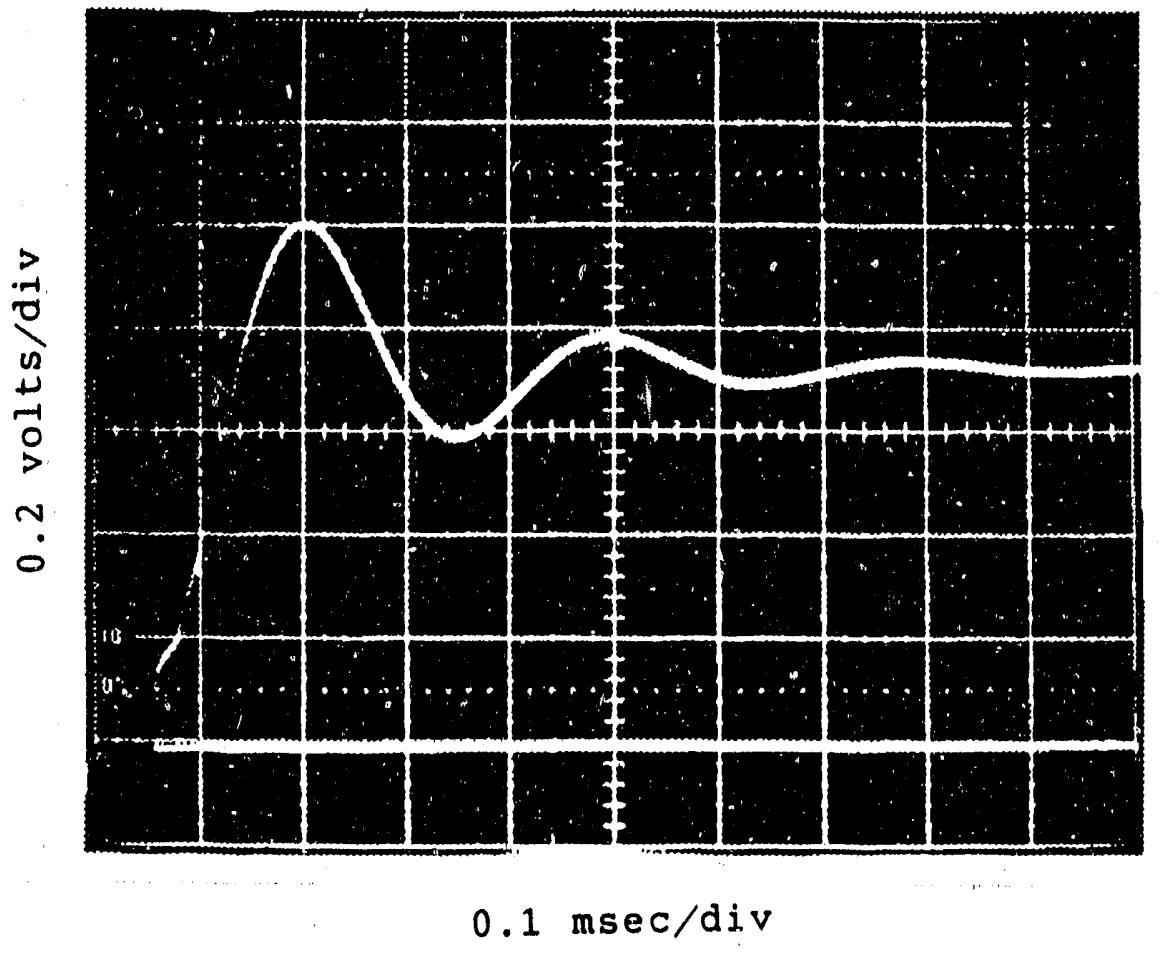

Figure 3-15. Oscilloscope photograph of LVT coil impedance test with no impedance-matching circuit (compare to Figure 3-14). 


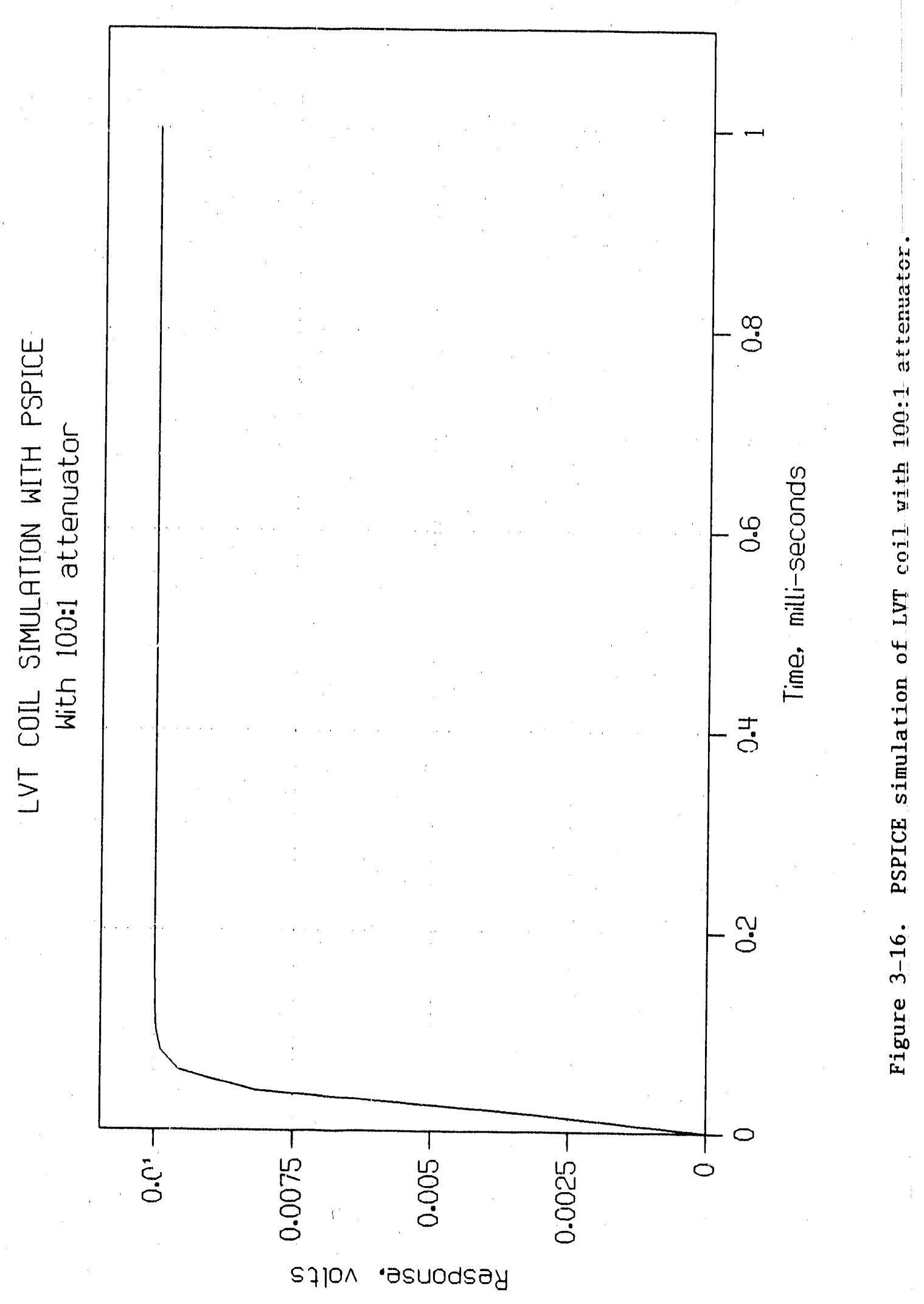




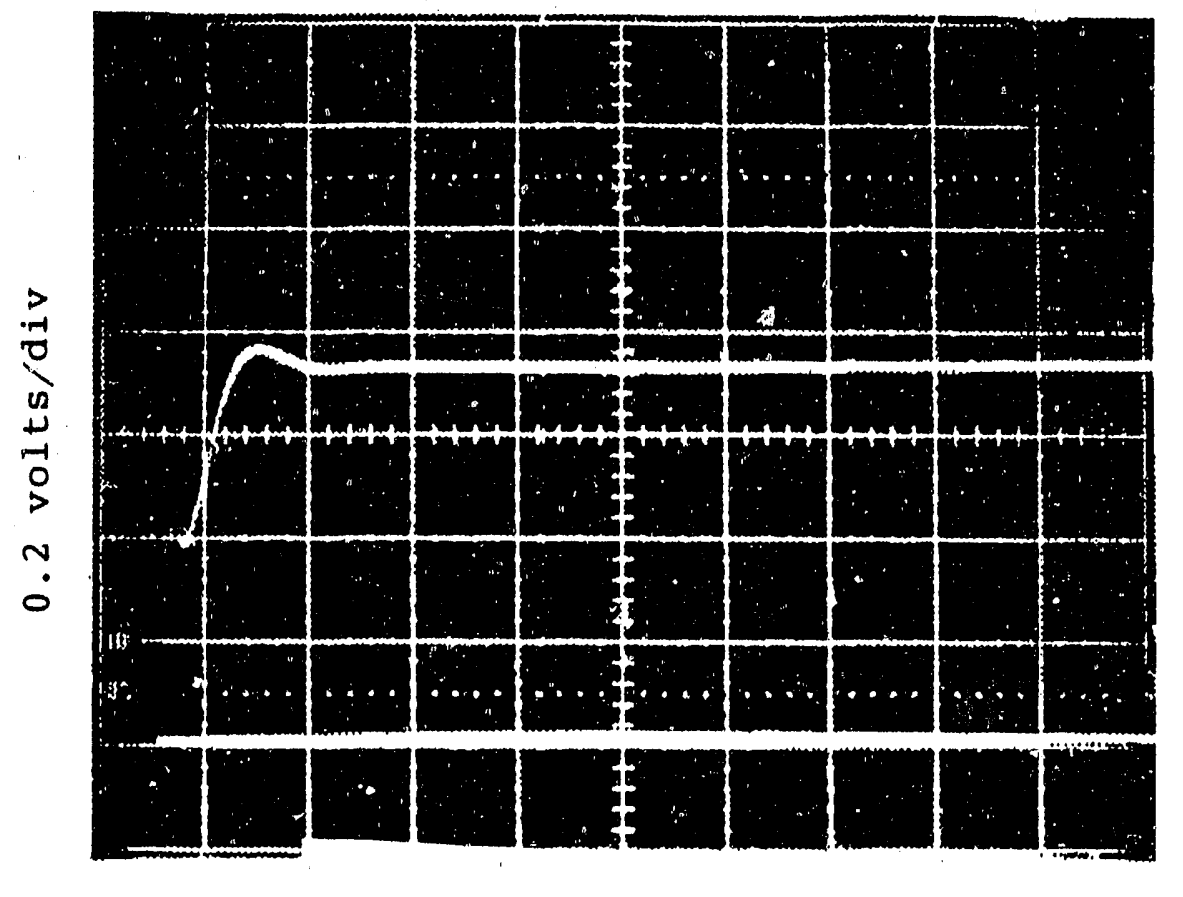

$0.1 \mathrm{msec} / \mathrm{div}$

Figure 3-17. Oscilloscope photograph of LVT coil with impedance test with 100:1 at tenuator installed (compare to Figure 3-15). 
Table 3-3. PSPICE simulation inputs for the 100:1 attenuating circuit.

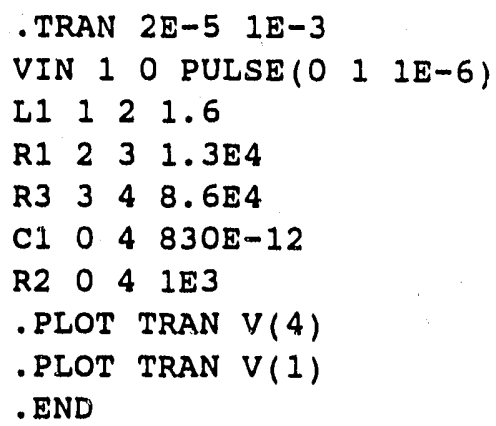

\title{
3.4 GAS GUN TESTING.
}

\begin{abstract}
After the response tests the gages were prepared for gas gun testing. The GRC 3 inch light gas gun is shown in Figure 3-18. For impulse gage testing the "Target Board" is replaced with an impulse gage in the target chamber. This gun is capable of accelerating projectiles to impact velocities ranging from 0.005 to $0.70 \mathrm{~mm} / \mu \mathrm{s}$ with impact tilt less than $0.5 \mathrm{mrad}$.
\end{abstract}

The projectile is propelled by a maximum pressure of 2000 psi nitrogen or helium gas, expelled by a single stage breech mounted on wheels and backed by a shock absorber. The gas is released by a pneumatically driven, fast opening valve.

Impact velocity is measured using three $p$ ns extending radially into the gun barrel that are sequentially shorted by the projectile as it leaves the muzzle. The relative time between pins is measured by time interval counters and the distance between pins measured using electrical micrometers prior to the shot. The accuracy of the measurement is better than 0.5 percent.

The gun barrel and target chamber are evacuated to a pressure less than 200 microns of mercury to eliminate air shock. Following impact, the projectile and target debris rupture a Mylar diaphragm at the rear of the target chamber and come to rest in a massive rolling catcher tank. 


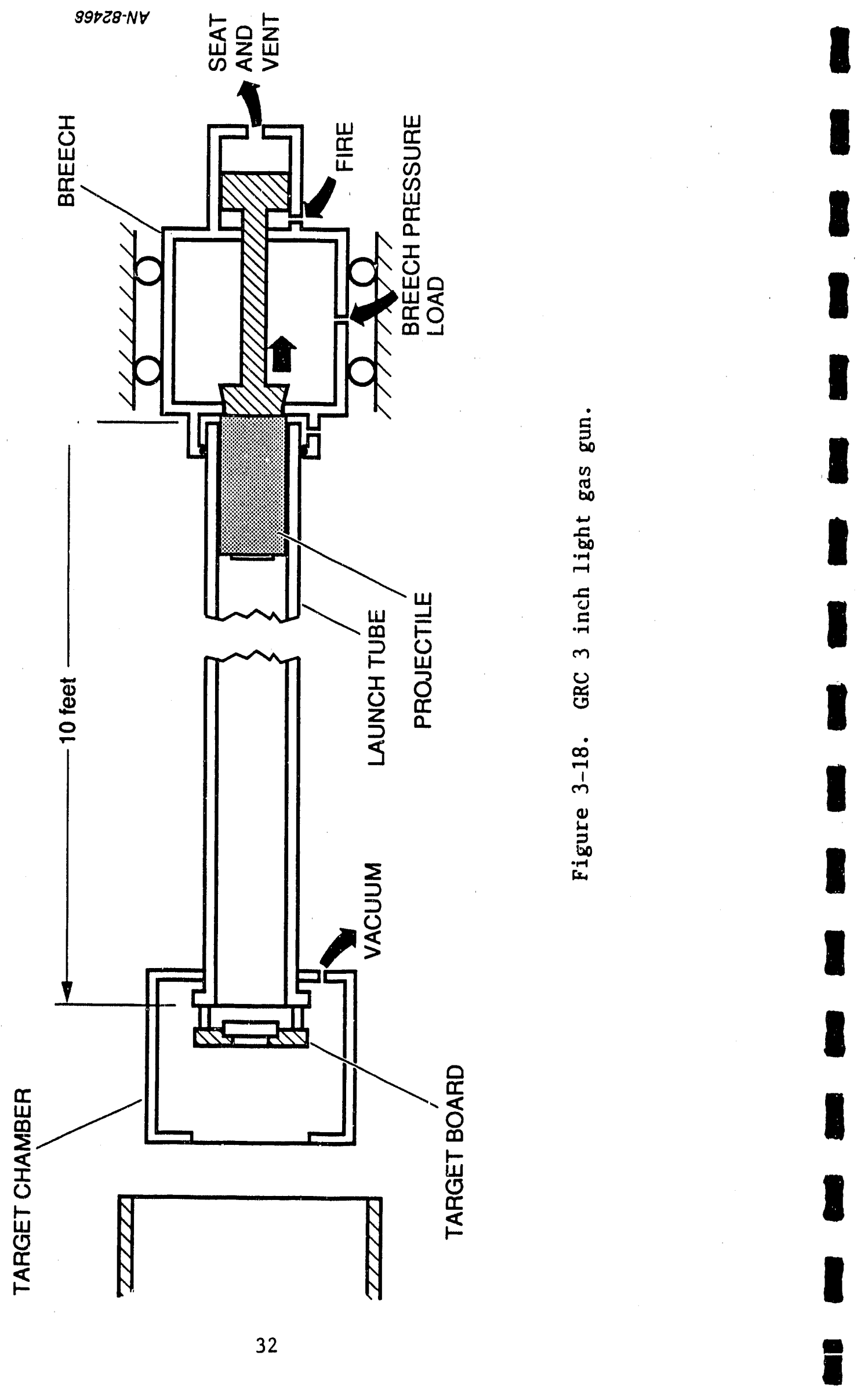


A sabot stripper was installed in the target chamber to remove the impactor from the sabot just prior to impact with the impulse gage. A detail of the target chamber is shown in Figure 3-19. The impact velocity measurement system supplies a trigger to the impulse gage recorders, which arrives about $50 \mu$ sec prior to the impact of the flyer on the gage.

Both oscilloscopes and electronic digitizers were ased to record the impulse gage output. The instrumentation schematic is shown in Figure 3-20.

Table 3-4 summarizes the gas gun tests. As the gas gun facility was being used after extensive modifications, data from the LVT coil and switch pins were not recorded successfully on all shots. Figure 3-21 shows LVT coil output from shot 5835. Figure 3-22 is the switch pin data for the same shot.

From Figure 3-21, the LVT indicates the velocity of the moving mass as $1095 \mathrm{~cm} / \mathrm{sec}$. This data reduction disregards the first $600 \mu s e c$ of the trace, the time before and during the gage acceleration. The impulse delivered to the gage, based on a total moving mass of 3478.4 grams, an "exposure area" of $14.64 \mathrm{~cm}^{2}$, and a gage velocity of 1095 $\mathrm{cm} / \mathrm{sec}$ (the average of the four switch pin intervals) was $260 \mathrm{ktap}$.

The indicated velocity from the switch pins for this measurement is summarized in Table 3-5. Variations in the velocity given by the pins is attributed to non planarity of the gage with the projectile, a problern which is not relevant in the VLos environment. The average velocity indicated by the last three switch pin intervals is 1152 $\mathrm{cm} / \mathrm{sec}$. This is within $5 \%$ of the indicated LVT velocity over the same time interval. 

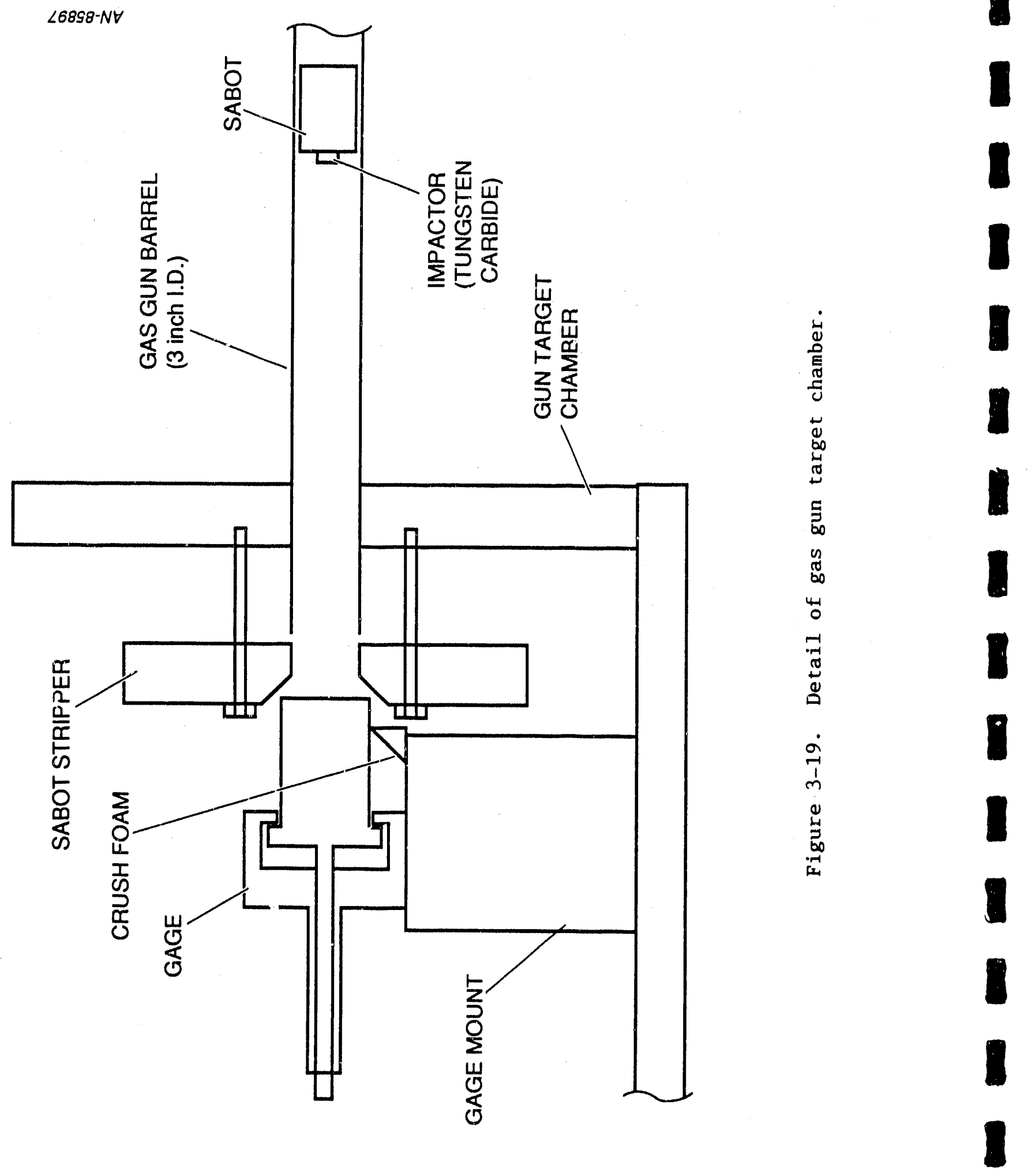


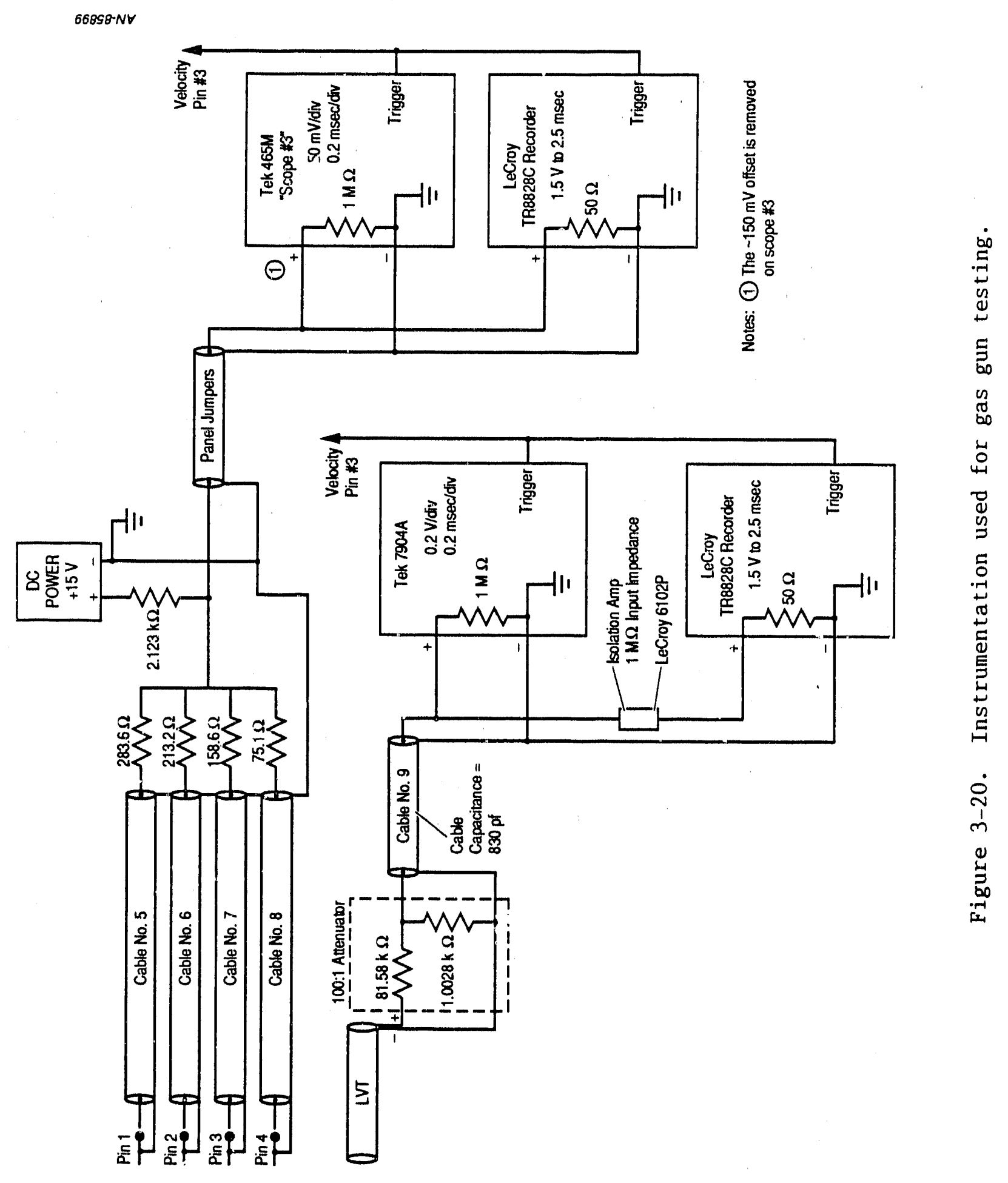




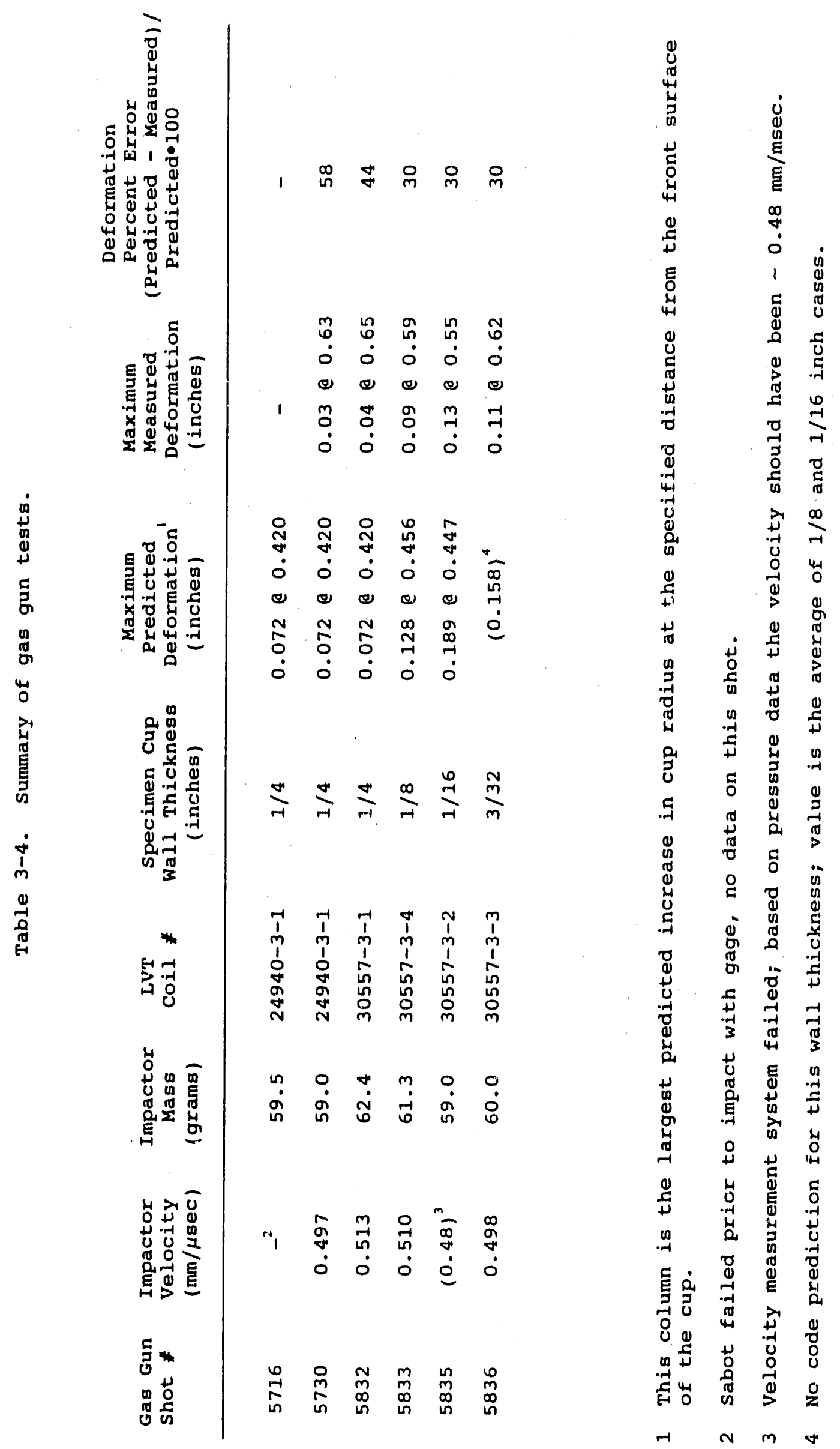




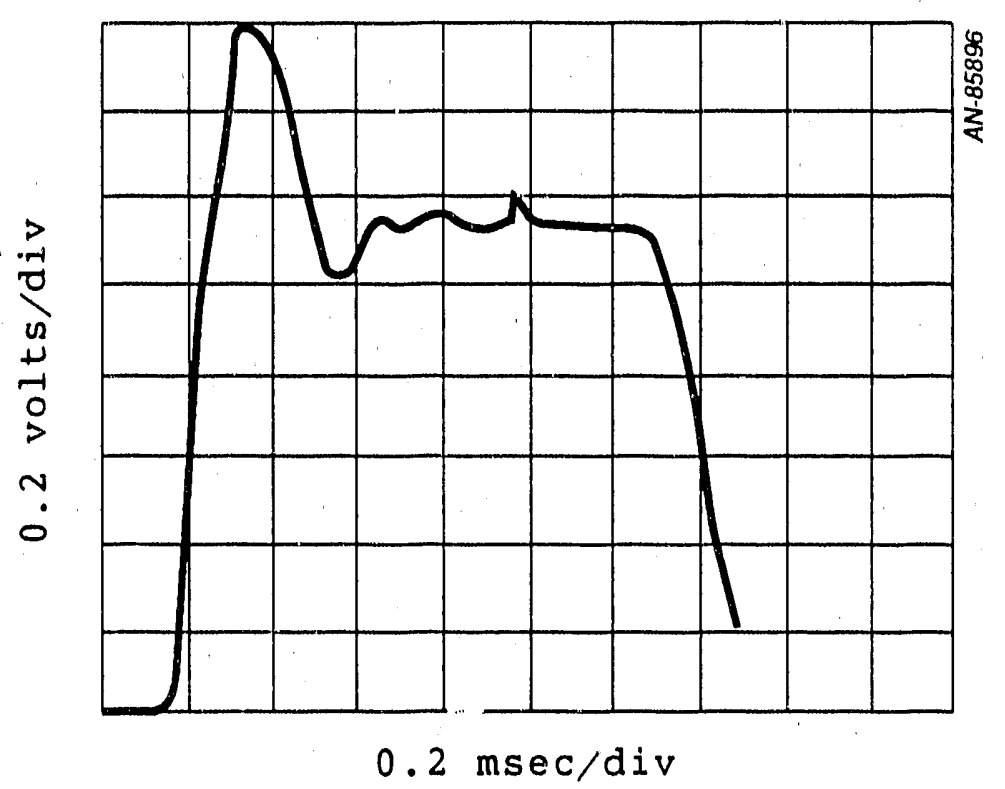

Figure 3-21. LVT coil output for gas gun shot 5835 .

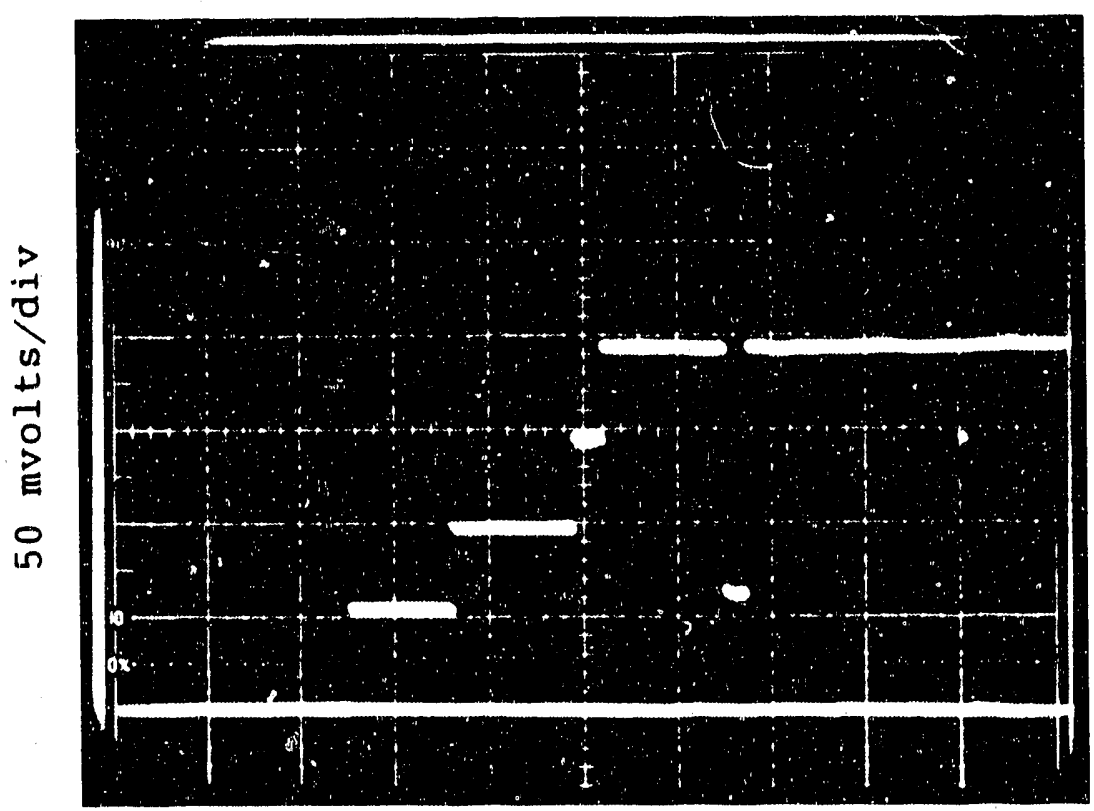

$0.2 \mathrm{msec} / \mathrm{div}$

Figure 3-22. Switch pin output for gas gun shot 5835 . 
Table 3-5. Switch pin velocity measurements for shot 5835 .

\begin{tabular}{|c|c|c|c|c|}
\hline & & $\begin{array}{c}\text { Distance } \\
(\mathrm{cm})\end{array}$ & $\begin{array}{c}\text { Time Interval } \\
(\mu \mathrm{sec})\end{array}$ & $\begin{array}{l}\text { Velocity } \\
(\mathrm{cm} / \mathrm{sec})\end{array}$ \\
\hline start & to Pin 4 & 0.427 & 500 & 854 \\
\hline $\operatorname{Pin} 4$ & to Pin 3 & 0.249 & 220 & 1131 \\
\hline Pin 3 & to Pin 2 & 0.249 & 250 & 996 \\
\hline Pin 2 & to $\mathrm{P}$ in 1 & 0.086 & 65 & 1328 \\
\hline
\end{tabular}

The free travel of the moving mass was 0.5 inch. Examination of the LVT trace shows that the full width, half maximum duration of the velocity record is $1.20 \mathrm{msec}$ or $1058 \mathrm{~cm} / \mathrm{sec}$ which correlates well with other measurements.

At $1.3 \mathrm{msec}$ the switch pin trace indicates a short. The short is probably due to the gage reaching the end of travel which causes large motions in the gage. Data following the end of travel should be disregarded.

Data from the first three shots (not shown) indicated that the switch pins may have broken contact for a short period of time as the gun was fired. Springs were used to seat the pins to mitigate this effect, but it seemed the pins were opening nonetheless. The springs were selected to cause no more than a $5 \%$ correction in impulse over the distance they were compressed.

To eliminate the early time opening of the ping, they were modified to work as shown in Figure 3-23. For the first three shots the copper jumper bar was not present. The circuit worked by making one brass contact positive and the other brass contact ground. The head of the pin shorted the two contacts. When the bottom of the pin was struck by the moving mass, the head lifted off the contacts and the circuit opened. 


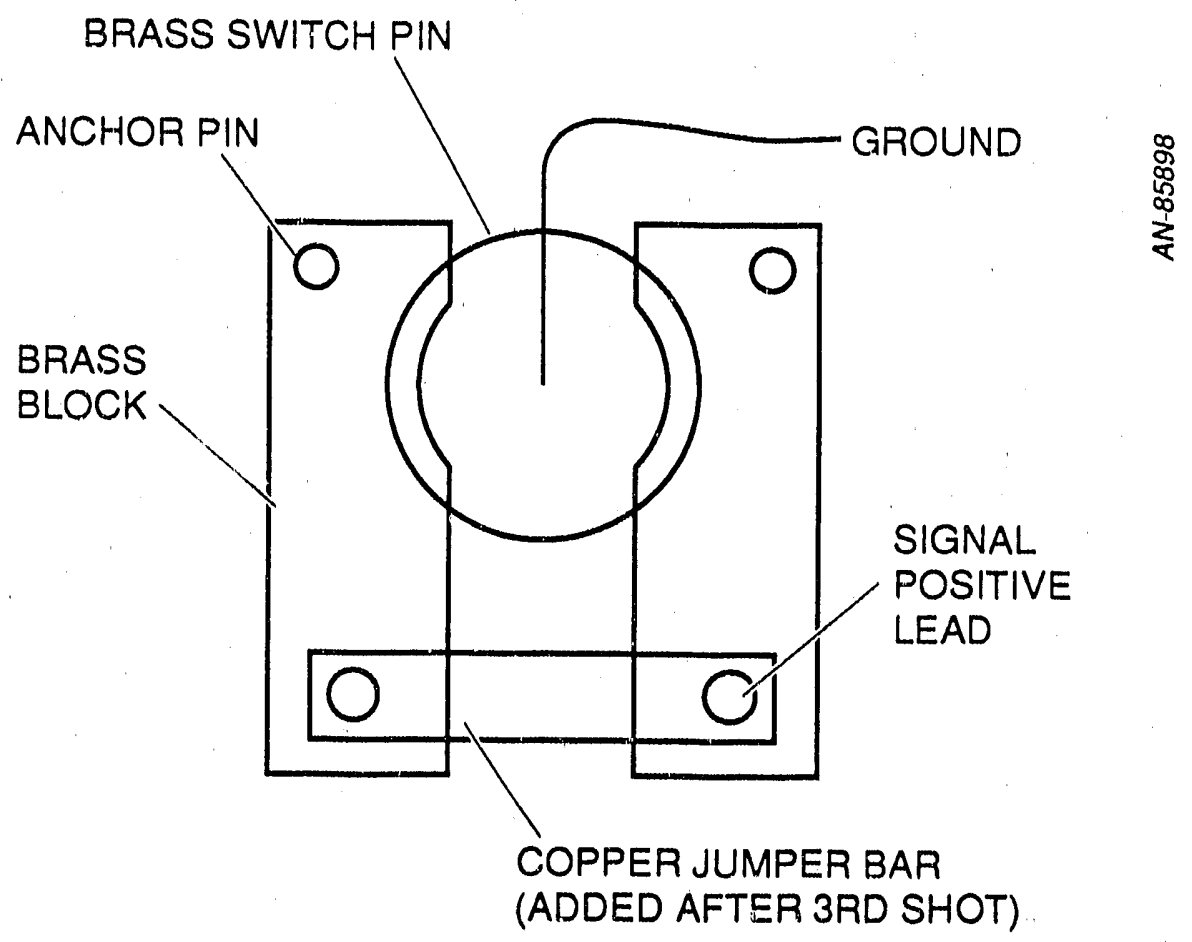

Figure 3-23. Modified switch pin viring showing copper bar joining brass contacts, making contacts positive and pin ground. 
For shot 5835 the copper jumper bar was added and the wiring of the circuit was modified. The pin was grounded and the jumper bar/brass contacts were made positive. In this configuration, even if the pin rocked slightly to one side at zero-time, the circuit would not open. The switch pin data trace (Figu: 3 3-22) shows that no early opening of the pins occurred.

The specimen cup deformations of Tables 2-1, 2-2, and 2-3 are plotted in Figures 3-24, 3-25, and 3-26. The measured specimen cup deformations are also shown. Figure 3-24, for the $1 / 4$ inch specimen cup wall, also contains a prediction for the generic, hypothetical UGT environment. Common to the predictions for all three specimen cup thicknesses is an over-prediction of deformation near the front surface of the specimen/specimen cup. This may be due to a small gap that was not modeled between the side of the specimen and the inside of the specimen cup, at the front surface. This gap is evident in Figure 3-4. The gap allowed some free expansion of the specimen before the specimen cup started to expand, and may explain the over-prediction of the observed damage.

The amount of deformation experienced by the specimen cups is predicted by the code to within $30 \%$ for the thin wall cases. In all caser less deformation was experienced by the specimen cups than was predicted. The $1 / 4$ inch wall is less well predicted, with an average error of 518 . It should be noted that the specimen cup used in shot 5716 and shot 5730 was not fabricated from the lot of certified 4340 material used for all the other cups. The material used in shots 5716 and 5730 was A-2 tool steel. Ihis may explain the large difference in predicted versus measured deformation seen in shot 5730 . If the deformation from shot 5730 is disregarded, then the difference in prediction versus measurement becomes 448 . 


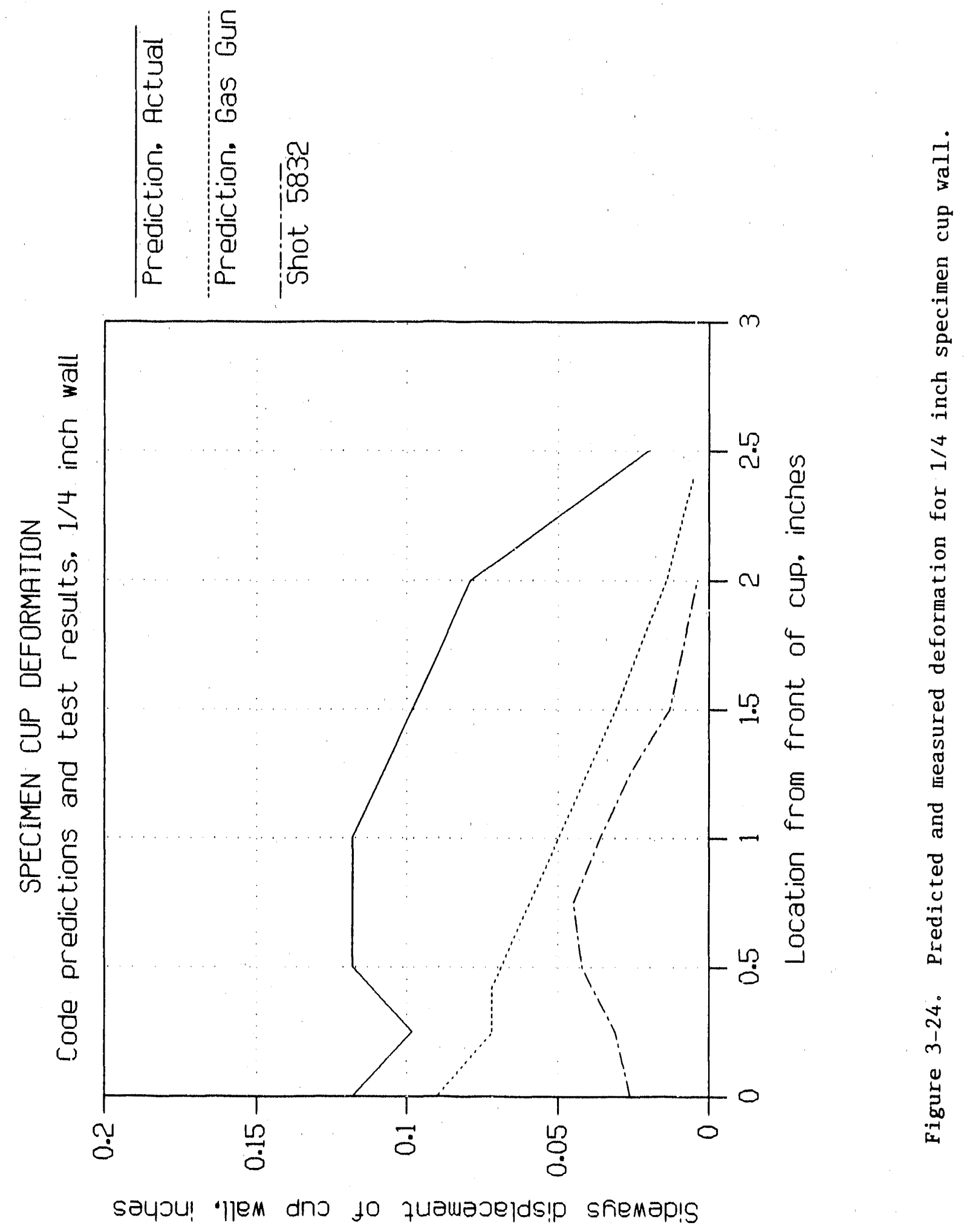



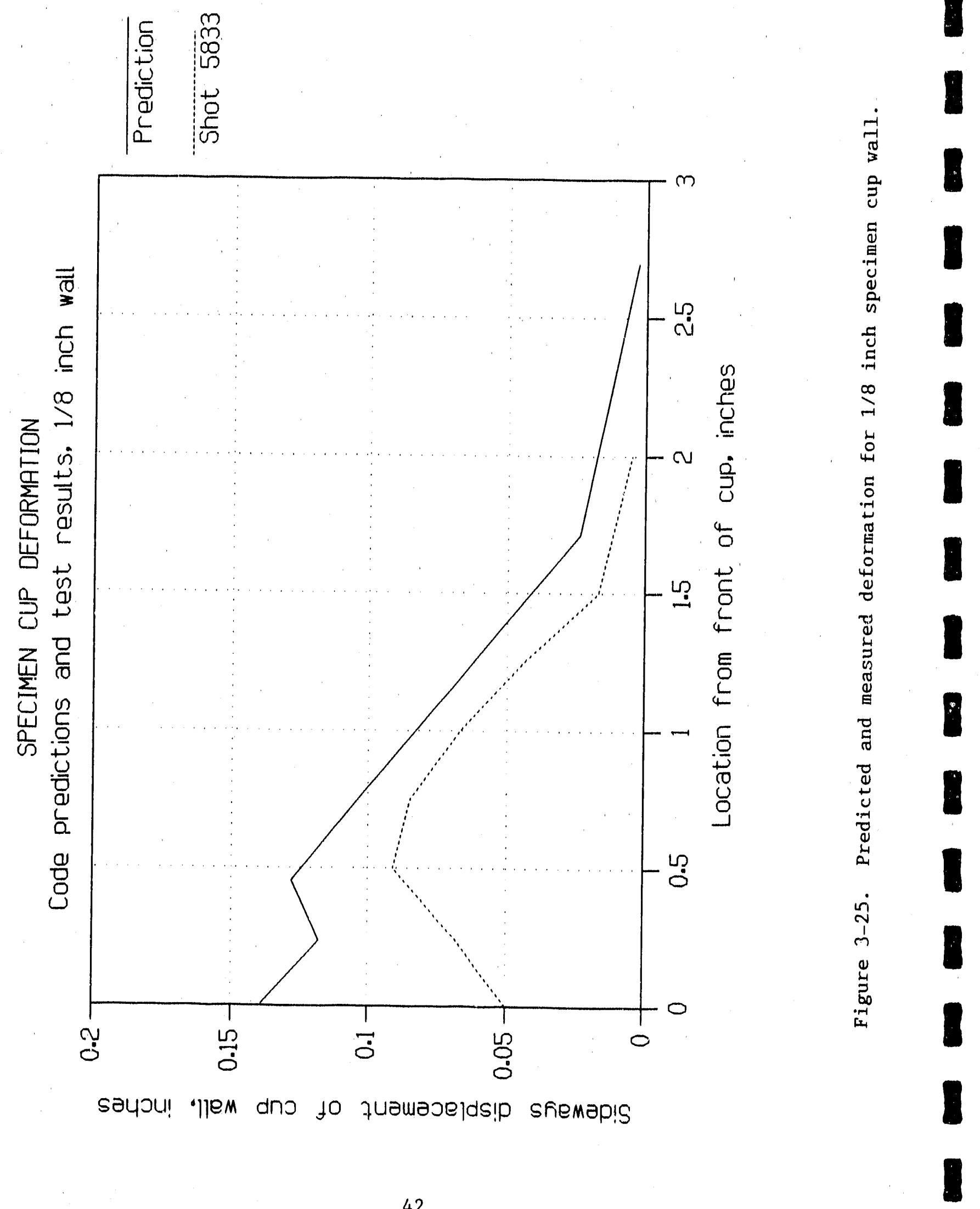


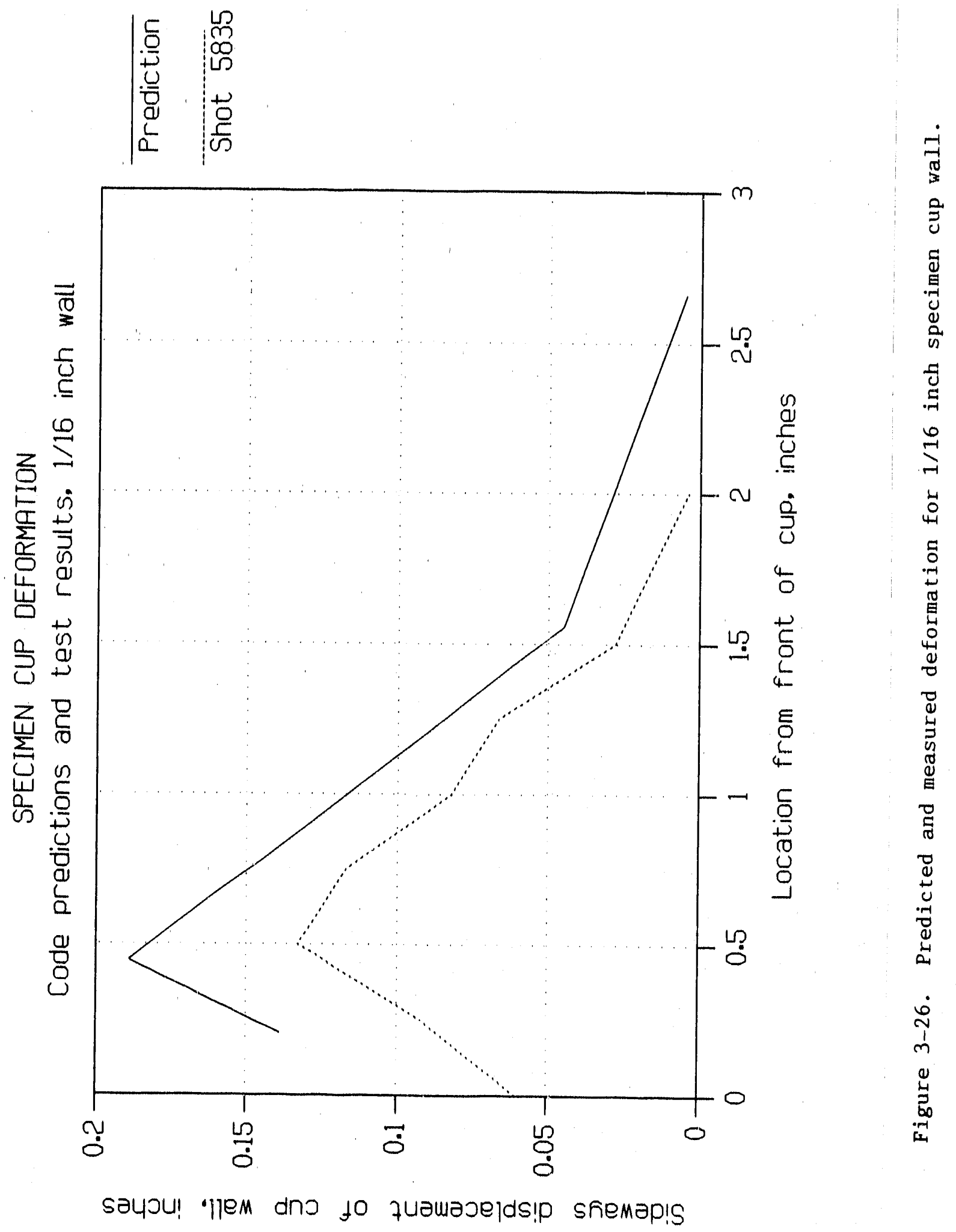


SECTION 4

SUMMARY AND CONCLUSIONS

Impulse gages were constructed and tested via flyer plate impact techniques in a 3 inch gas gun. Lessons were learned concerning readout design and model applicability which will allow these gages to be used in VLOS UGT events.

The gage operated at an impulse level of over 250 ktap. Gages with intentionally weakened walls (1/2 and $1 / 4$ of the design thickness) also successfully measured $250 \mathrm{ktaps,} \mathrm{which} \mathrm{demonstrated} \mathrm{a} \mathrm{large}$ strength margin.

The two-dimensional hydrocode used for gage predictions in the VLOS UGT event environment predicts gage gurvival at 150 ktaps, the highest impulse predicted. The same code overpredicted the gas gun test results by 30-448 while still predicting gage survival even for the reduced wall thickness tests, giving confidence to the UGT survival prediction.

The gage will provide sufficient information to be read out in 1 msec. Both bench measurements and the gas gun tests show that it takes about $300 \mu s e c$ for the gage to come to mechanical equilibrium. Accurate velocity measurements can be made in the remaining $700 \mu s e c$.

Modifications were made to the switch pin design to ensure noisefree operation through early-time vibrations.

It was demonstrated that LVTs will work for this application. Use of an LVT requires care in impedance matching and recording to ensure good results.

These gages should undergo a shot-configuration proof-test prior to fielding. The tests should produce high stress in the specimen cup 
to allow direct verification of the design. The gages should be operated vertically for these tests which limits the choice of testbeds. Explosive testing may be the solution to achieving high stress in the vertical orientation. The successful completion of such a test series should result in the confidence required to field these gages in a vios UGT.

\footnotetext{
This gage design is predicted to be able to measure impulses greater than 150 kbar within 1 millisecond in special effects UGTs.
} 
SECTION 5

LIST OF REFERENCES

1. R. Globus, W. Naumann, D. Hunt, and E. Chang, GoLDSTONE Instrumentrtion Development Report (U), General Research Corporation, CR86-1065, September 1986 (SECRET/RESTRICTED DATA).

2. W. Naumann and K. Peterman, DELAMAR Final Report (U), General Research Corporation, CR-88-1.032, November 1987 (SECRE'T/RESTRICTED DATA /CNWDI).

3. P.C. Rose and W.J. Naumann, Stress and Impulse Gage Development, General Research Corporation, CR-89-1083, I March 1989.

4. D.V. Keller et. al., Differential Momentum Experiments on CYPRESS (U), Effects Technology Inc., DASA-2413, 29 August 1969 (RESTRICTED DATA).

5. E.J. Steele, R.E. Wengler, and E.A. Anderson, MINUTE GUN Series, MINT LEAF Event, Project officers Report-Project 8.92, Composite Vulnerability Experiments (U), Effects Technology Inc., POR-6412, 14 May 1971 (SECRET/RESTRICTED DATA).

6. E.J. Steele, W.J. Naumann, and D.V. Keller, MINUTE GUN Series, HUDSON MOON Event, Project officers Report, Copper and Tantalum Stress-Time and Momentum Experiments (U), Effects Technology Inc., POR-6458, 20 August 1971 (SECRET/RESTRICTED DATA).

7. M.H. Subilia, E.J. Steele, and P. Boettcher, Experiment Plan-DIDO QUEEN Experiment Vos L1060-L1063, L1072-L1077, L1080-L1085: HFR Lethality and Overlay Phenomenology Experiments (U), Effects Technology Inc., ETI-73-1029, 12 January 1973 (SECRET/RESTRICTED DATA).

8. W.R. Myers, D.A. Suppes, E.L. Walsh, and D. C. Williams, MINUTE GUN Series, DIDO QUEEN Event, Lethality Phenomenology Experiments Kaman Sciences Corp., POR-6783, 9 April 1975 (SECRET/ RESTRICTED DATA).

9. W.M. Isbell and W.J. Naumann, TRI...The Development of a FastResponse Time-Resolved Impulse Gage, Effects Technology Inc., DNA4658F, 30 April 1978.

10. E. Chang et. al., DNA/DFSP Experiments in MISSION CYBER, Final Data Summary Report, General Research Corporation., CR-88-1012, 4 March 1988.

11. C.W. Cook, E.S. Ames, and R.W. Morris, The Linear Velocity Transducer Momentum Gage (U), Sandia National Laboratories, Albuquerque, SC-DR-69-531, November 1969 (SECRET/RESTRICTED DATA). 
12. K.D. Peterman, Makewire Gage Operation and Characteristics, General Research Corpration, CR-89-1093, 23 April 1990.

13. R.E. Tokeim et. al., Special Effects Program Stress Wave Response Lethality Study, SRI International, DNA-TR-82-193, 15 October 1983 (SECRET/FORMERLY RESTRICTED DATA) .

14. A.J. Watts et. al., Thin Film Transport (PUFF-TFT) Computer Code Development, Ktech Corporation, AFWL-TR-88-66 Parts 1 and 2, June 1988.

15. AUTODYN Users Manual Version 2.1, Century Dynamics Inc., 903 Paramount Road, Oakland, CA. 94610, 1989.

16. P.M. Holland et. al., Hydrocode Results for the Penetration of Continuous, Segmented, and Hybrid Rods Compared With Ballistic Experiments, to be published in the International Journal of Impact Engineering.

17. P.J. Mallozzi, B.P. Fairand, and R.G. Jung, Effects of High-Intensity Photon Fluences (U), Battelle Memorial Institute, AFWL-TR71-101, JUly 1972 (SECRET/RESTRICTED DATA).

18. D.L. Johnson, HYPUF Upgrade Final Report, MCDonnell Douglas Astronau-ics Co., MDC-H5234, January 1989 (to be published as a Defense Nuclear Agency report).

19. Trans-Tek Incorporated, P.0. Box 338, Route 83, Ellington, Connecticut $06029(203 / 872-8351)$.

20. PSPICE User's Manual, May 1986, Microsim Sorporation, 23175 La Cadena Drive, Laguna Hills, CA. 92653 (714/770-3022). 
APPENDIX A

LISTING OF TFT INPUT FILE THAT MODELED GAS GUN TESTS 


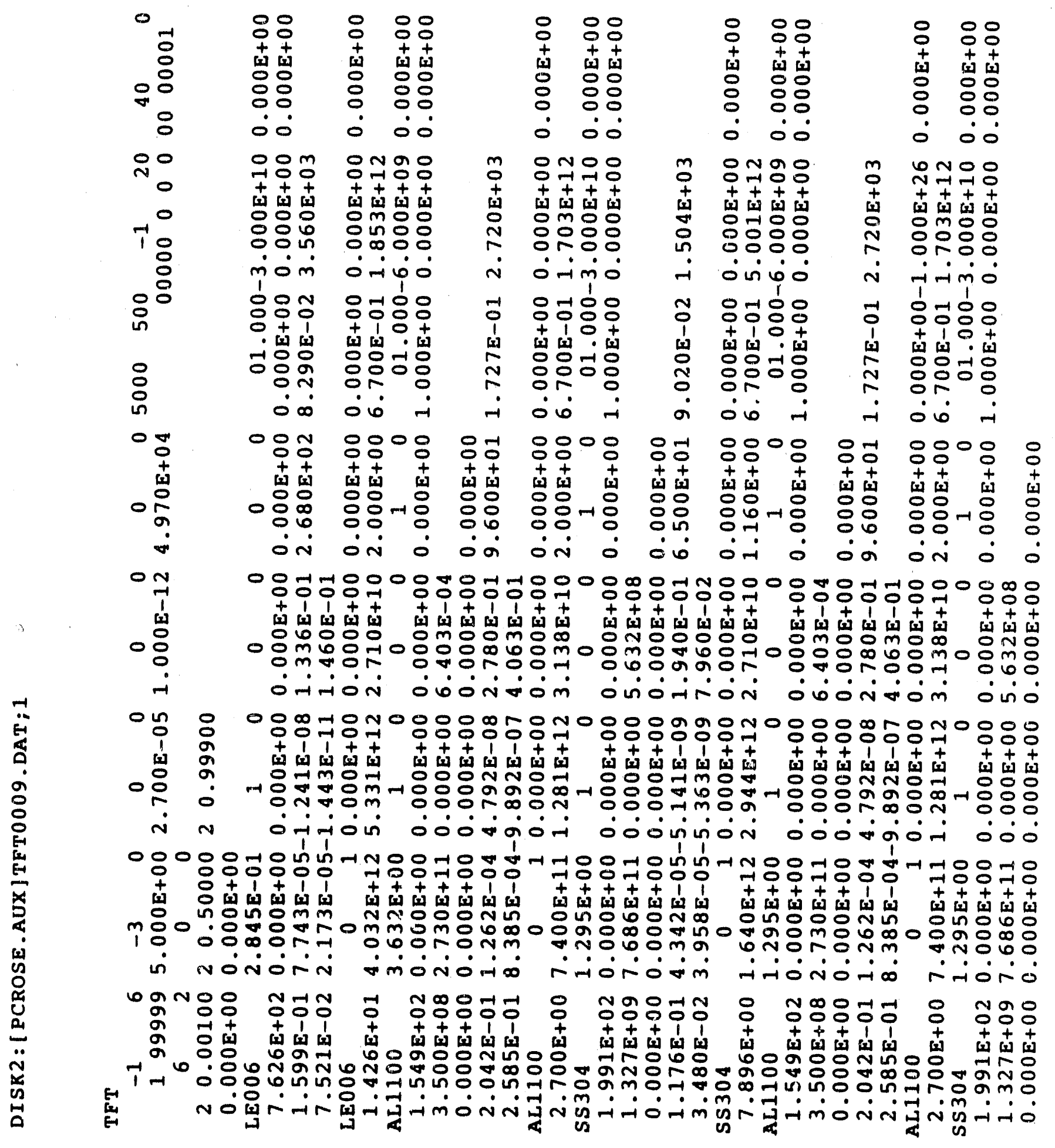




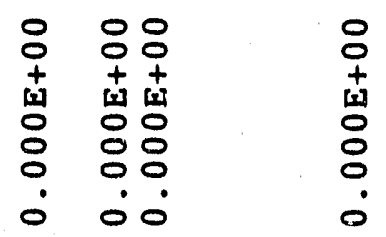

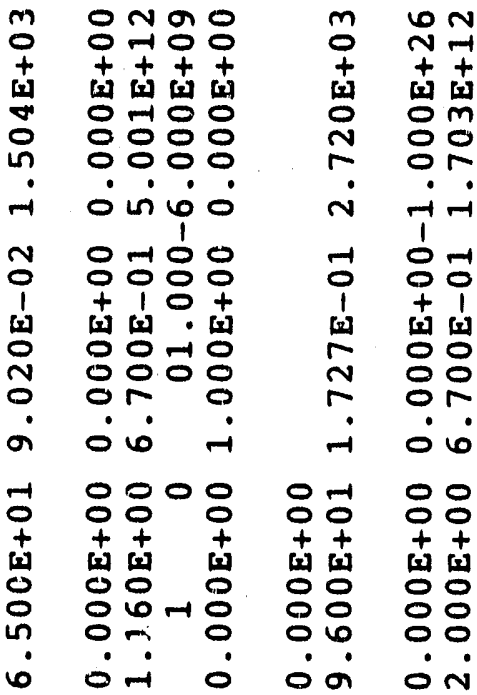
-1 NOOOOOONO $000+1000000+$

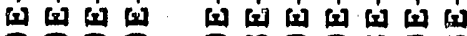

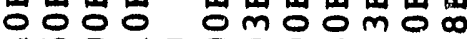

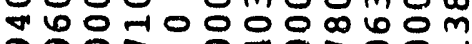
anor o 0 orol تர் $\dot{0} \dot{0} \dot{0} \dot{0} \dot{0}$

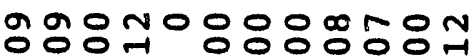

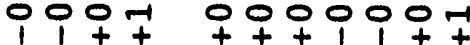

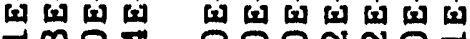
- mo $000 N N O$ - 6 임ㅇㅇㅇㅇㅇㅇㅇㅇ vín 0ं0ன் 光组m $0, \quad 700+1000$

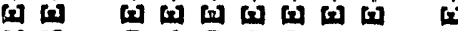

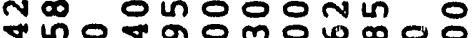
m

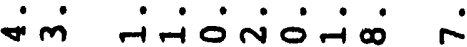

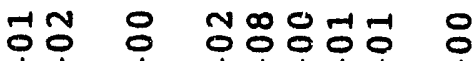
$11+t+t 11+$ 6。

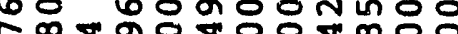
N $\dot{-i m}$ ध 
APPENDIX B

IMPULSE GAGE ENGINEERING DRAWINGS

B-1 

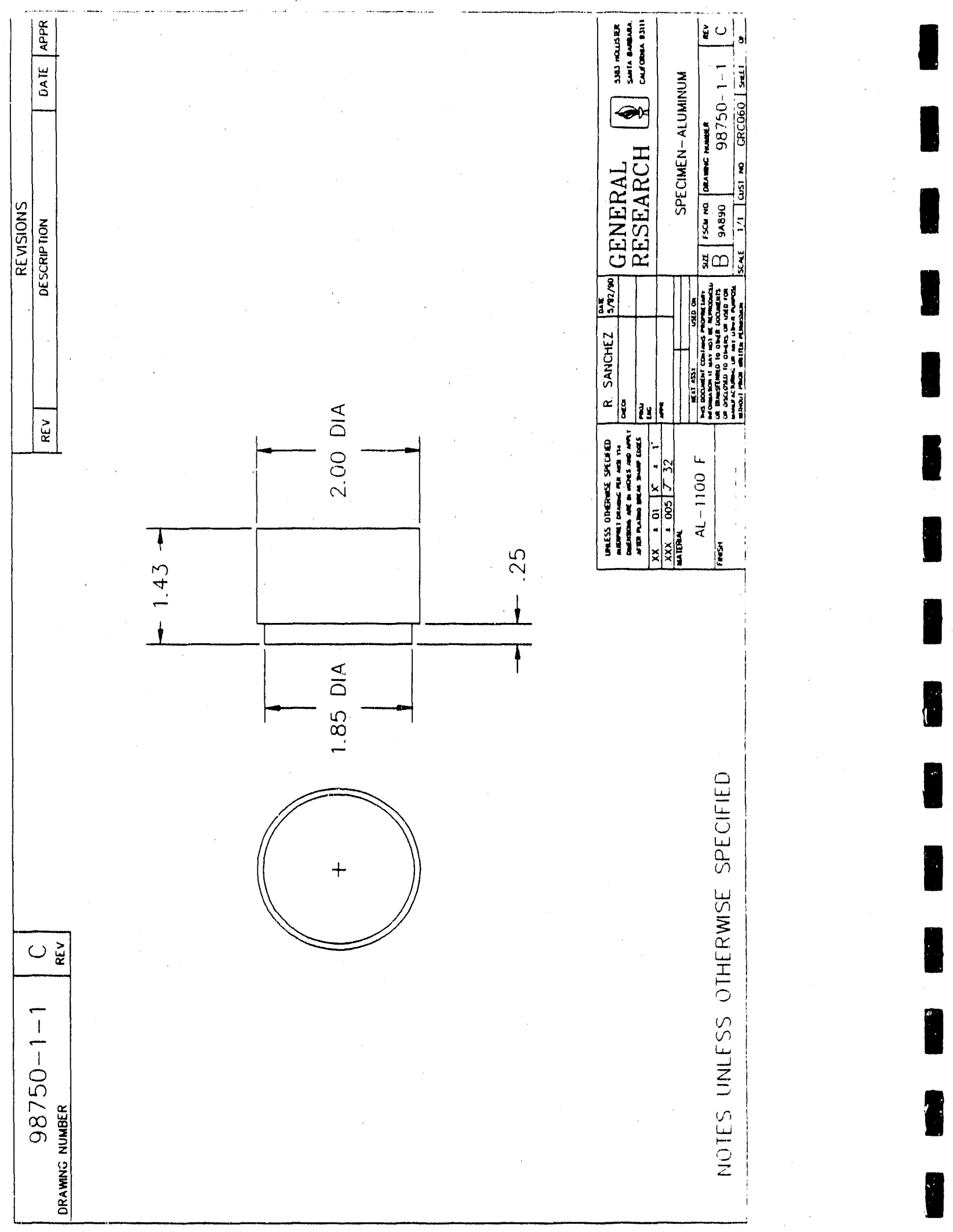


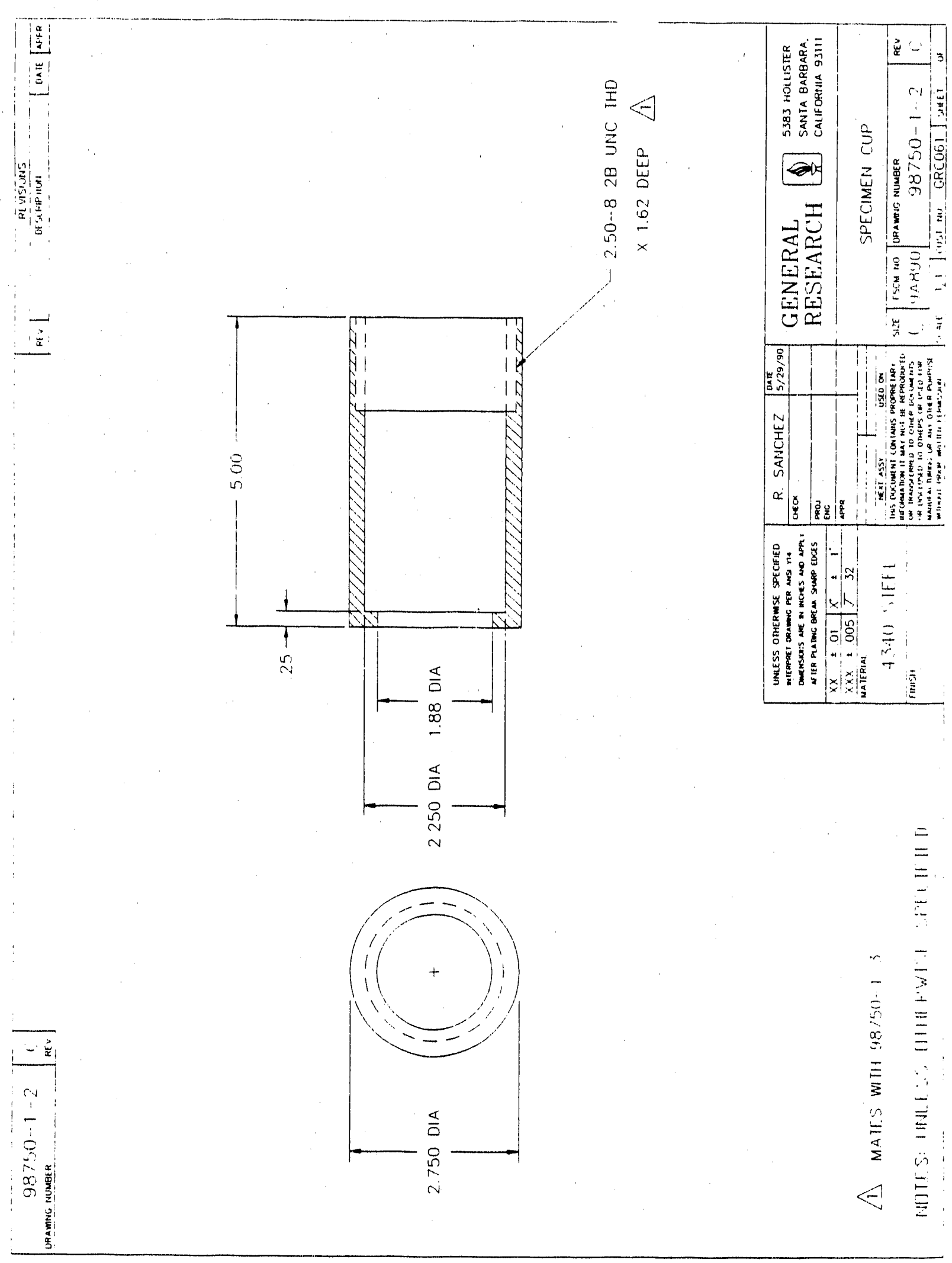

B-3 


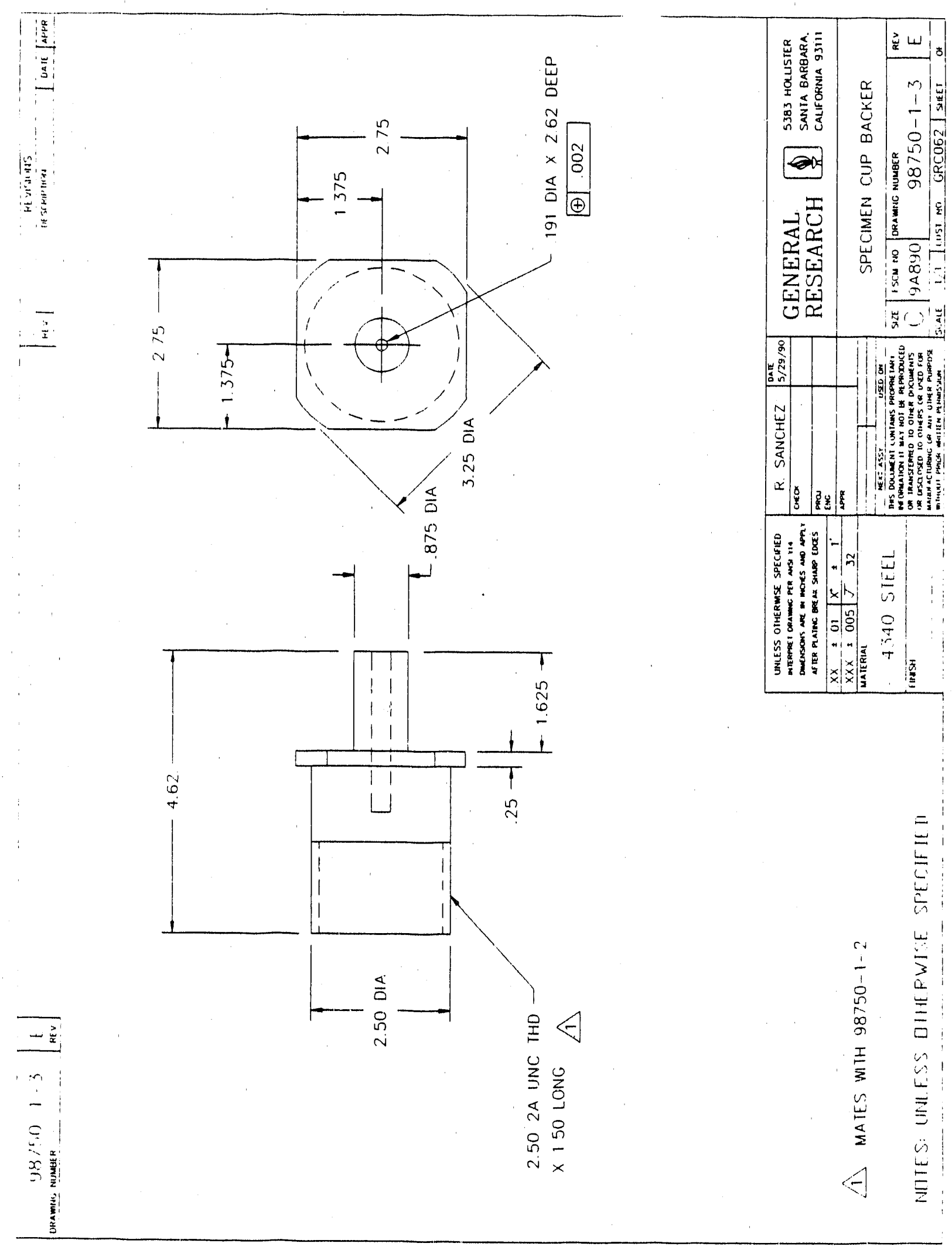




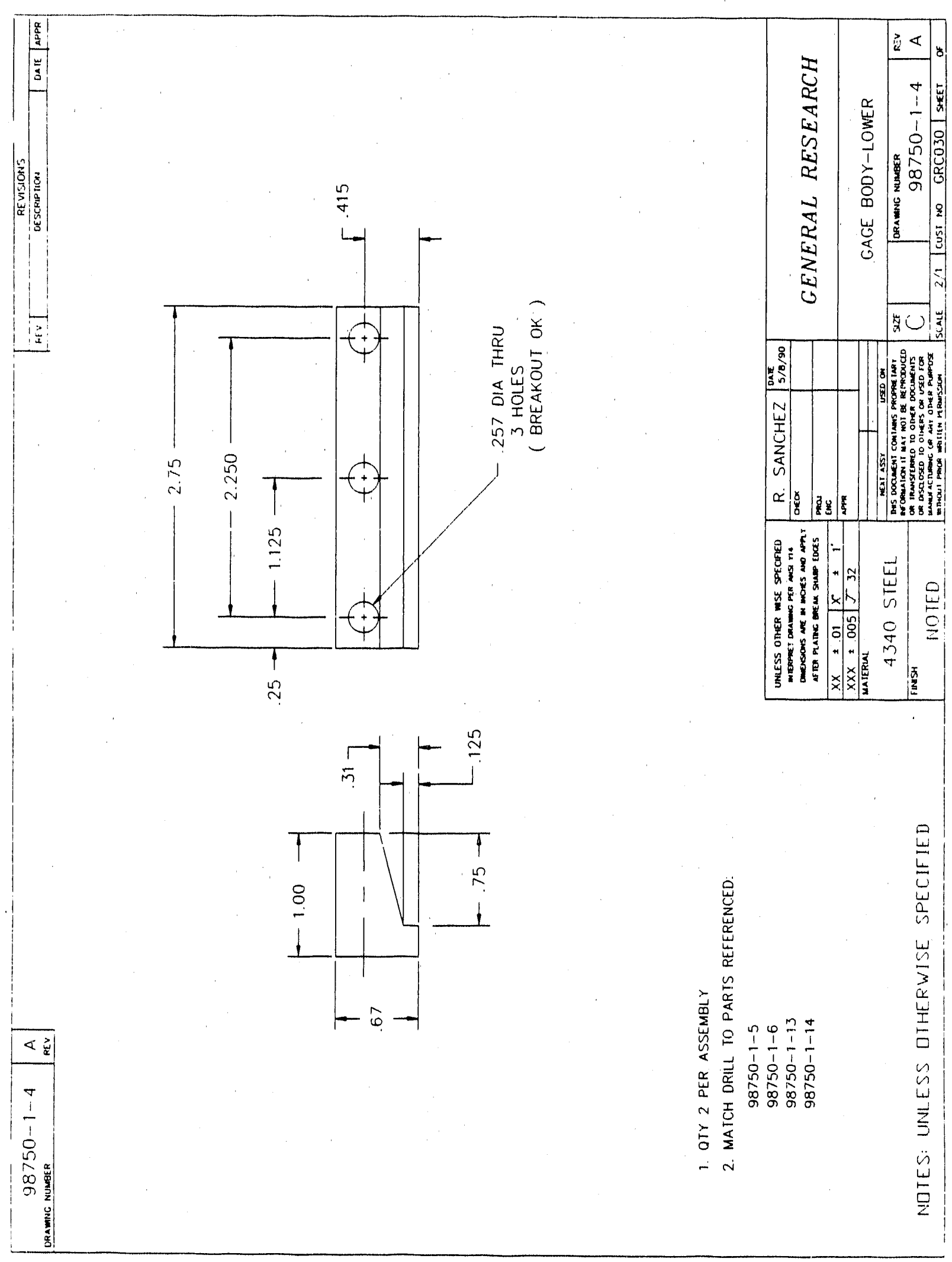




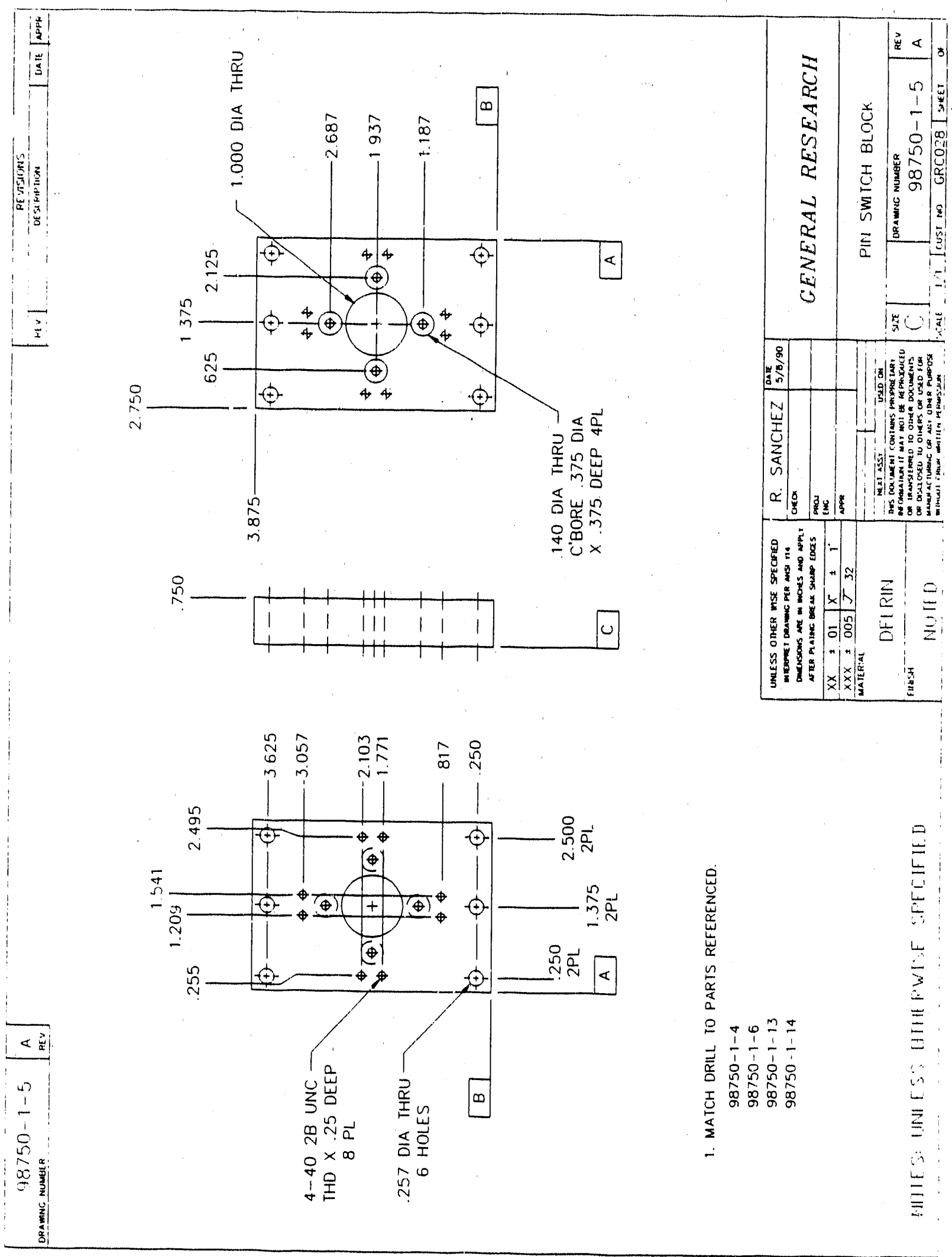




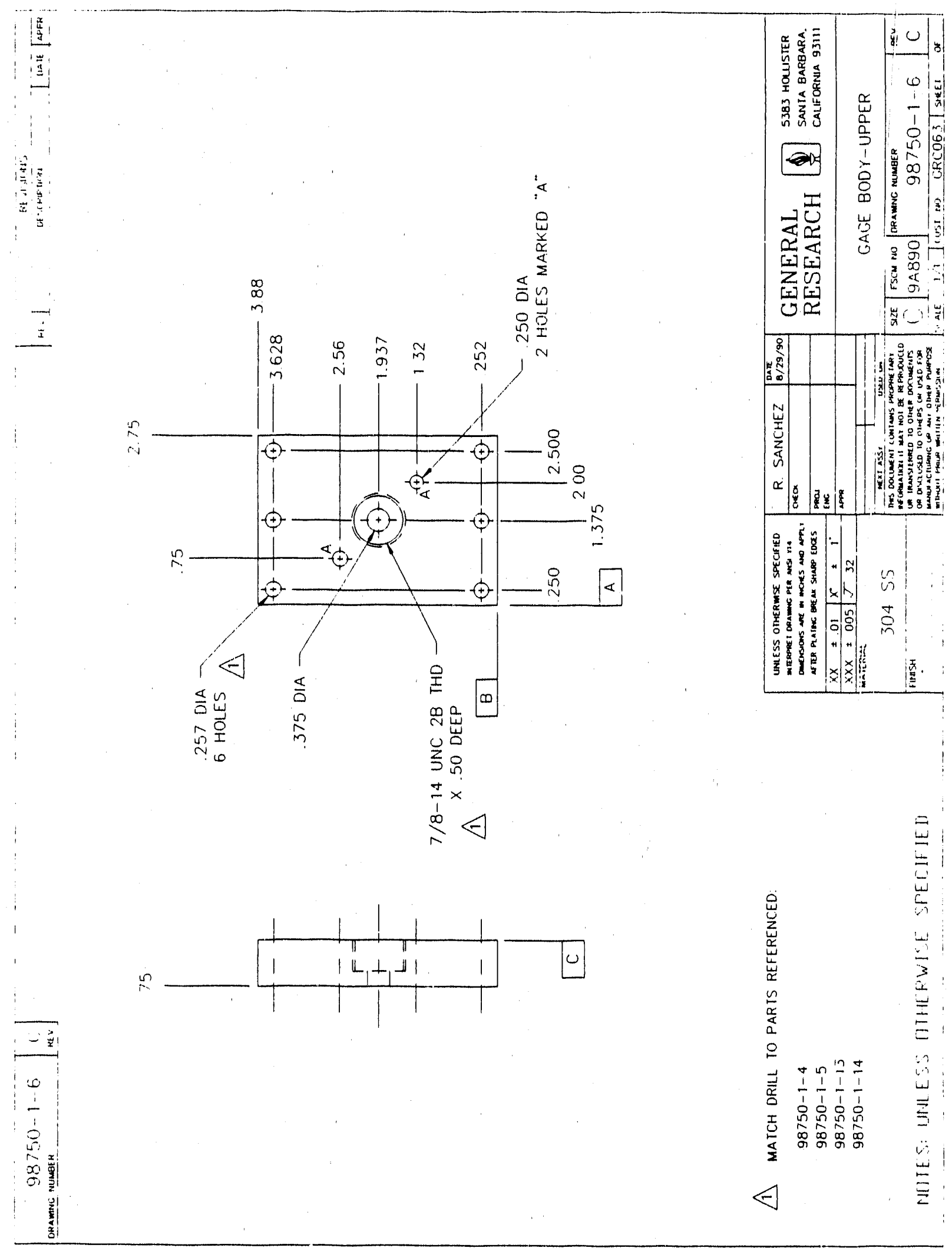




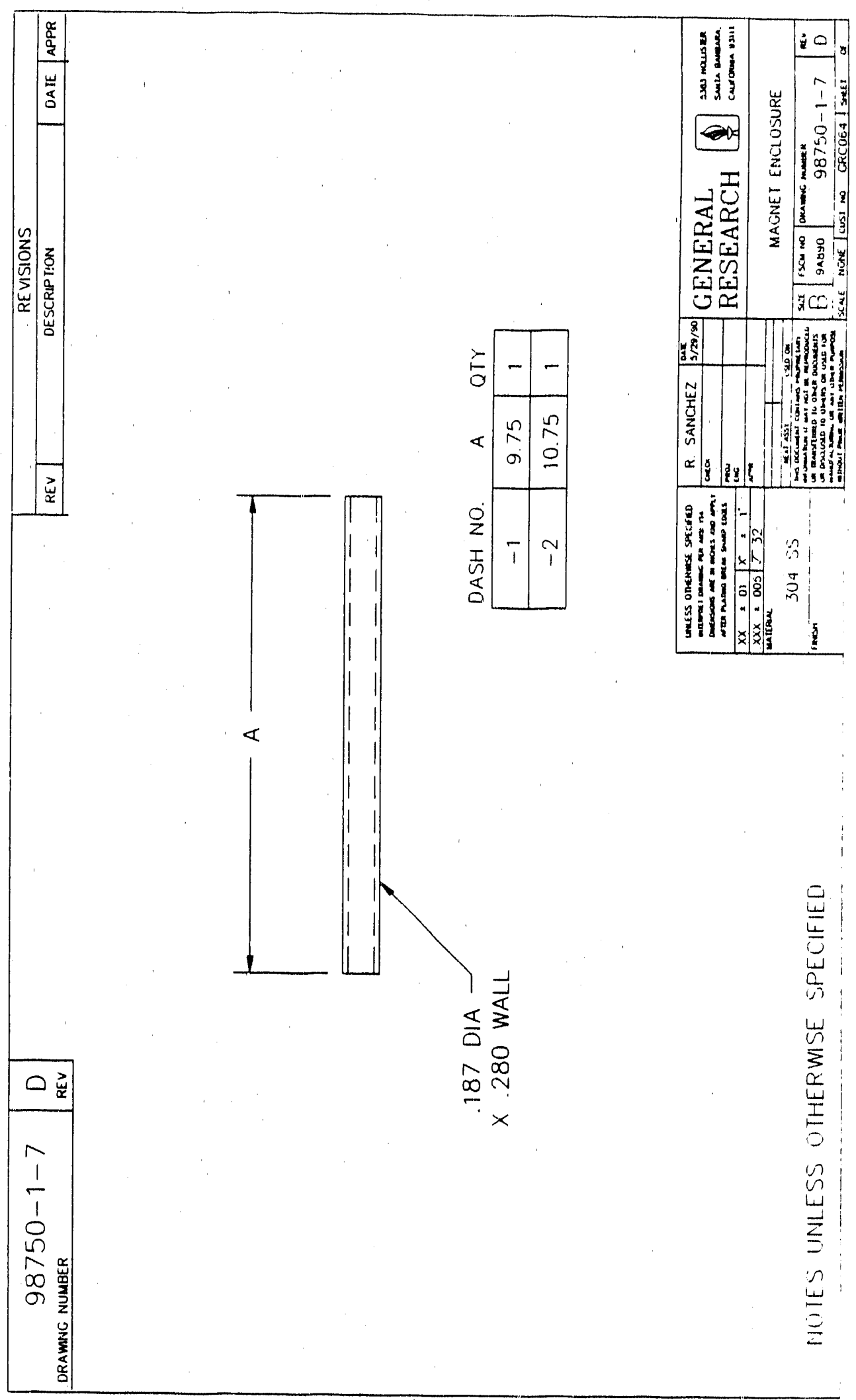




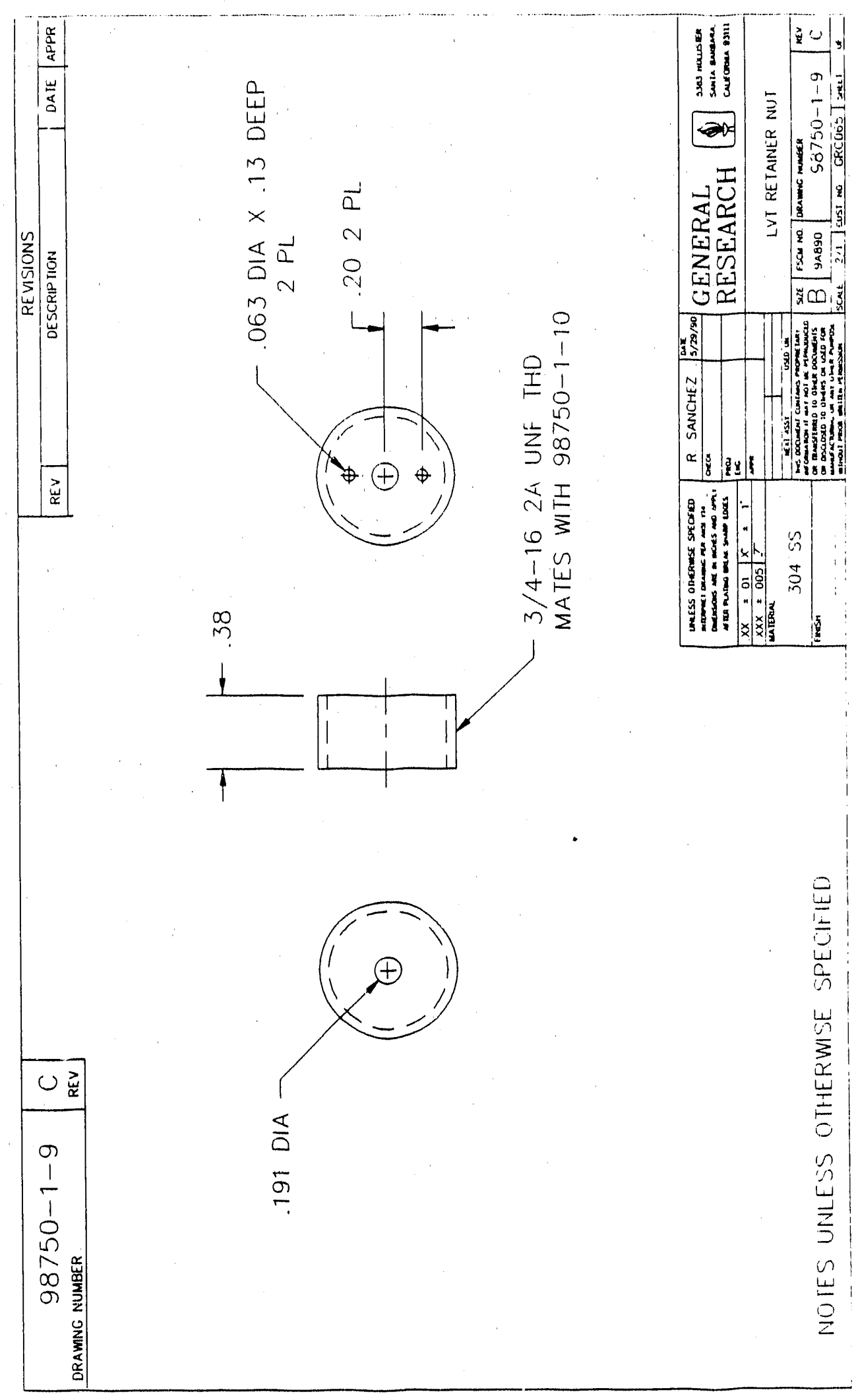




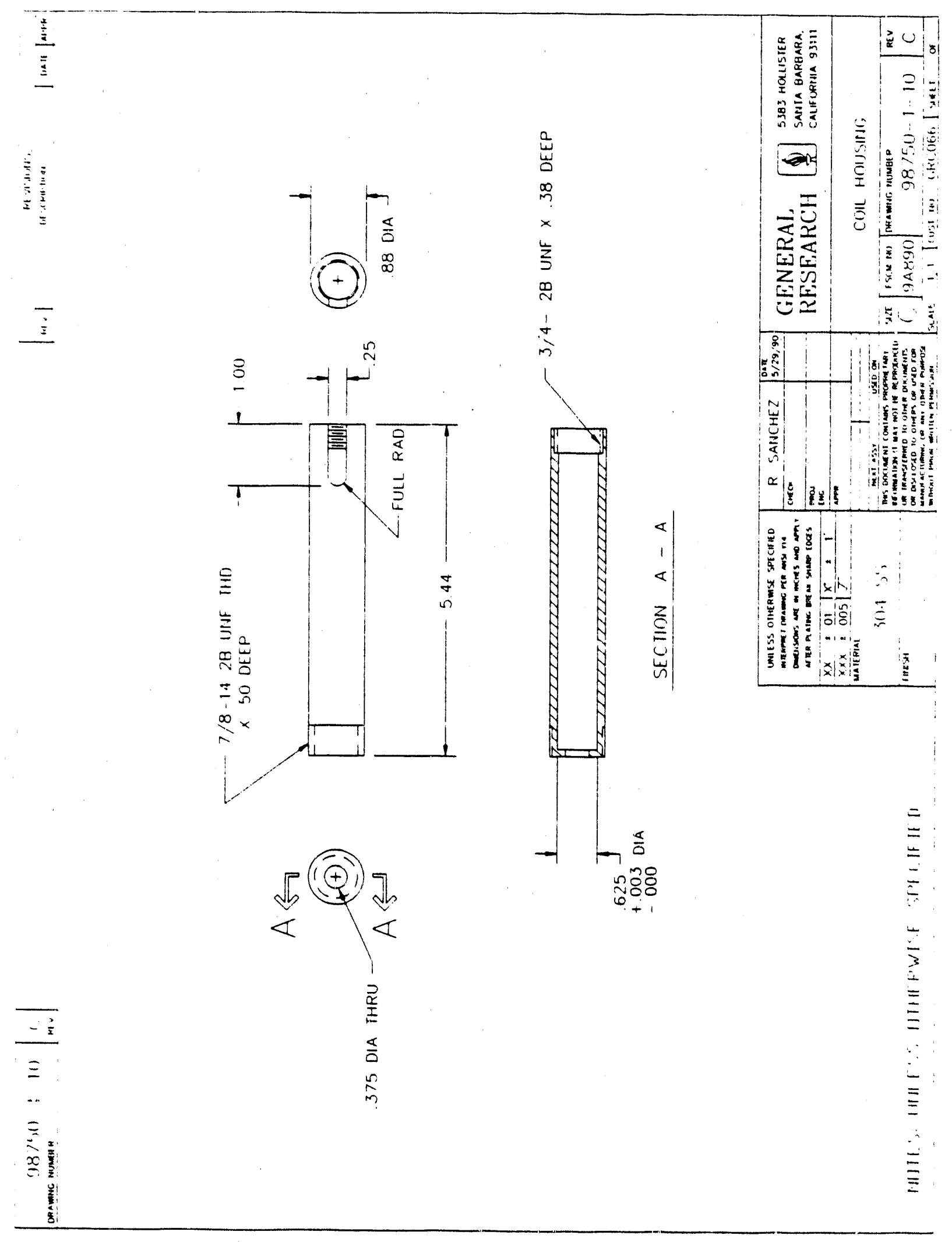




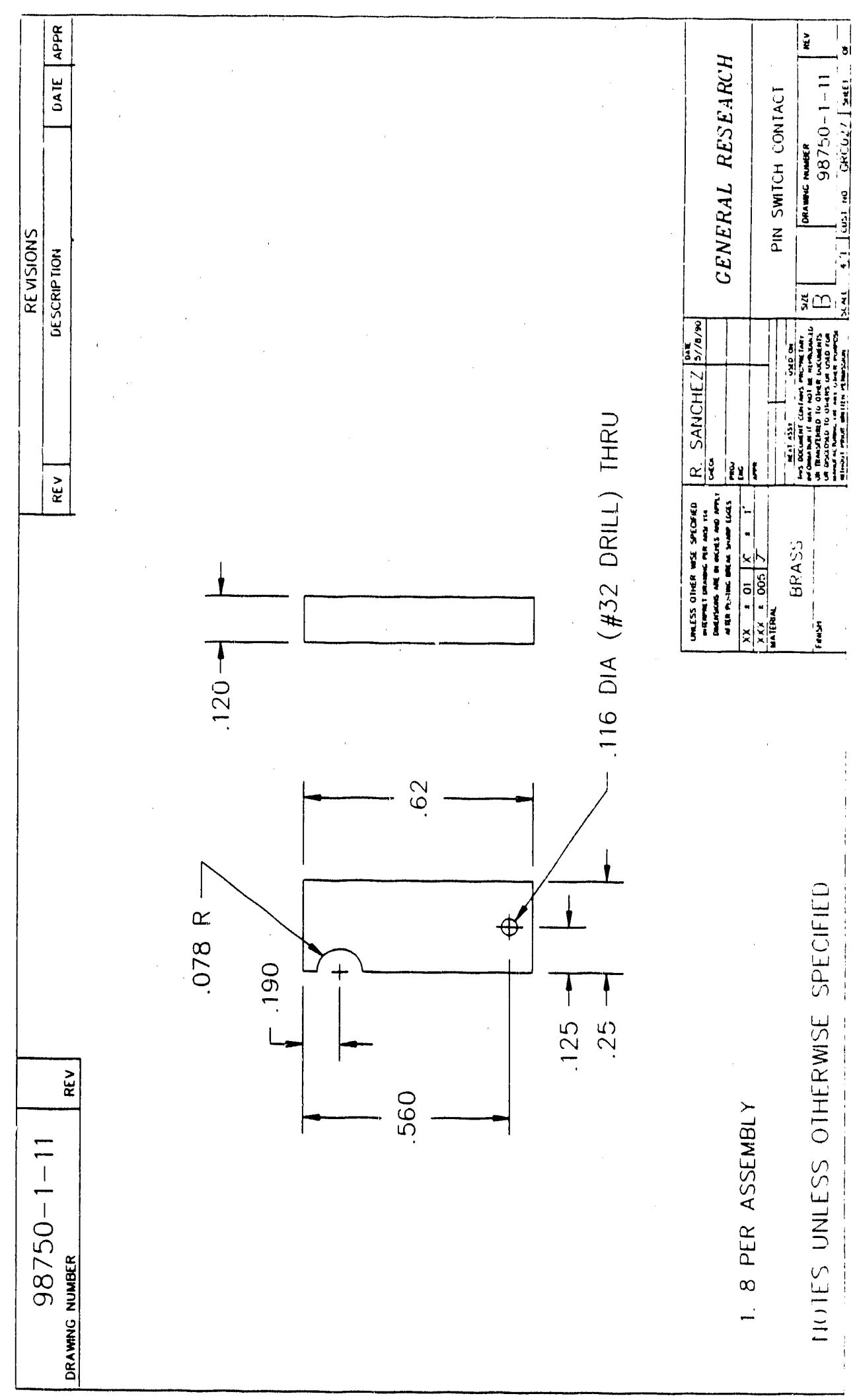




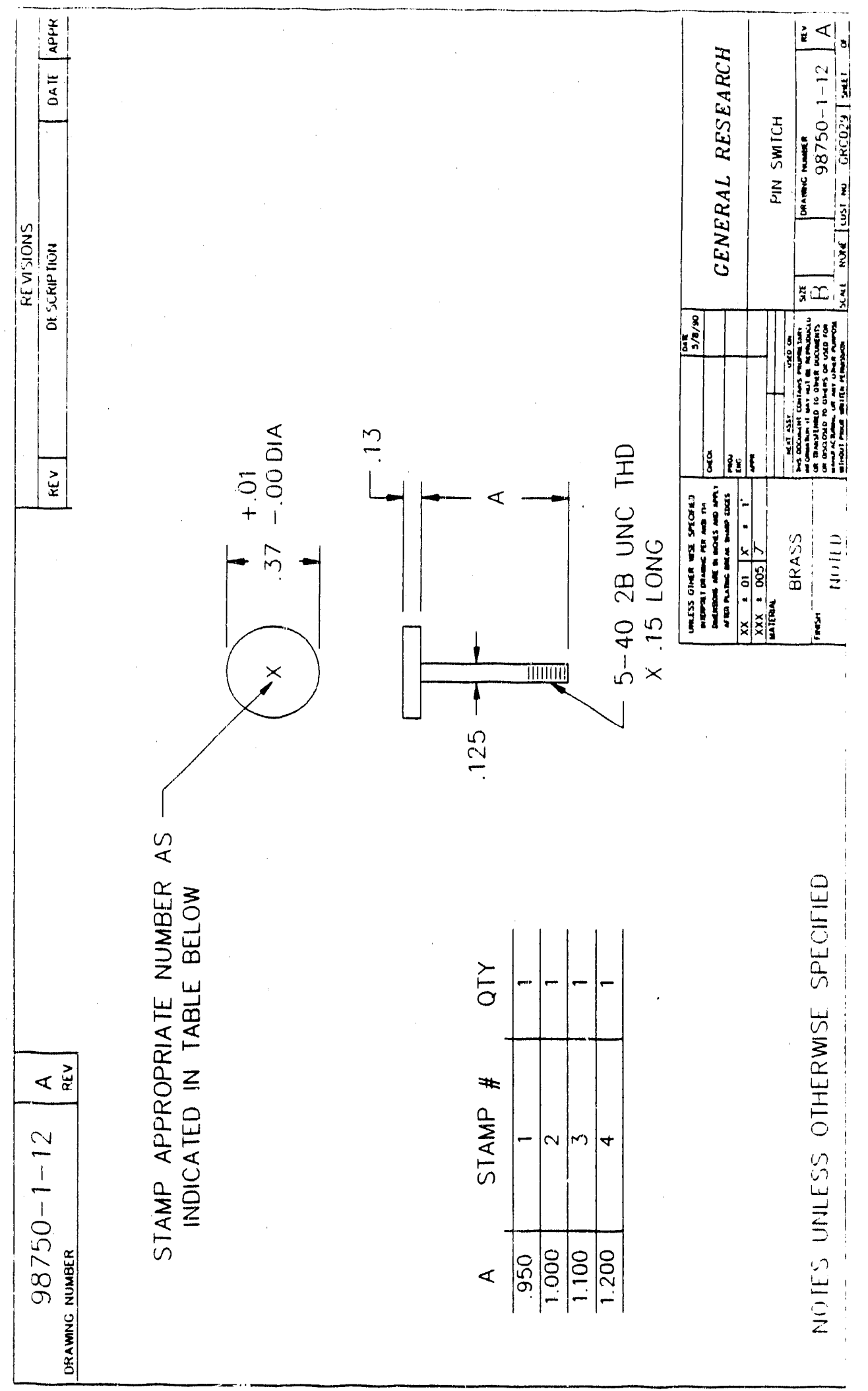

B-12 


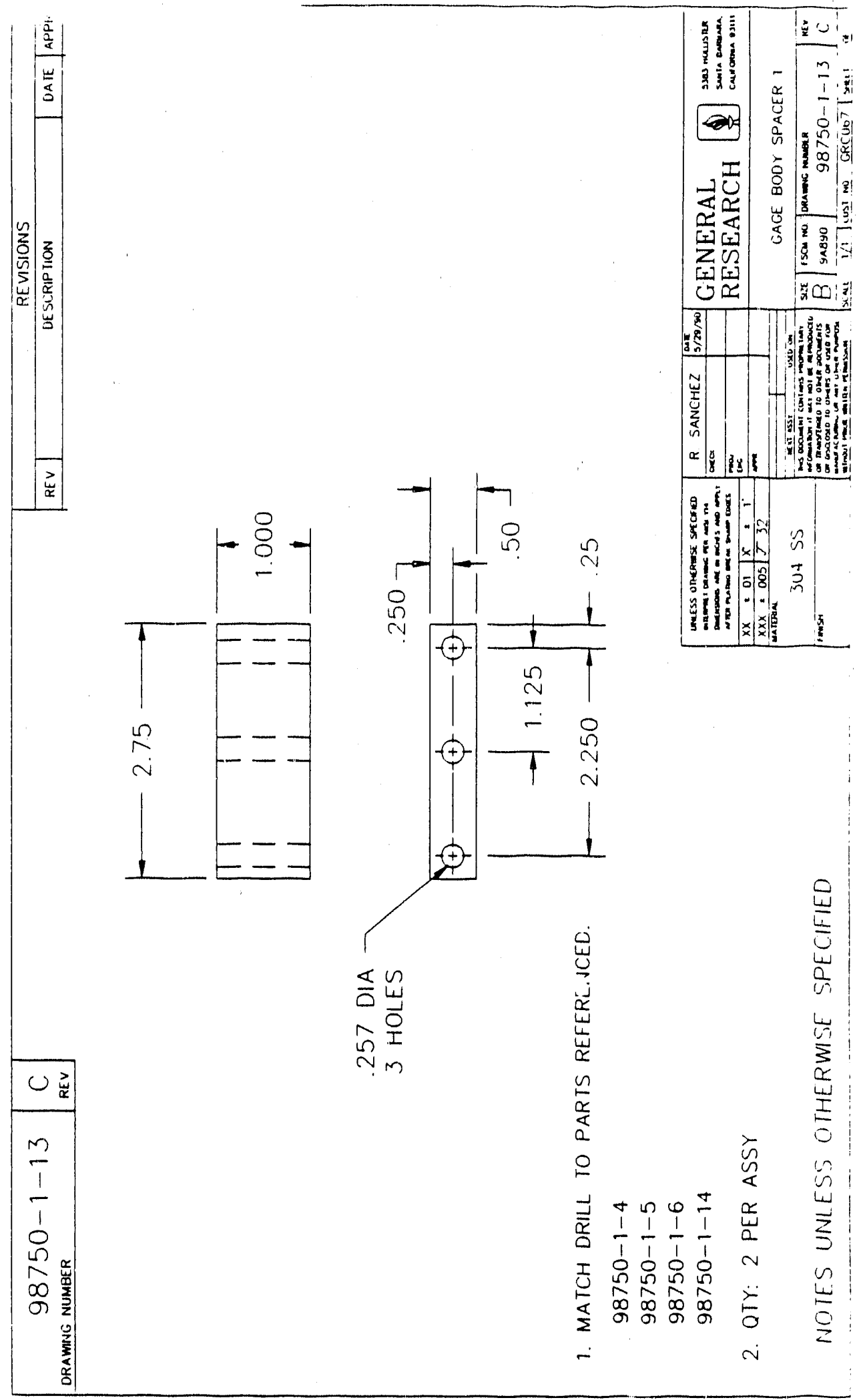



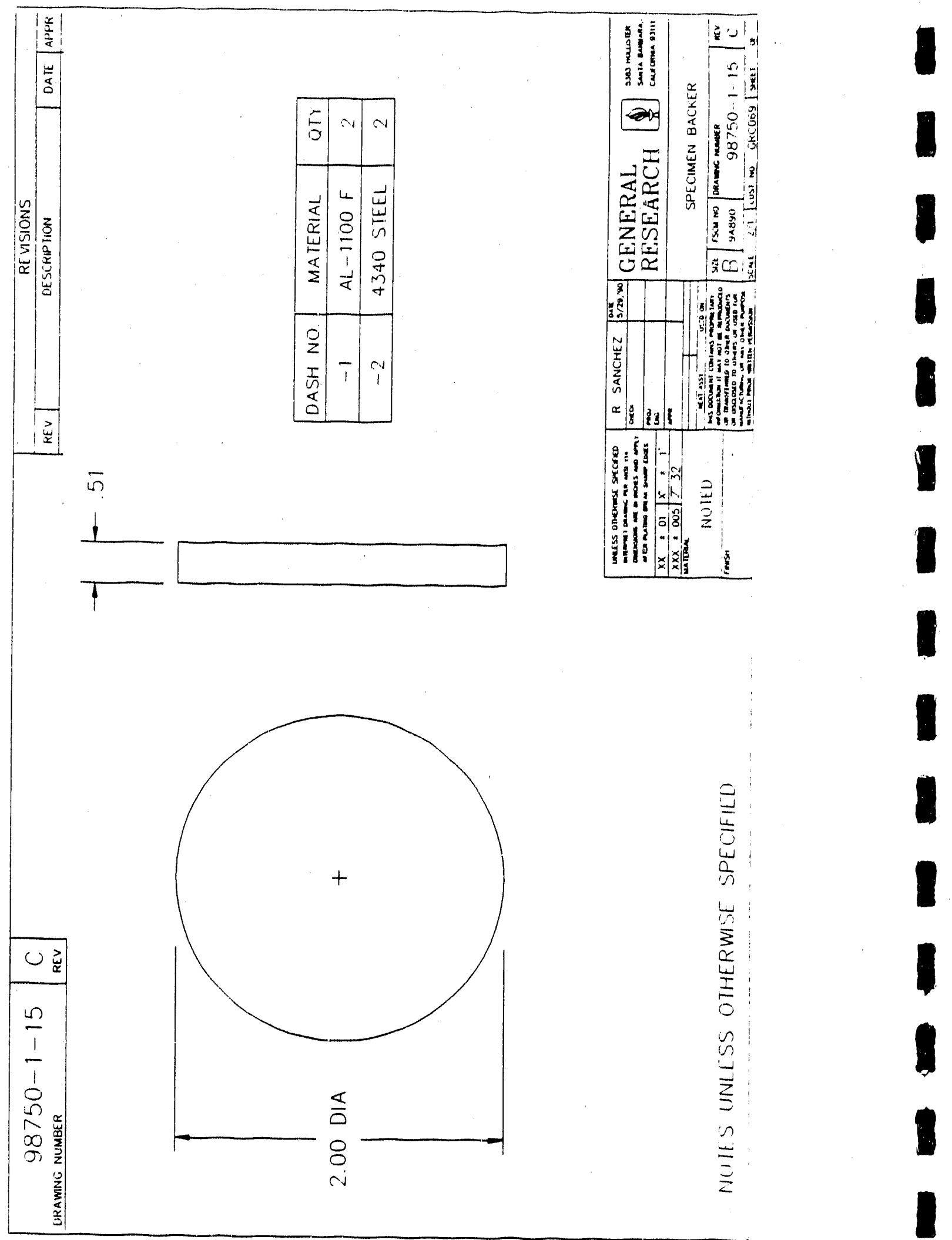


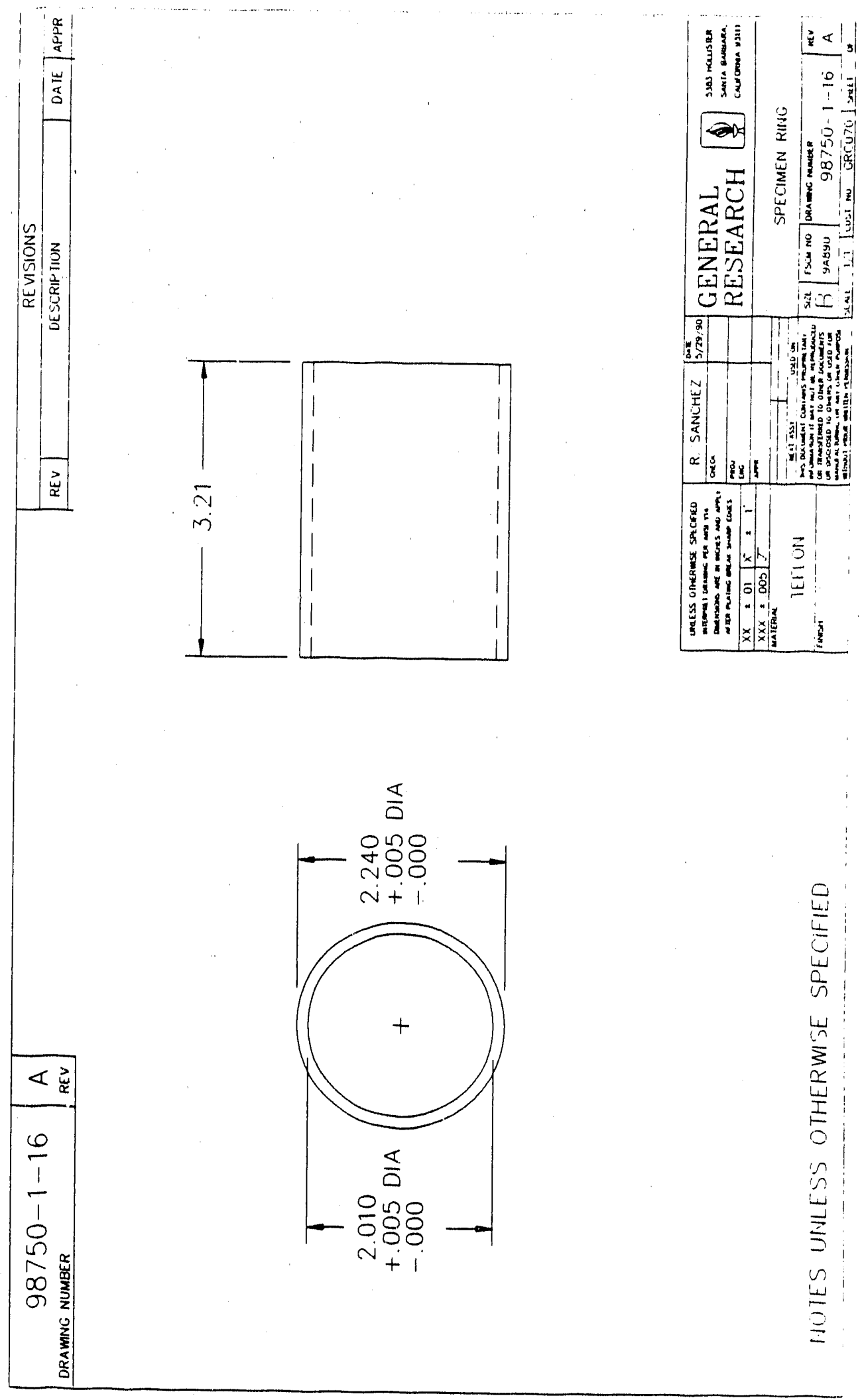

B- 15 



B-1 6 


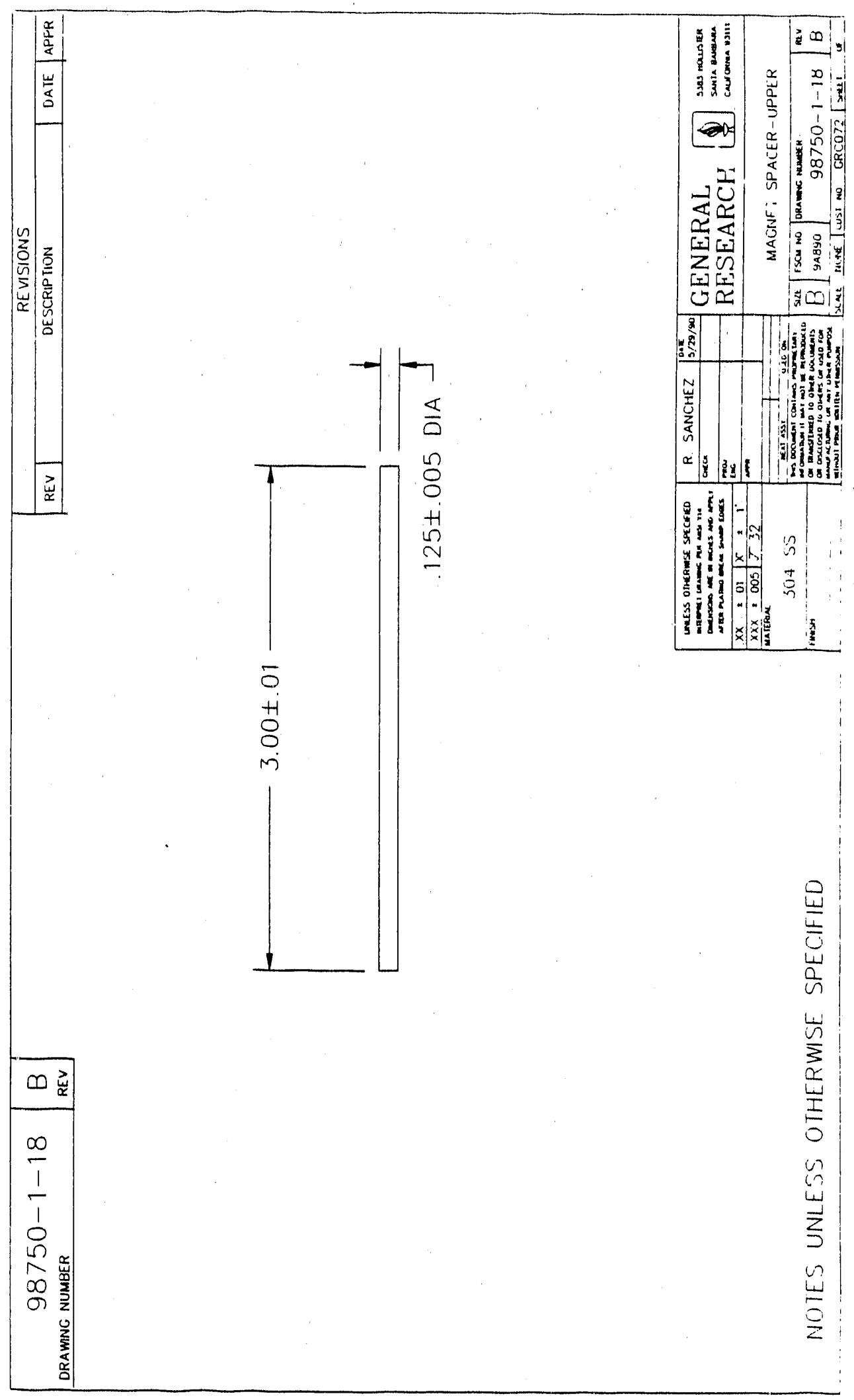

B- 17 


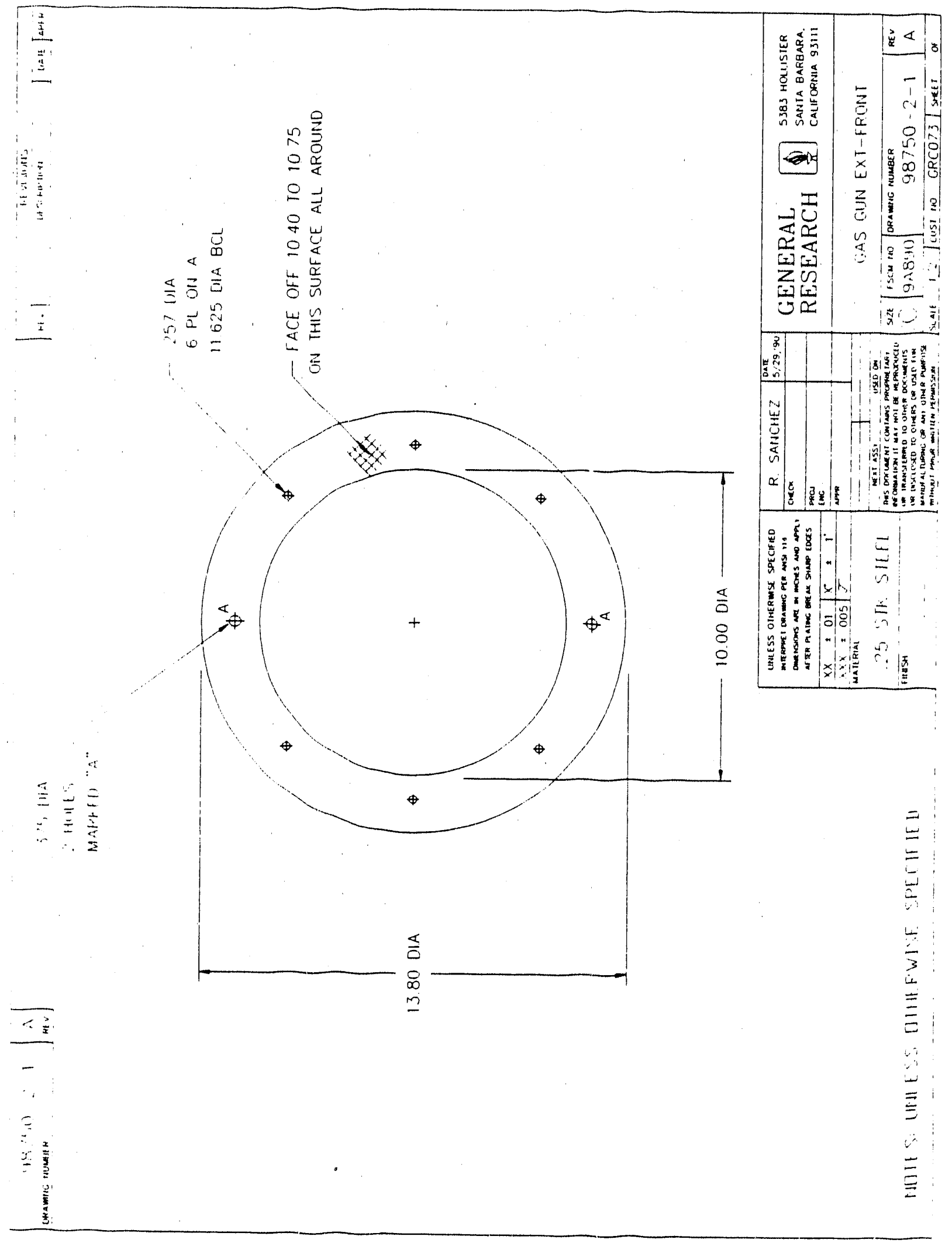




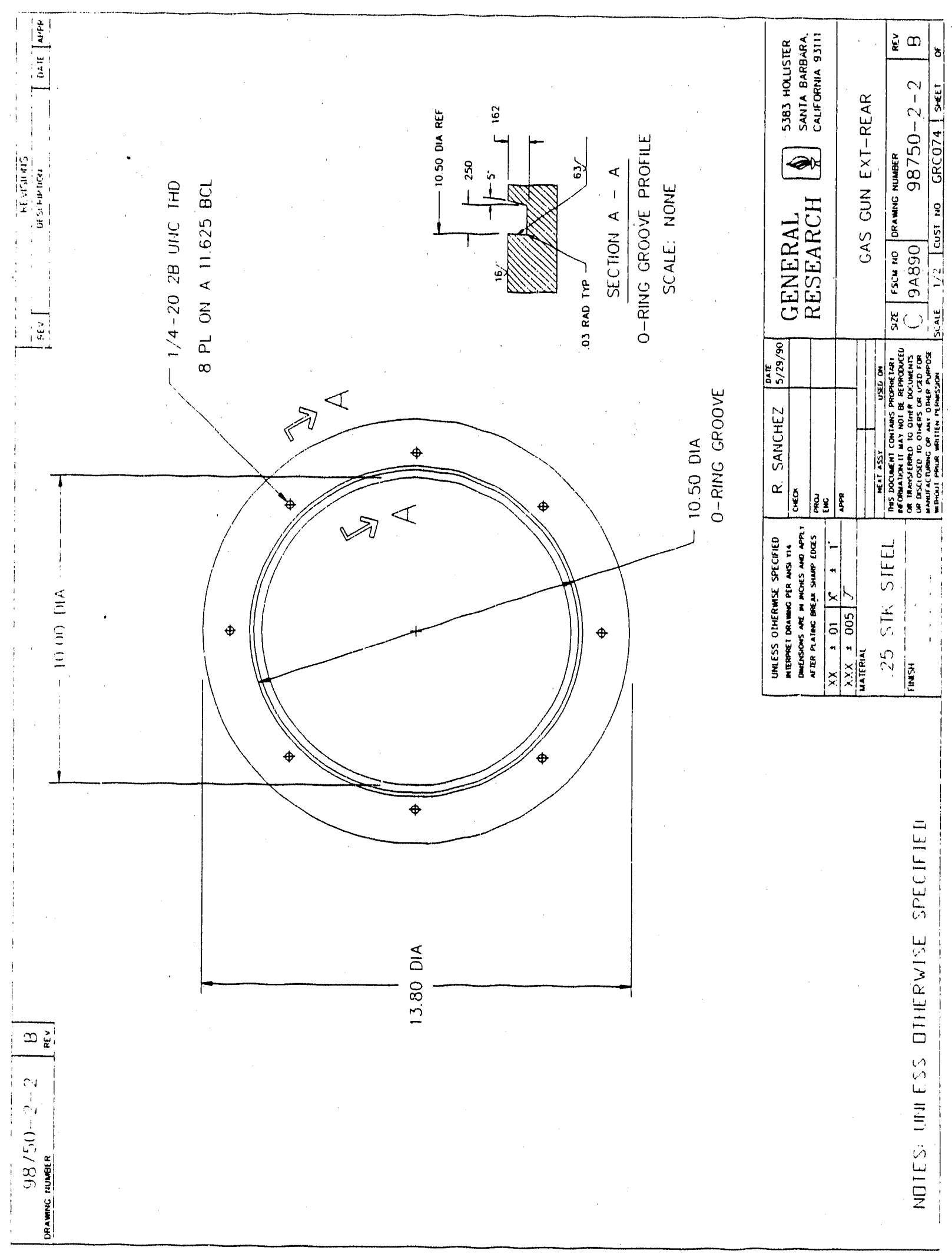




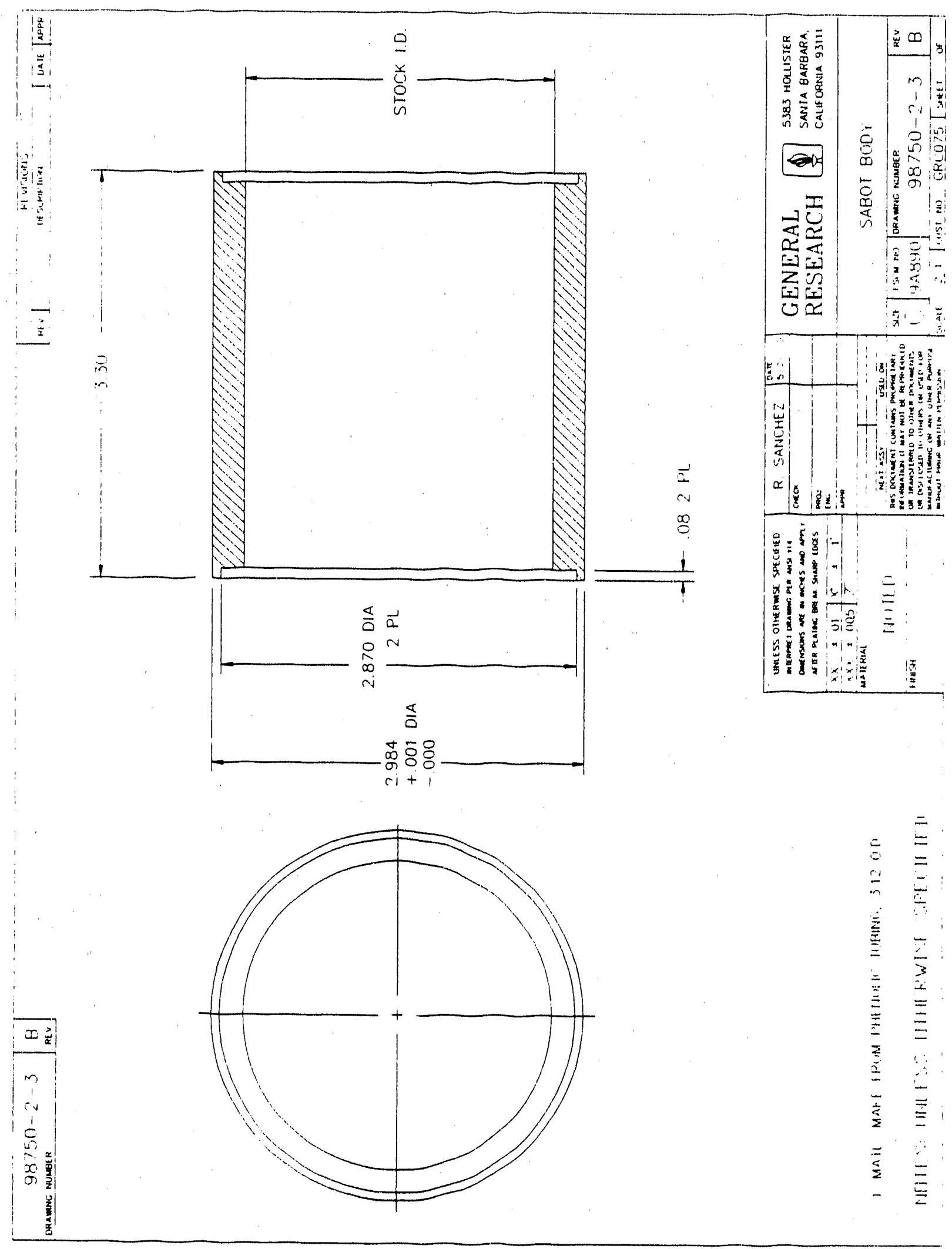




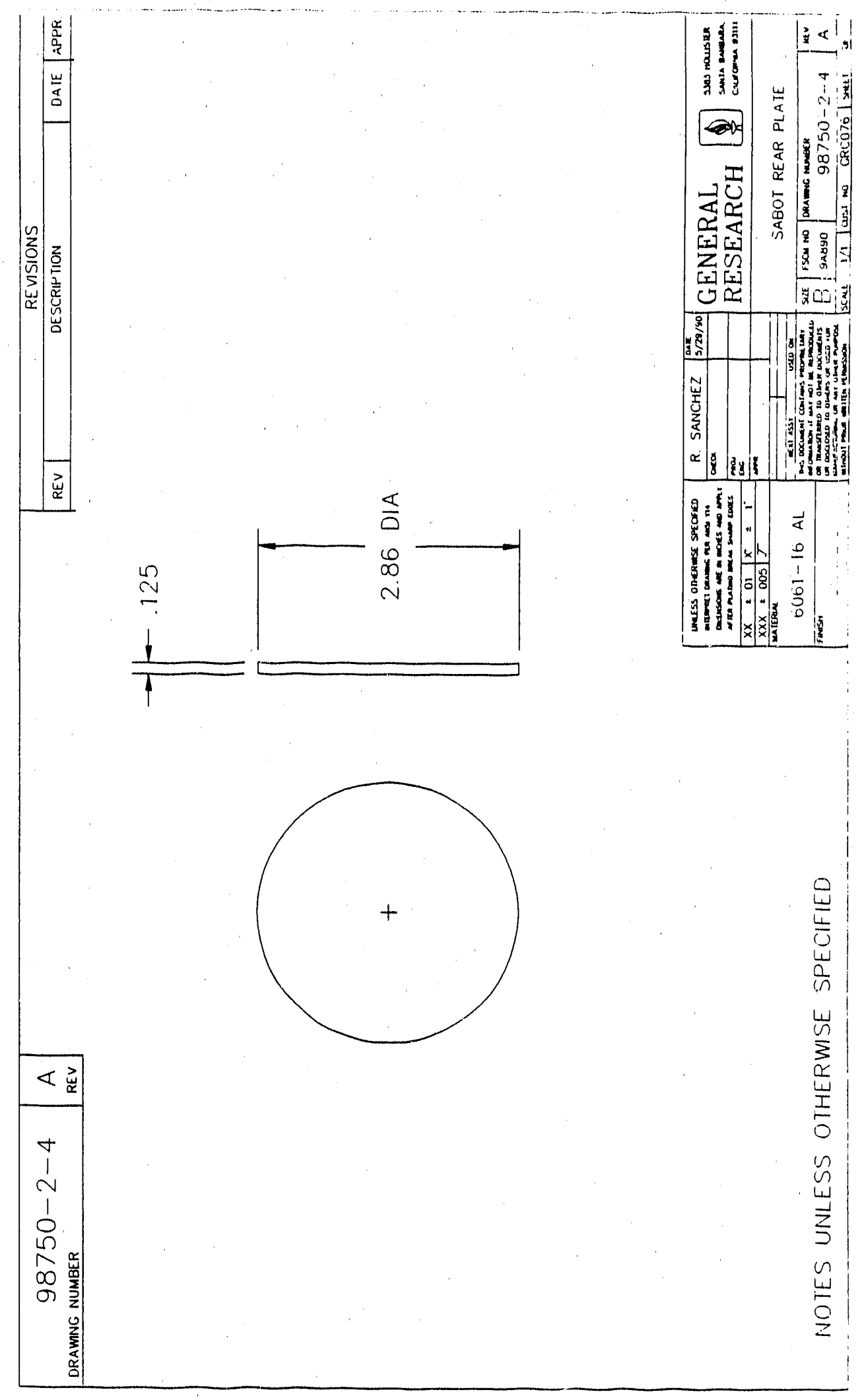

$B-21$ 


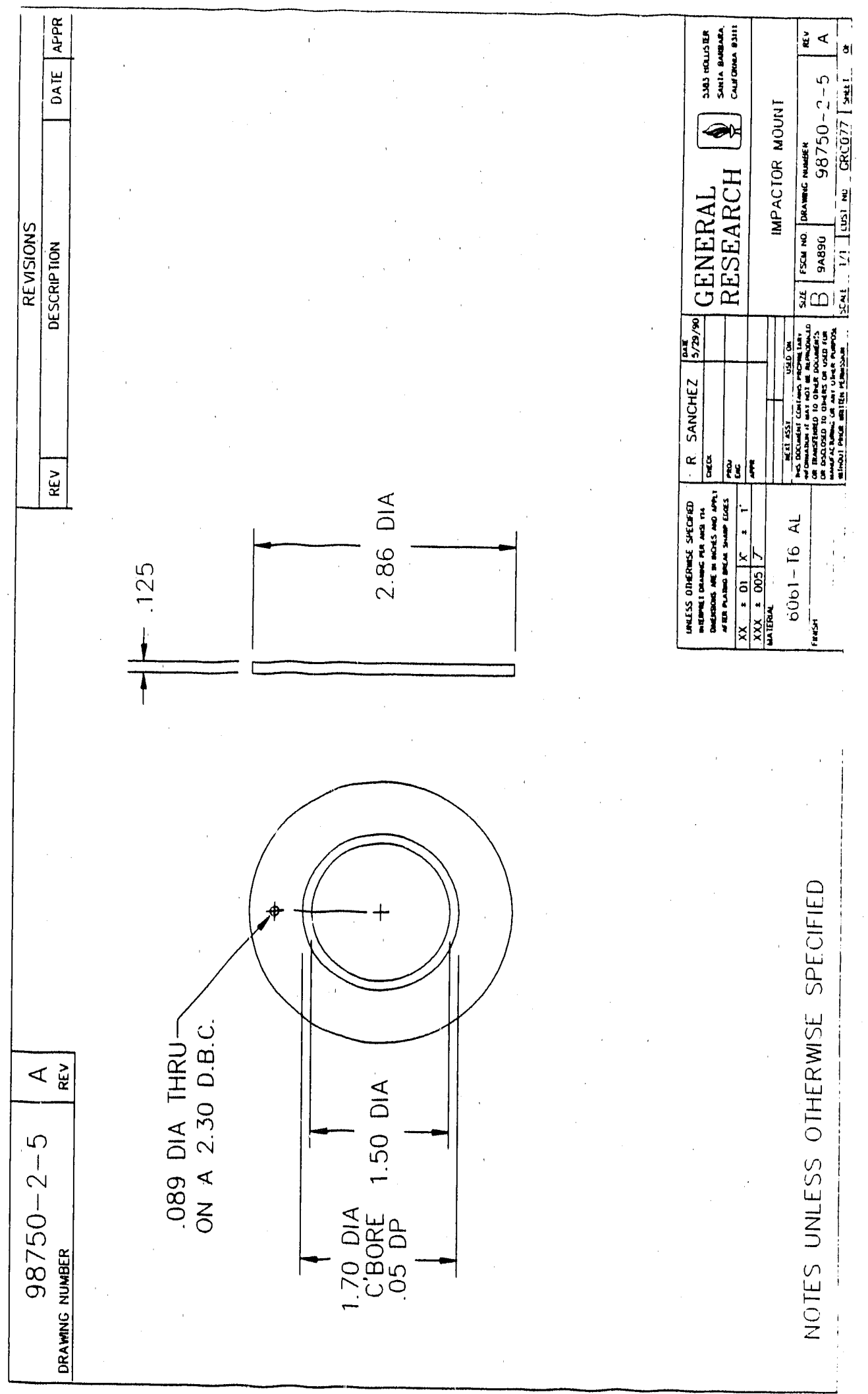



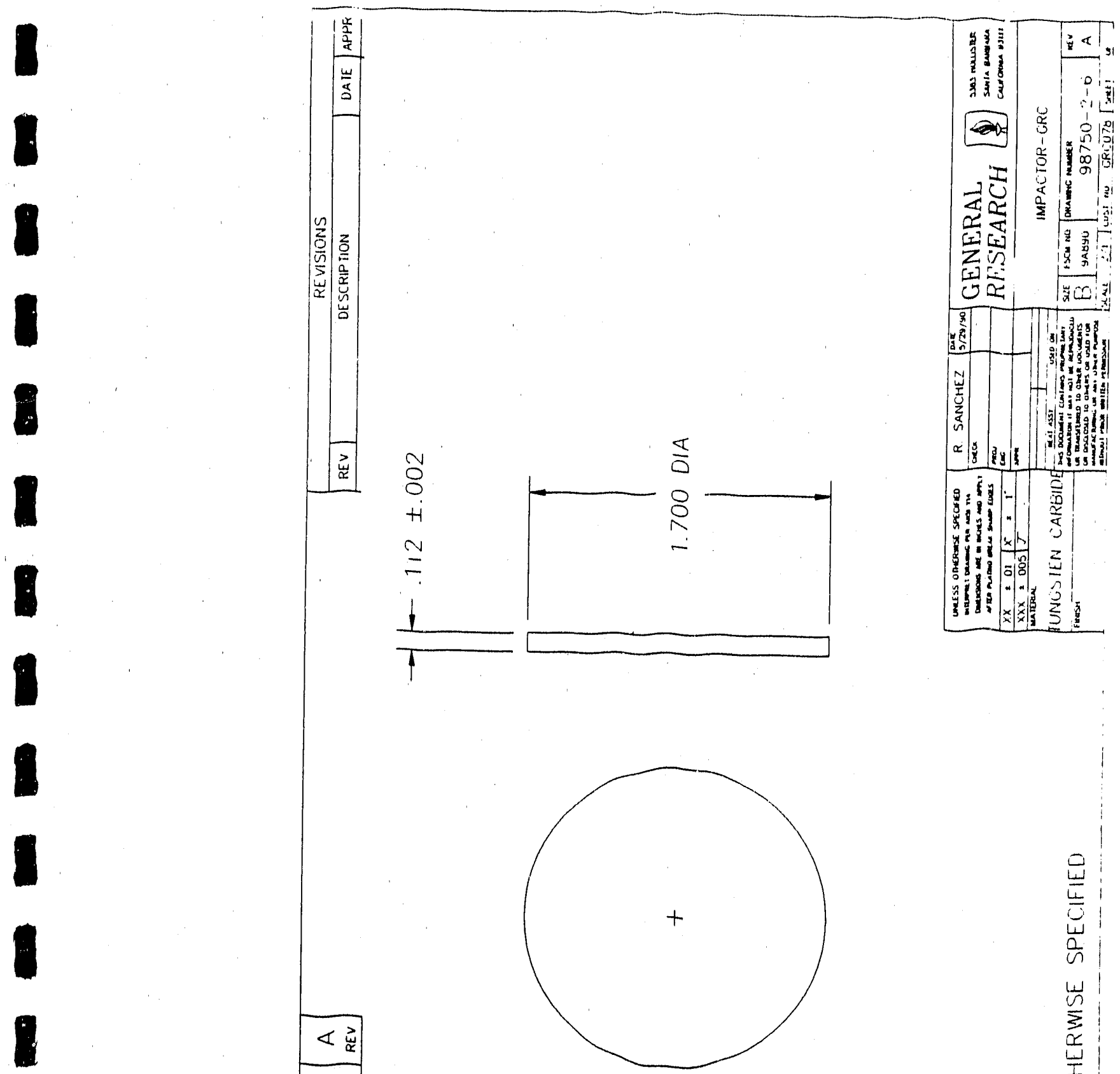

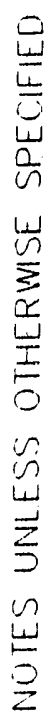




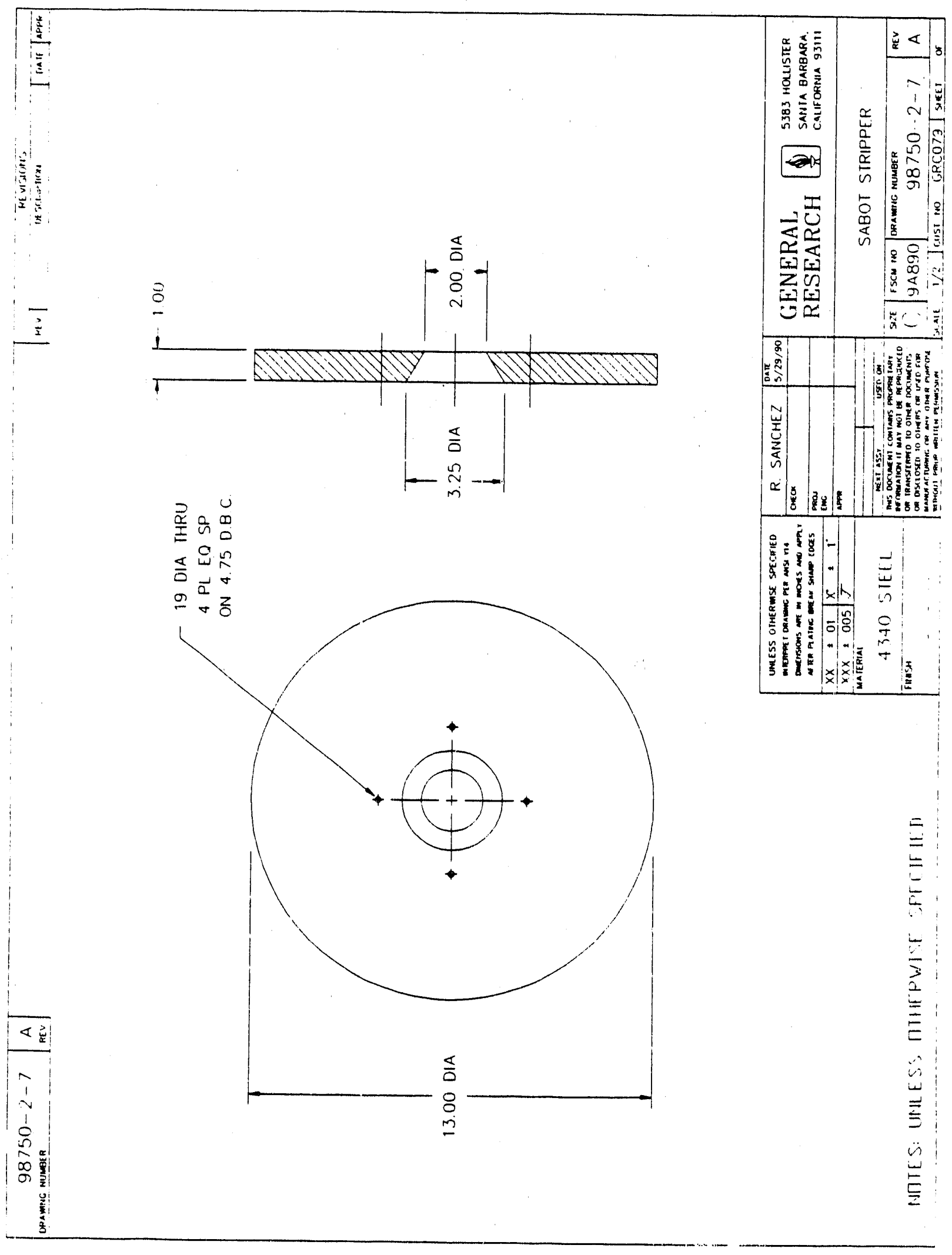


A.D. MACKAY, InC.

10 Noris Broutway

P.O. Box G

Red Hook NY !2571-0046

(914) 738-1033

PACKING SUP

INVOICE NO: 27178

I N $N$ O I C E

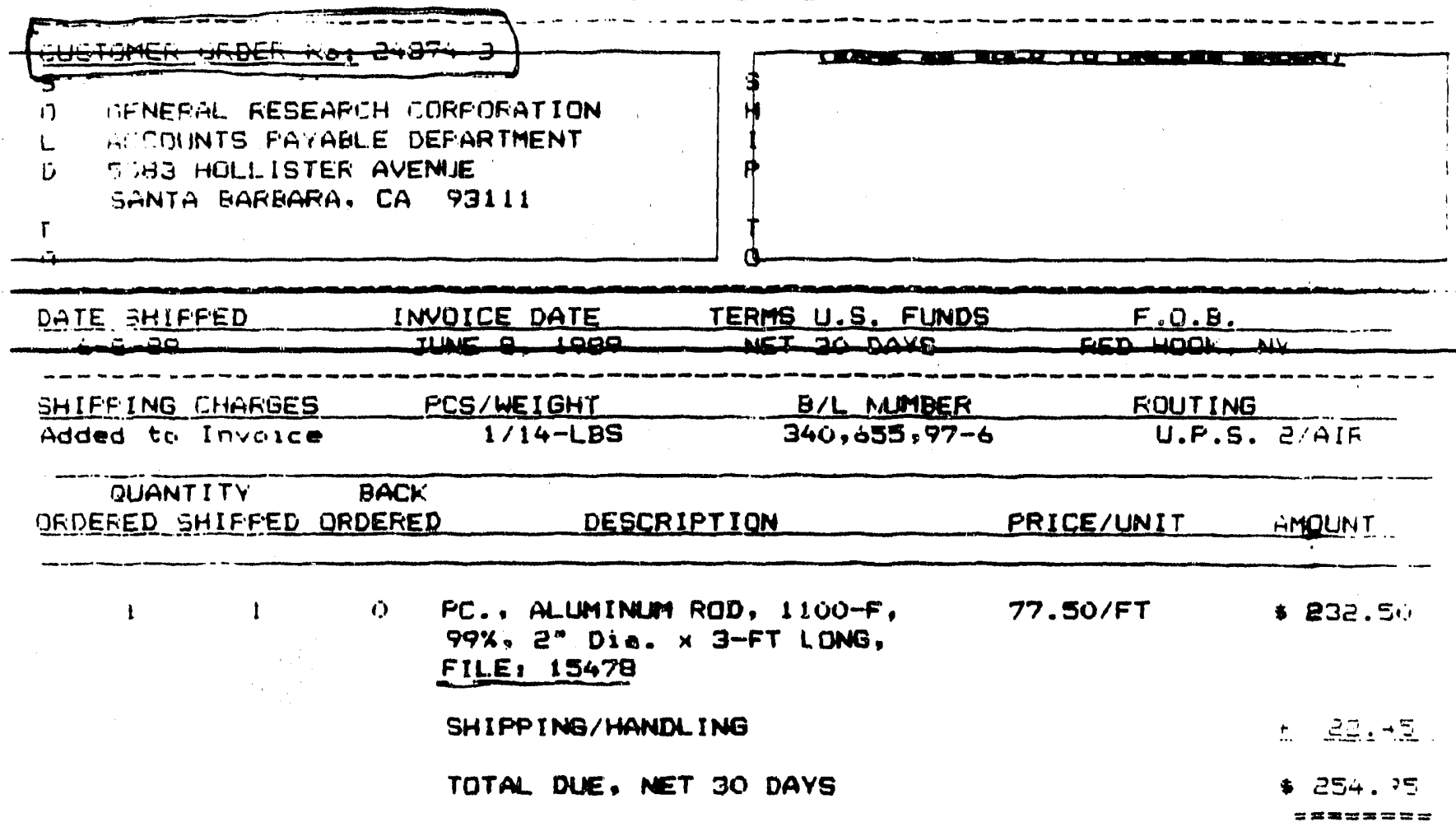

\section{PACKING SUPP}

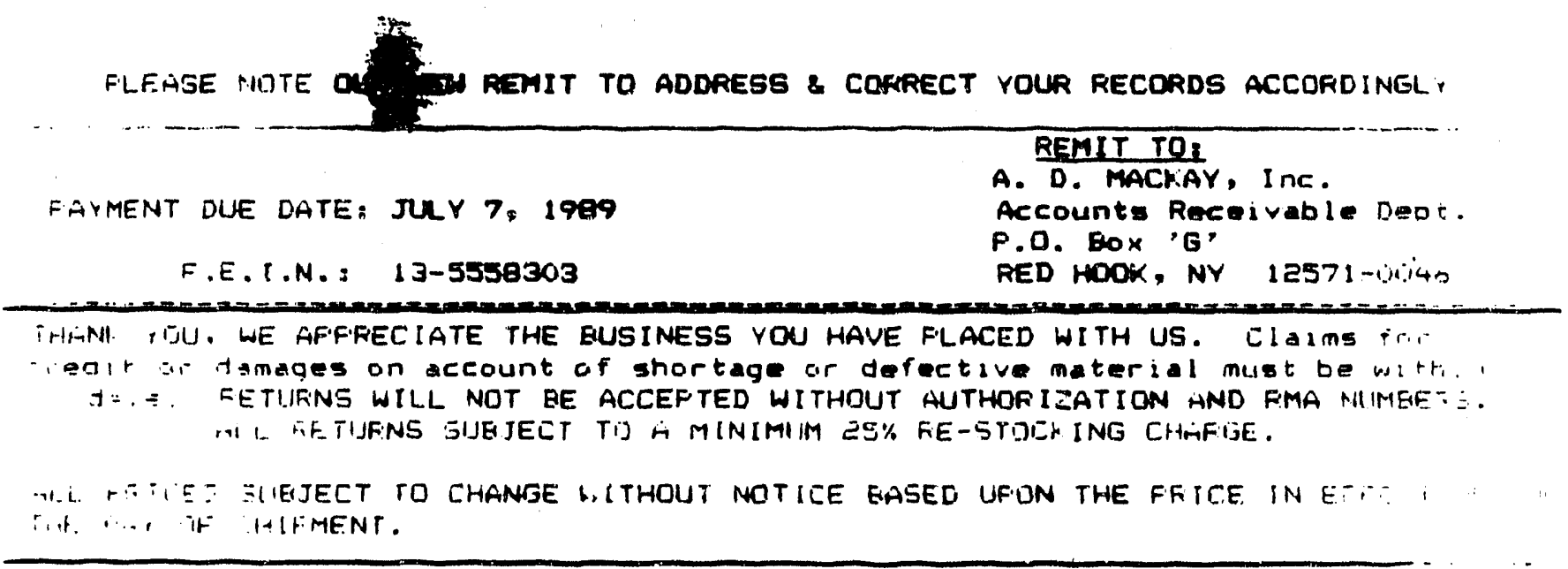




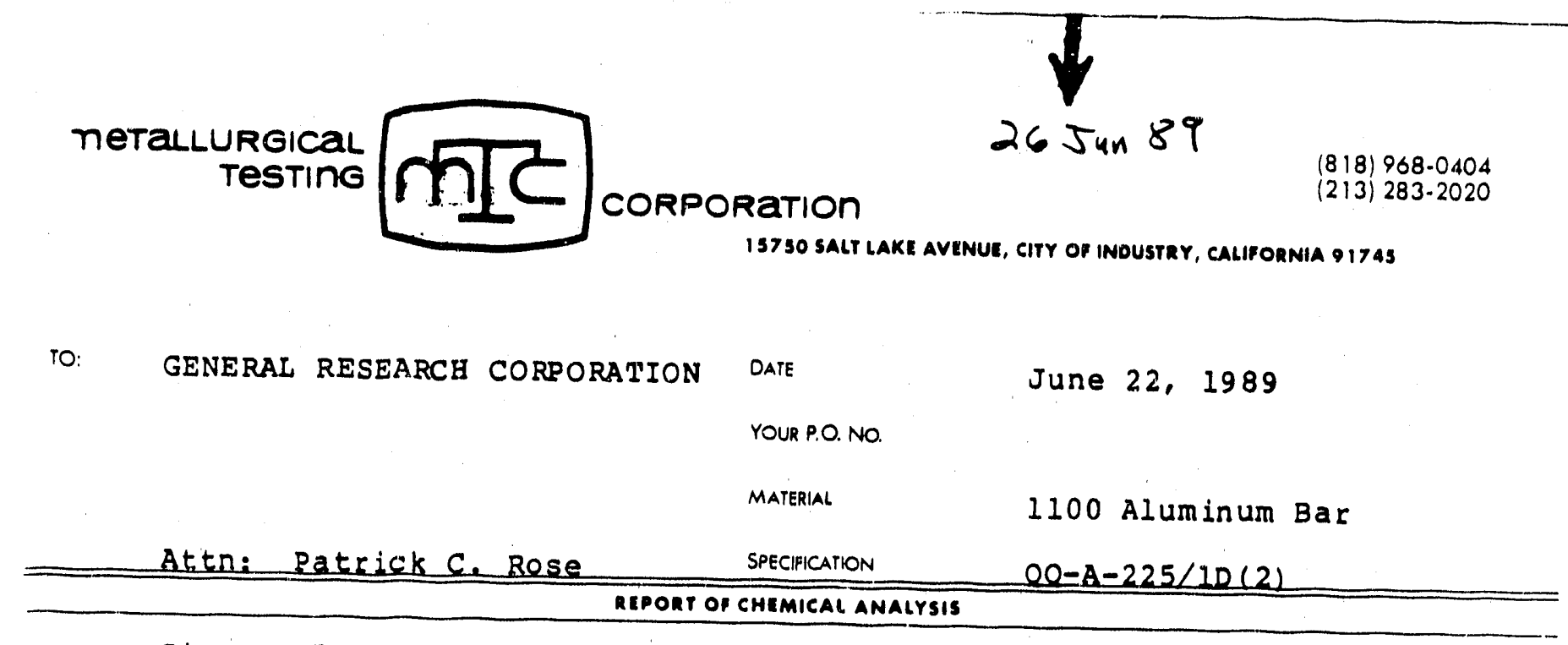

Size: 2" Diameter

Job No. 987.53

asoratokr no. 69-2605C

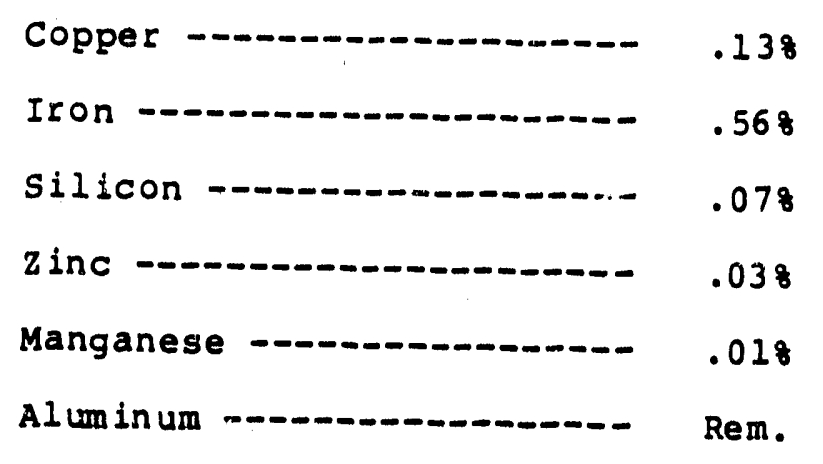

MEETS SPECIFICATION REQUIREMENTS

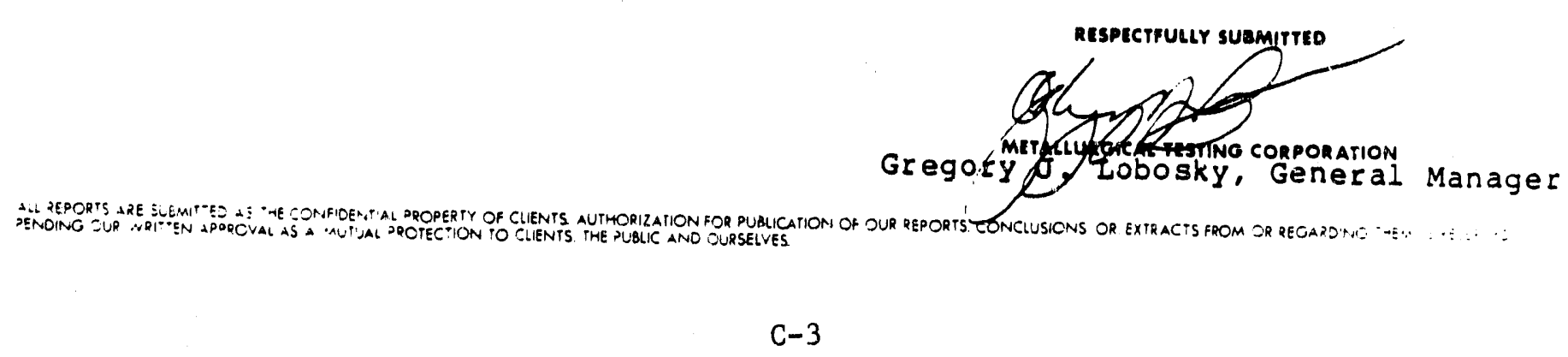




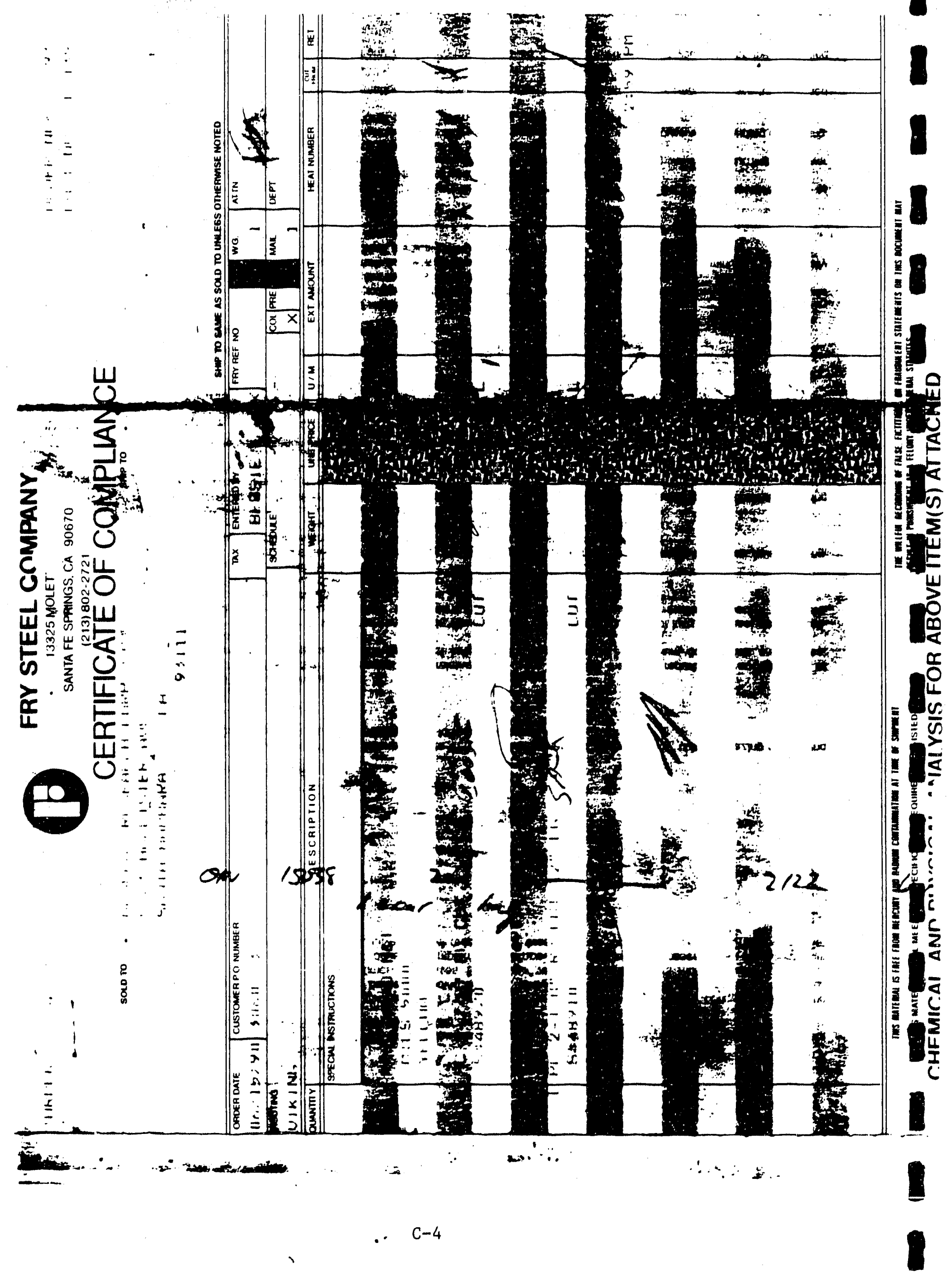




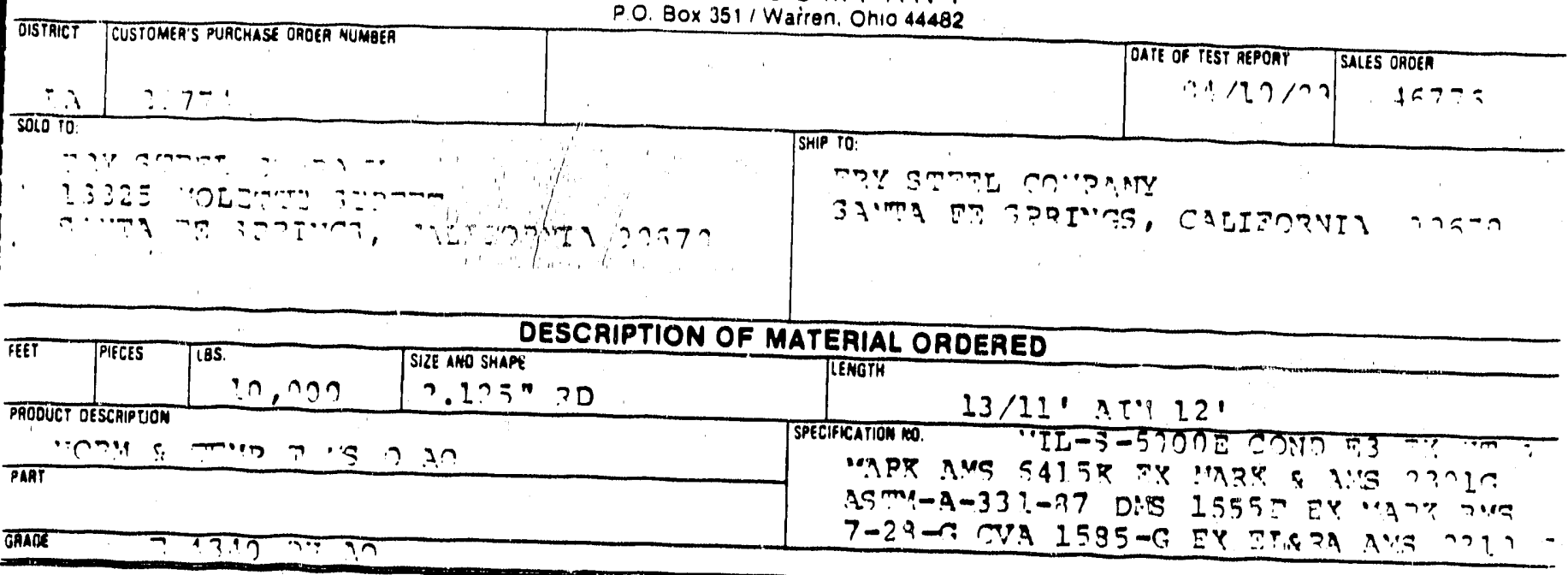

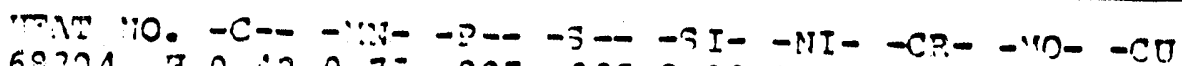

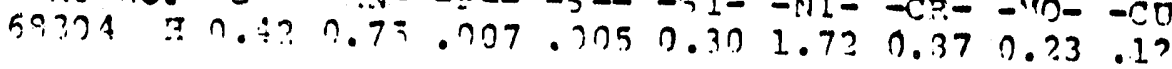

$\begin{array}{llllllllllllllllllllllllll}\text { IMIITY } & 1 & 2 & 3 & 1 & 5 & 5 & 7 & 8 & 7 & 10 & 11 & 12 & 13 & 14 & 15 & 16 & 18 & 20 & 24 & 28 & 32 & 6.2 & 3 Z Z\end{array}$

$-2-$

PMRDITESS :

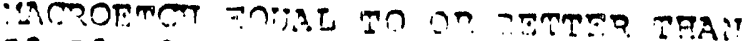

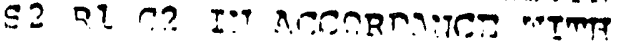

Asm? $381-79(74)$.

-

MATERIAL PAODUCED AND CERTIFIED TO SPECIFICATIONS SHOWM ABOVE. NO ADOITIONAL CEATIFICATION IS IMPLIED OA WAARANTED.
FRY STEY CO, CERTIFHS THAT THWS IS

A THUE COPY of THE ORGIMAL MILL TEST REPONT NO ON FILE RECEIVED ANO INSPECTED

APR 201989

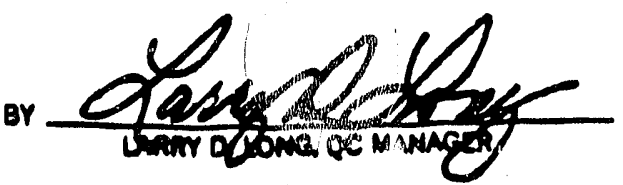

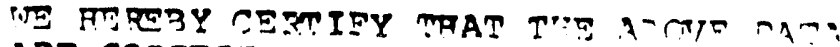
ARE CORPEC: AS COITHAIVER IN TH

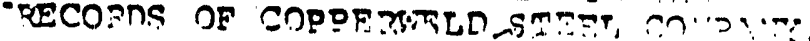
TORYL N. KIEQR :IET 7TTFASE GUPV. 


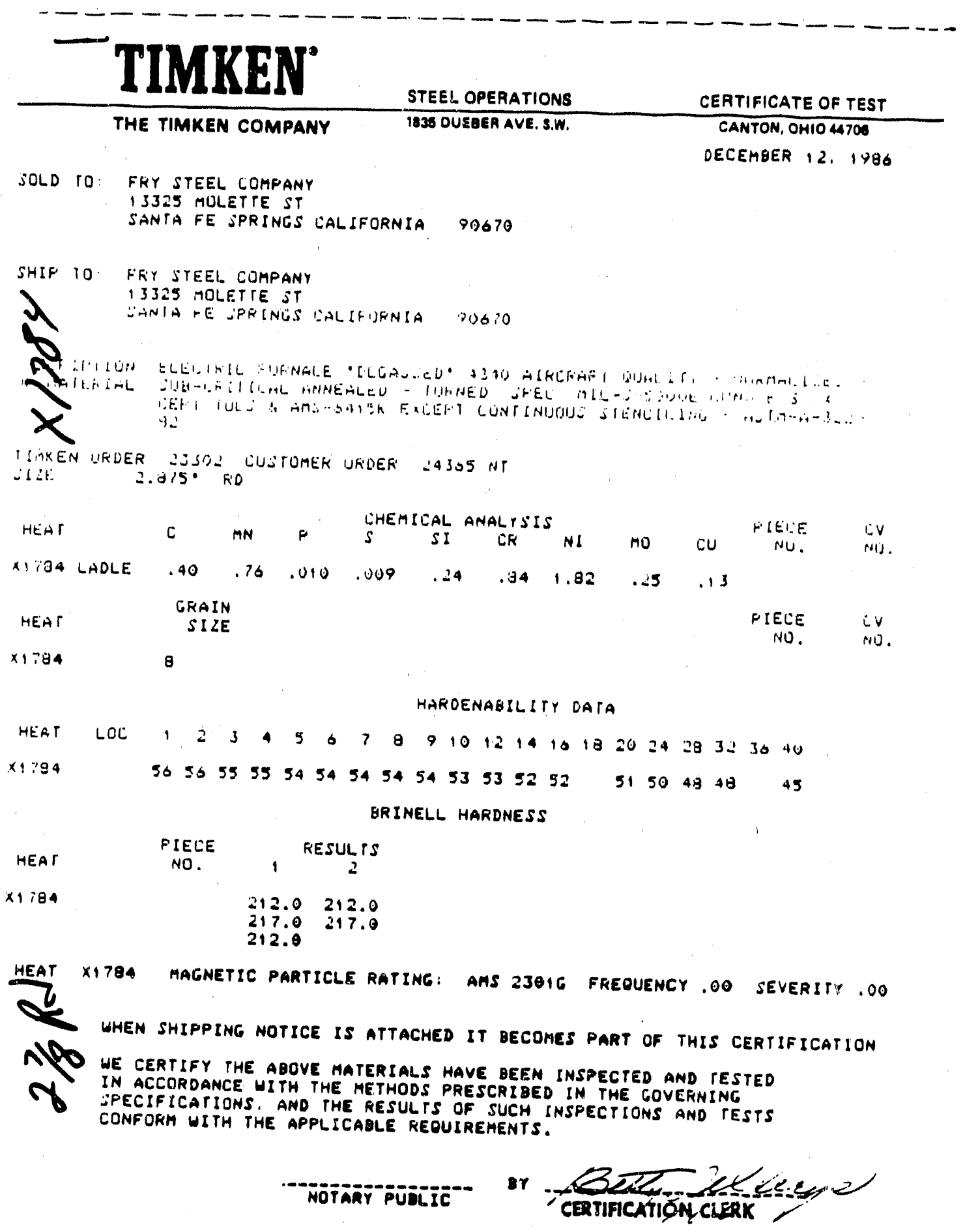


MIL-S-5000E

12 November 1982

SUPERSEUING

MIL -S - 50000

8 March 1971

\title{
MILITARY SPECIFICATION
}

STEEL, CHROME-NICKEL-MOL YBDENUM (E4340) BARS AND REFORGING STOCK

This soecification is aporoved for use by all Dedartments and Agencies of the Department of Defense.

1. SCOPE

1.1 Scode. This soecification covers electric furnace steel bars and reforging stock of aircraft auality.

1.2 Classification.

1.2.1 Physical condition. Bars shall be furnished in one of the following physical conditions, as specified (see 6.2):
(A) As forged
(B) As rolled
(C) Annealed
(D) Normalized
(E) Normalized and tempered
(F) Hardened and tempered, 130,000 psi minimum yield strength

\begin{abstract}
Beneficial comments (rocommendations, additions, deletions) and any pertinent data which may be of use in improving this document should be addressed to: Eno ineering Specifications and Standards Department (Code 93), Naval Air Engineering Center, Lakehurst, $N J$ 08733, by using the self-addressed Standardization Document Improvement Proposa? (DO Form 1426) apdearing at the end of this document or by letter.
\end{abstract}

FSC 9510 


\section{$M ! L-S-5000 E$}

1.2 .2 Surface conditions. Bars shall be furnished in one of the following conditions, as soecified (see 6.2):

(1) Black as forged or rolled

(2) Pickled or blast cleaned

(3) Rough turned

(4) Cold drawn

(5) Turned, ground, and Dolished

(6) Turned and polished

1.3 Sizes and shapes. Bars and reforaing stock shall oe urnished in the sizes and shades specifted (see 6.2).

2. APPLICABLE DOCLMENTS

2.1 Government documents.

2.1.1 Soecifications and standards. Unless otherwise soecified, the following specifications and standards of the issue listed in that issue of the Department of Defense Index of Soecifications and Standards (DoDISS) specified in the solicitation, form a part of this specification to the extent specified herein.

SPECIFICATIONS

MILITARY

MIL - I -6868

Inspection Process, Magnetic Particle

MIL - I -8950

Inspection, Ultrasonic, Wrought Metals, Process for

STANOARDS

FEDERAL

FED-TEST

METHOD-STD 151

FED-STD-183

Metals; Test Methods

Continuous Ident ification Marking of Iron and Stee I Products

STANDARDS

MILITARY

MIL-STD-163 Steal Mill Products Preparation for Shioment and Storage 


\section{MIL - S-5000E}

(Copies of specifications and standards required by contractors in connection with specific acouisition functions should be obtained from the contracting activity or as directed by contractina officer.)

2.2 Other publications. The following documents form a part of this specification to the extent specified here in. The issues of the documents which are indicated as DOD adopted shall be the issue listed in the current DoDISS and the supolement thereto, if aDdicable.

SOCIETY OF AUTOMOTIVE ENGINEERS, INC.

AMS 2301 Aircraft Quality Steel Cleanliness, Magnetic Particle inspection Procedure

(Applications for copies should be addressed to: Society of Automotive Engineers, Inc., 400 Commonwealth Drive, Warrendale, PA 15096).

AMERICAN SOCIETY FOR TESTING AND MATERIALS (ASTM)

ASTM A 29 General Requirements for tot-rolled and cold

Finished Carbon and Alloy Steel Bars

ASTM A 255 End Quench Test for Hardenability of Steels, Method of

ASTM E 8 Tension Testing of Metallic Materials, Methods of

ASTM E 10 Brinell Kardness of Metallic Materials, Test Method for

ASTM E 18 Rockwell Hardness and Rockwell Suderticial Haroness of of Metallic Materials, Test Methods for

ASTM E 112 Estimating Average Grain Size of Metals, Methods for

ASTM E 381 Macroetch Testing, Inspection, and Rating Stee 1

Products, Comprising Bars, Billets, Blooms and Forgings

(ADplications for copies should be addressed to the American Society for Testing and Materials, 1916 Race Street, Philadelphia, PA 19103).

(Industry association specifications and standards are generally available for reference from libraries. They are also distributed among technical groups and using Federal agencies).

2.3 Order of precedence. In the event of a conflict between the text of this soecification and the references cited herein, the text of this sDecification shall take precedence. 
$M I L-\supset-$ JUUUL

\section{REQUIREMENTS}

3.1 Material quality. The steel shall be oroduced by electric furnace practice and shall be of aircraft quality conforming to AMS 2301 except that a maximum average frequency $(F)$ rating of 0.34 and a maximum average severity (S) rating of 0.25 shall noply for all sizes and oroducts. In addition, AMS 2301 specimens which contain indications reoresenting non-metallic inclusions over 1.00 inch in length shall be subject to rejection.

3.1.1 Ultrasonic inspection. When specified, bars or intenmediate mill products and reforging stock shall be ultrasonically inspected in accordance with MIL-I-8950. The minimum quality level shall be as soecified below (see 4.6):

Dimensions (inches)
$1-1 / 2$ to 9 thickness
Larger than 9

Ultrasonic Classification

$1-1 / 2$ to 9 thickness

3.2 Chemical composition. The chemical composition shall be as specified in Table T.

TABLE I. Chemical Comoosition.

\begin{tabular}{|c|c|c|}
\hline Element & $\begin{array}{l}\text { Analysis } \\
\text { (percent) }\end{array}$ & $\begin{array}{l}\text { Check Analysis } \\
\text { Tolerance (Dercent) I/ }\end{array}$ \\
\hline $\begin{array}{l}\text { Carbon } \\
\text { Manganese } \\
\text { Pho sphorus } \\
\text { Sulfur } \\
\text { Silicon } \\
\text { Nickel } \\
\text { Chromiun } \\
\text { Molyodenum } \\
\text { Copper }\end{array}$ & $\begin{array}{l}0.38-0.43 \\
0.65-0.85 \\
0.025(\max ) \\
0.025(\max ) \\
0.15=0.35 \\
1.65-2.00 \\
0.70-0.90 \\
0.20-0.30 \\
0.35(\max )\end{array}$ & $\begin{array}{l} \pm 0.02 \\
\pm 0.03 \\
\mp 0.005,-0.00 \\
+0.005,-0.00 \\
\pm 0.02 \\
\mp 0.05 \\
\mp 0.03 \\
\mp 0.02 \\
\mp 0.03,-0.00\end{array}$ \\
\hline
\end{tabular}

I/ Individual determinations may varv from the specified range to the extent shown in the check analysis column, excedt that the elements in any heat shall not vary both above and below the specified range. For sizes over 100 sauare inches in cross-sectional area, the check analysis shall be negotiated.

3.3 Hardenability. End-auench hardenability values for the steel in all specified conditions shall be Rockwell C-50 minimum at $20 / 16$ inch and Rockwell C -45 minimum at $32 / 16$ inch.

3.4 Grain jize. The austenite orain size shall be oredominantly No. 5 or finer with grains as large as No. 3 dermissible. 


\section{MIL -S-5000E}

3.5 Macrostructure. Visual examination of deeo-acid-etched reforaing stock in sizes up to and including 36 square inches shall be eoual to or better than $S-2, R-1$ and $C-2$; sizes over 36 to and including 100 souare inches shall be equal to or better than $S-2, R-2$, and $C-2$ of ASTM E 381 . Product forms other than reforaing stock shall be macroscodic examined at. a section thickness not less than 3 inches and shall be equal to or better than $S-2, R-1$, and $C-2$ of ASTM E 381 .

3.6 Decarburization. Unless otherwise specified, the deoth of decarburization of products in surface condition (2) or (4) shall be not greater than the following limits (see 6.2):

\begin{tabular}{|c|c|}
\hline $\begin{array}{l}\text { Nominal Diameter or Distance } \\
\text { Between Opposite Faces (Inches) }\end{array}$ & $\begin{array}{l}\text { Maximum Deoth of } \\
\text { Decarourization (Inches) }\end{array}$ \\
\hline $\begin{array}{l}\text { Up to } 0.375 \text { inc } 1 . \\
\text { Over } 0.375 \text { to } 0.500 \text { inc } 1 \text {. } \\
\text { Over } 0.500 \text { to } 0.625 \text { inc } 1 \text {. } \\
\text { Over } 0.625 \text { to } 1.000 \text { inc } 1 \text {. } \\
\text { Over } 1.00 \text { to } 1.50 \text { incl. } \\
\text { Over } 1.50 \text { to } 2.00 \text { inc } 1 \text {. } \\
\text { Over } 2.00 \text { to } 2.50 \text { incl. } \\
\text { Over } 2.50 \text { to } 3.00 \text { incl. }\end{array}$ & $\begin{array}{l}0.010 \\
0.012 \\
0.014 \\
0.017 \\
0.020 \\
0.025 \\
0.030 \\
0.035\end{array}$ \\
\hline
\end{tabular}

1/ The value soecified as the maximum deoth of decarburization is the sum of Ehe complete plus the partial decarburization.

3.6.1 When detemining the deoth of decarburization, it is permissible to disregard local areas provided the decarburization of such areas does not exceed the limits specified in 3.6 by more than 0.005 inch and the width is 0.064 inch or less.

3.6.2 Products furnished in surface conditions (3), (5), and (6) shall be free from decarburization.

3.6.3 When intended for reforging purooses, the above decarburization limits shall not apply.

3.7 Surface and ohysical conditions. Unless otherwise soecified, bars 1-1/2 inches or less in diameter or thickness shall be furnished in condition $(C)-(4)$, and bars over $1-1 / 2$ inches in diameter or thickness shall be furnished in condition $(C)-(2)$.

3.8 Hardness limits.

3.8.1 The hardness for material in physical conditions $(C)$ and $(E)$ shall be not more than Brinell 235 (Rockwell C 22) when furnisiod in surface conditions (1), (2), or (3). 
3.8.2 The hardness for material in physical conditions (C) and (E) shall be not more than Brinel? 265 (Rockwell $(-27)$ when furnished in surface condition (4).

3.9 Mechanical orooerties of condition $(F)$ steel. Unless otherwise specified, the mechanical properties of oroducts suodied in condition $(F)$ in sizes uo to and including 3 inches in the last dimension shall conform to the limits specified in Table II (see 6.2).

TABLE II. Mechanical uroderties of condition (F) stee l. II

\begin{tabular}{|c|c|c|c|c|}
\hline $\begin{array}{c}\text { Tensile Strength } \\
(\min ) .\end{array}$ & \multicolumn{2}{|c|}{$\begin{array}{l}\text { yield Strength at } \\
0.2 \text { oercent of set or } \\
\text { extension indicated } \\
\text { (min) | Extension } \\
\begin{array}{l}\text { under load }\end{array}\end{array}$} & $\begin{array}{l}\text { Elongation } \\
\text { in } 2 \text { inen. } \\
\text { (min) }\end{array}$ & $\begin{array}{l}\text { Reduction } \\
\text { in area } \\
(\min )\end{array}$ \\
\hline psi & psi & $\begin{array}{l}\text { inches in } 2 \\
\text { inches }\end{array}$ & Dercent & percent \\
\hline 150,000 & 130,000 & 0.0127 & 14 & 53 \\
\hline
\end{tabular}

$1 /$ When products in condition $(F)$ are ordered with mechanical properties differing from those specified in 3.9 or when products in condition $(F)$ are offered in sizes larger than 3 inches in the least dimension, the mechanical properties shall be as agreed uoon the supolier and the purchaser.

3.10 Identification of product. Each bar shall be identified in recordance with FED-STD-183. The markings snall include the heat number of the metal and number of this specification. 29.

3.11 Tolerances. Tolerances shall conform to the limits of ASTM A

3.12 Workmanship. Material shall be sound, of uniform ouality and condition, free from pioes, and shall not contain laos, cracks, twists, seams, or other defects detrimental to the fabrication or performance of parts. Steel melting practice shall produce metal complying with all requirements of this specification.

3.12.1 Cold drawn bars. Cold drawn bars shall be free from scale. Drawing shall oe accomplished after all heat-treating oderations ave been combleted; nowever, stress relieving should be accomplished after drawing. 


\section{QUALITY ASSURANCE PROVISIONS}

4.1 Resporsibility for insoection. Un less otherwise soecified in the contract or Durchase order, the contractor is responsible for the performance of all inspection reauirements as soecified herein. Exceot as otherwise specified, the contractor may utilize his own facilities or any commercial laboratory accedtable to the Government. The Government reserves the right to perform any of the inspections set forth in the specification where such inspections are deemed necessary to assure supdies and services conform to prescribed requirements.

4.2 Classification of tests. All the tests reauired for the testing of the product are classified as accedtance tests, for which necessary sampling techniaues and methods of testing are soecified in inis section.

4.2.1 Inspection conditions. Unless otherwise soecified, all inspections shall be preformed in accordance with the test conditions specified in the apolicable test method document or apolicable oaragraph(s) in the specification.

4.2.2 Inspection lot. An insoection lot shall include all mill forms of one heat, condition and size oresented for acceptance at one time, and when heat treated, from the same process and the same batch.

4.3 Examination of oroduct. Samoles selected at random in accordance with Table II! shall be examined for combliance with surface condition, identification, dimensional, marking, workmanship, and preparation for delivery requirements.

TABLE-III. Sampling for examination of Droduct.

\begin{tabular}{|l|c|c}
\hline Lot Size & Sample Size & Acceptance number \\
\hline 1 to 65 & 4 & 0 \\
66 to 110 & 5 & 0 \\
11 to 300 & 7 & 0 \\
301 to 500 & 10 & 0 \\
501 to 800 & 15 & 0 \\
Over 800 & 25 & \\
\hline
\end{tabular}

4.4 Chemical analysis.

4.4.1 Sampling. Samples for check chemical analysis shall be selected to reoresent each heat $s$ steel in accordance with requirements of method 111.2 of Federal Test Method St andard No. 151.

4.4.2 Specimens. Samoles for check chemical analysis shall be taken Darallel to the axis of the billet seiected, at a point midway between the center and surface, exceot that material less than $1 / 4$ inches thick shall be sampied through the entire cross-section. The sampie shall consist of not less than 2 ounces of material. 
4.4.3 Test method. Samoles shall be Dreoared in accordance with Method 111.2 of Federal Test Method Standard No. 151, and shall be testeo by wet chemical, soectrograohic, or other analytical methods. In the event of disoute, analysis shail be wet chemical methods.

4.5 Steel cleanliness insoection. The material shall be mognetic Darticle inspected in accordance witn MIL-I-6868 to comply with the steel cleanliness requirements of AMS 2301.

4.6 Ui:rasonic inspection. Insoection shall be in accordance with MIL-I-8950. Surface roughness shall not exceed 125 roughness height rating (RHR) at 5 meoahertz ( $\mathrm{mhz}$ ) and 250 RHR at $2.25 \mathrm{mhz}$ and lower frequencies. The surface roughness of the reference standards shall not vary more than olus or minus 25 RHR from the surface roughness of material being tested.

\subsection{Hardenability.}

4.7.1 Sampling. One or more samoles for end-quench hardenability test shall be selected from each heat of steel from which material is oresented for acceptance.

4.7.2 Preoaration of soecimens. Specimens for the end-quench hardenability test shall conform to ASTM A 255. The steel shall be nomalized prior to machining the test specimen by heating $1,6000 \pm 100 \mathrm{~F}$, holding at this temperature for $i$ hour and cooling in still air.

4.7.3 Test method. End-quench hardenability test shall be conducted in accordance with ASTM A 255 . Soecimens shall be austenitized at $1,550^{\circ} \pm$ 100F. Tests shall establish compliance with 3.3 .

\subsection{Grain size.}

4.8.1 Samplina. One or more samoles shall be selected to reoresent each heat of steel from which material is submitted for acceptance.

4.8.2 Test method. Soecimens shall be sectioned and polished to appropriate fineness by metallographic methods and suitably etched to reveal the grain structure. The austentite grain size shall be determined in accordance with ASTM $\varepsilon 112$.

\subsection{Macrostructure.}

4.9.1 Sampling. Two or more sample slices at least $1 / 4$ inch thick shali be selected to represent each heat of steel from which material is submitted ior acceotance.

4.9.2 Procedure. The samples shall be prepared in accordance with ASTM E 381. The etched samples shall meet the reouirements of 3.5 .

\subsection{Decarburization.}

4.10.1 Sampling. If the ourchaser has reason to susoect that the decarburization limits soecified herein may have been exceeded, samoles shali be selectec for determination of the deden of decarburization. 
4.10.2 Test method. Depth of the zone of decarburization below a surface shall be determined by examination of a metallographic specimen or specimens reoresenting the entire cross section of bars 1 inch or less in diameter or width. With bars of 1 inch in diameter, the section shall exhibit not less than 1 linear inch of the original surface of the bar. This specimen shall be oolished, etched with 5 percent nital, and examined at $100 x$ magnification.

4.11 Hardness of bars in ohysical conditions (C) and (E).

4.11.1 Sampling. At least five bars of each condition and size shall be tested to determine conformance with hardness values of 3.8 . When less than five bars are ordered, each bar shall be tested.

4.11.2 Test method. Hardness testing shall conform to ASTM $E 10$ or ASTM E 18.

4.12 Mechanical properties of condition (F) steel.

4.12.1 Sampling. One or more samoles shall be selected from the lot.

4.12.2 Specimens. Tensile test specimens shall conform to the round type specimens of ASTME 8 . For bars up to $11 / 2$ inches in diameter or thickness, the axis of the test specimen shall coincide with the central axis of the bar; for bars $11 / 2$ inches and over, the axis shall be located midway between the center and the surface of the bar. The axis of specimens shall be parallel to the direction of rolling or drawing.

4.12.3 - Test method. Tensile tests shall be conducted in accoraance with ASTM E 8. Yield strength shall be determined by the offset or extension-under-load methods.

4.13 Certified test reoorts. Heats which have been tested and found to comply with the requirements of this specification shall be acceptable. Each shipment from these heats shall be accompanied by test reports, in duplicate, showing compliance with requirements for chemistry, hardenability, mechanical properties, arain size, ultrasonic properties, macrostructure and magnetic particle frequency/severity ratings.

4.14 Rejection and retest. Failure of a specimen to comply with specified requirements shall cause rejection of the materials represented. However, at the discretion of the contractor/supplier, retest will be Denmitted. A retest sample of five specimens, one from each of $f$ ive bars, shall be tested to renlace each failed soecimen from the original sample. If one retest specimen fails, the materials represented shall be rejected. Rejected material may be reprocessed and resubmitted.

4.15 Packaging. Packaging shall be examined for conformance to section 5 . 
5. PACKAGING

\subsection{Packaging.}

$5.1 .1 \quad$ Level A. The materials shall be orooerly separated by condition and size when orepared for delivery. The bars shall be oreserved and packaged in accordance with MIL-STO-163.

5.1 .2 Level C. The material shall be preserved and pacxagec in accordance with commercial practice.

\subsection{Packing.}

5.2.1 Level A. The material shall be packed in accordance with MIL-STD-163.

5.2.2 Level $C$. The materials shall be orepared for shioment in accordance with commercial practice to assure carrier acceptance and safe transportation at the lowest rate to the point of delivery and shall meet, as a minimum, the requirements of carrier rules and regulations adolicable to the
mode of transportation.

5.3 Markina of shipments. Marking and labeling shall be in accordance with MIL-5TO- 163.

6. NOTES

6.1 Intended use. Steel covered by this specification is intended for usc in the manufacture of highly stressed a ircraft parts reuviring high.
hardenability.

6.2 Ordering data. Procurement documents should specify the
lowing: following:

a. Title, number, and date of this specification.

b. Physical and surface conditions. (See 1.2.1, 1.2.2, and 3.9.1).

c. Size and shape.

d. When bars are intended for reforging purooses, it should be so stated.

e. If decarburization limits closer than those specified in 3.6 are described.

f. Exact lengths and length tolerances, if mill lenoths are not acceptable.

9. Levels of packaging and packing required (see section 5).

n. Whether ultrasonic inspection is required (see 3.1.1). 
6.3 Changes from orevious issue. Asterisks are not used in this revision to identify changes with respect to the orevious issue due to the extensiveness of the chanaes.

Custodians:

Anmy - MR

Navy - AS

Air Force - 20

Review activities:

Anmy - EA, ER, MI

Air Force - 99

OLA - IS

User activities:

Anmy - AT
Preparing activity:

Navy - AS

(Project No. 9510-0370)

8 


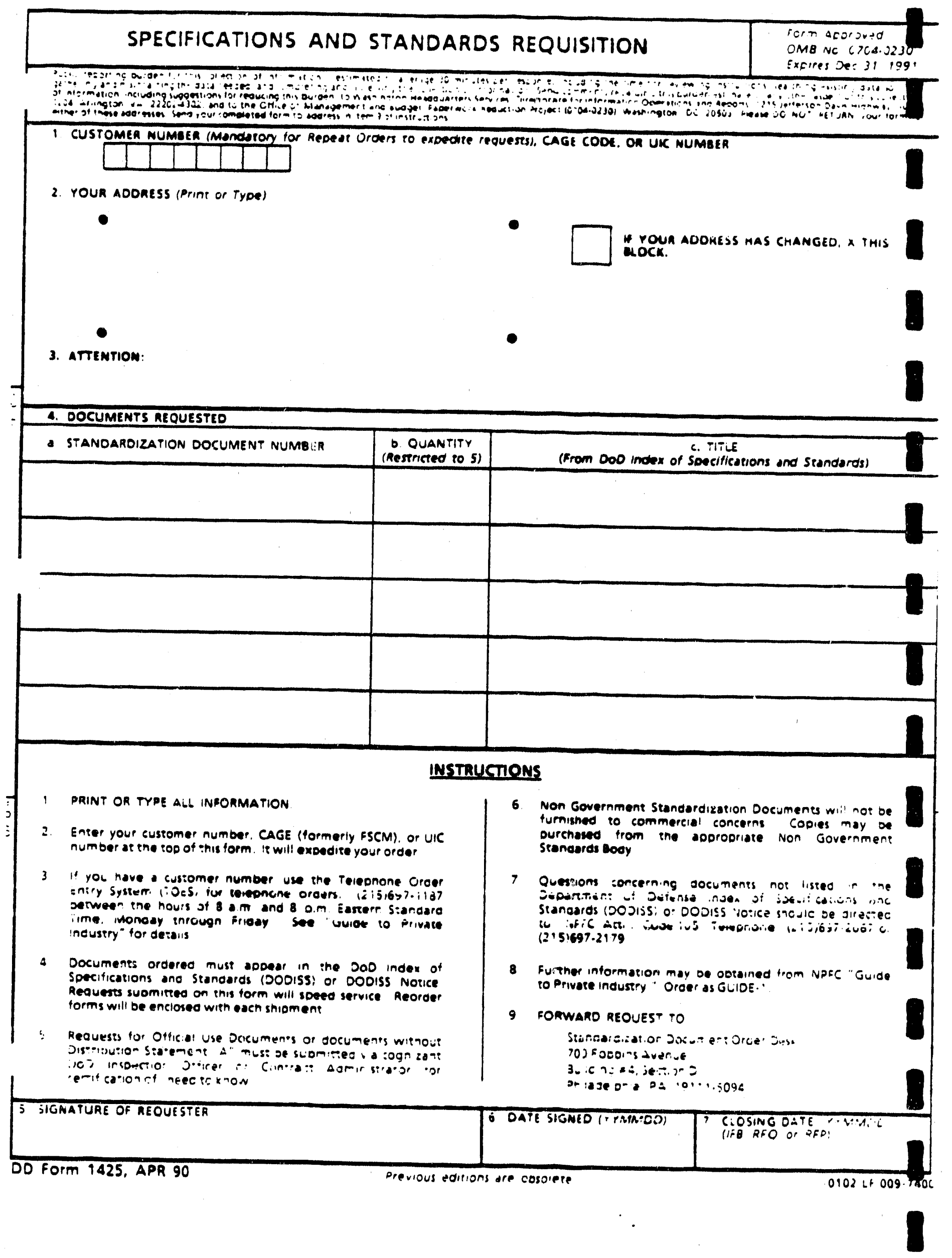


IASTRUCTIONS: In a contununs effor to make our standardization documente bethe, the DoD provides thin form for une in

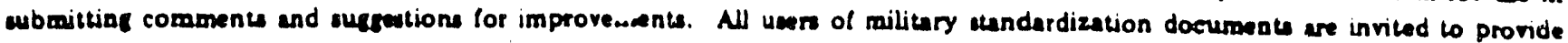
aresention. This form may t, detached, folded along the lines indicaled, wped along the looke odye (DO NOT STAPLE), and

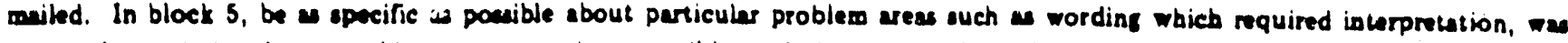
100 ngid, restrictive, looke, ambiguous, or wes incompatible, and give propoced wording changes which would alleviake the problems. Enter is block 6 any remarks not related to a epecific paragraph of the document. If block 7 is filled out, an acknowledgement will be miled to you mthin 30 days to lot you know that your comments were received and are beins concidered.

NOTE. This form $\mathrm{m} \cdot \mathrm{y}$ not be used to request copies of documents, nor to request aiven, devistions, or clarification of specification requirements on current contracts. Comments subinitted on this form do not conatitute or imply authorization to waive any portion of the referenced document(o) or to amend contractual requirements.

DEPARTMENT OF THE NAVY

Commanding officer

Naval Air Engineering Center

Systems Engineering Standardization Department

(SESD), Code 93

Lakehurit. NJ 08733

official Busines:

denaltr ron pmivate use 8300

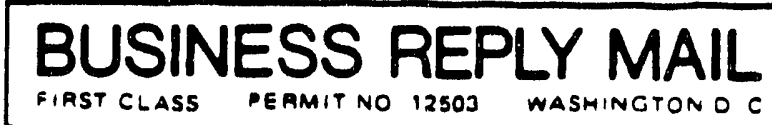

POSTAGE WILL BE PAID BY THE DEPAATMENT OF THE NAVY

Commanding Officer

Naval Air Engineering Center

Systems Engineering Standardization Department

(SESD). Code 93

Lakehurst, NJ $087 \overline{3}$
NO mostage

NGCESPAAY

IF MAILEO

IN THE

UNITED STATES
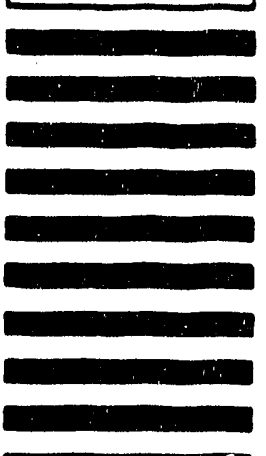

ATTN: TJM (9322) 


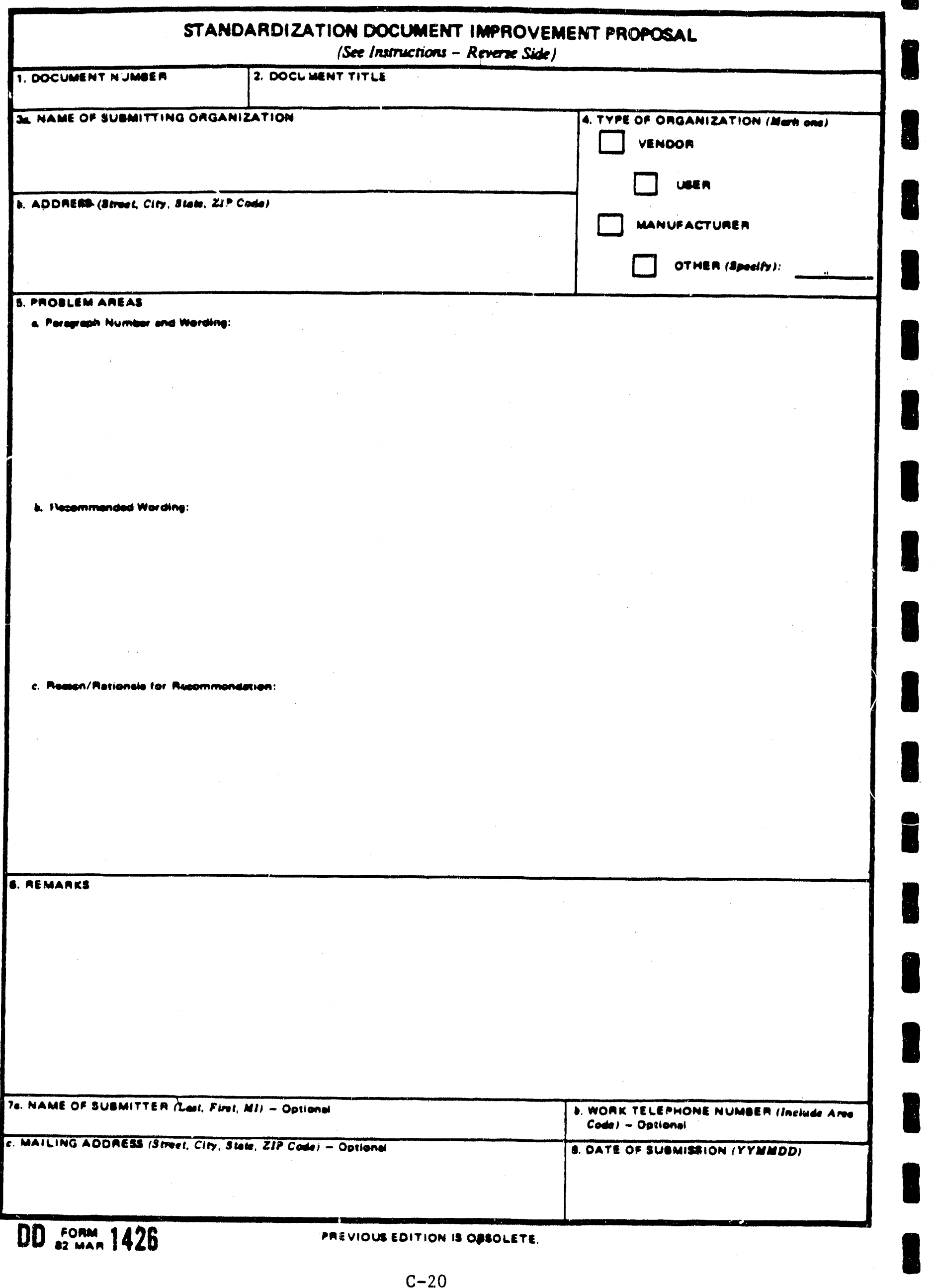



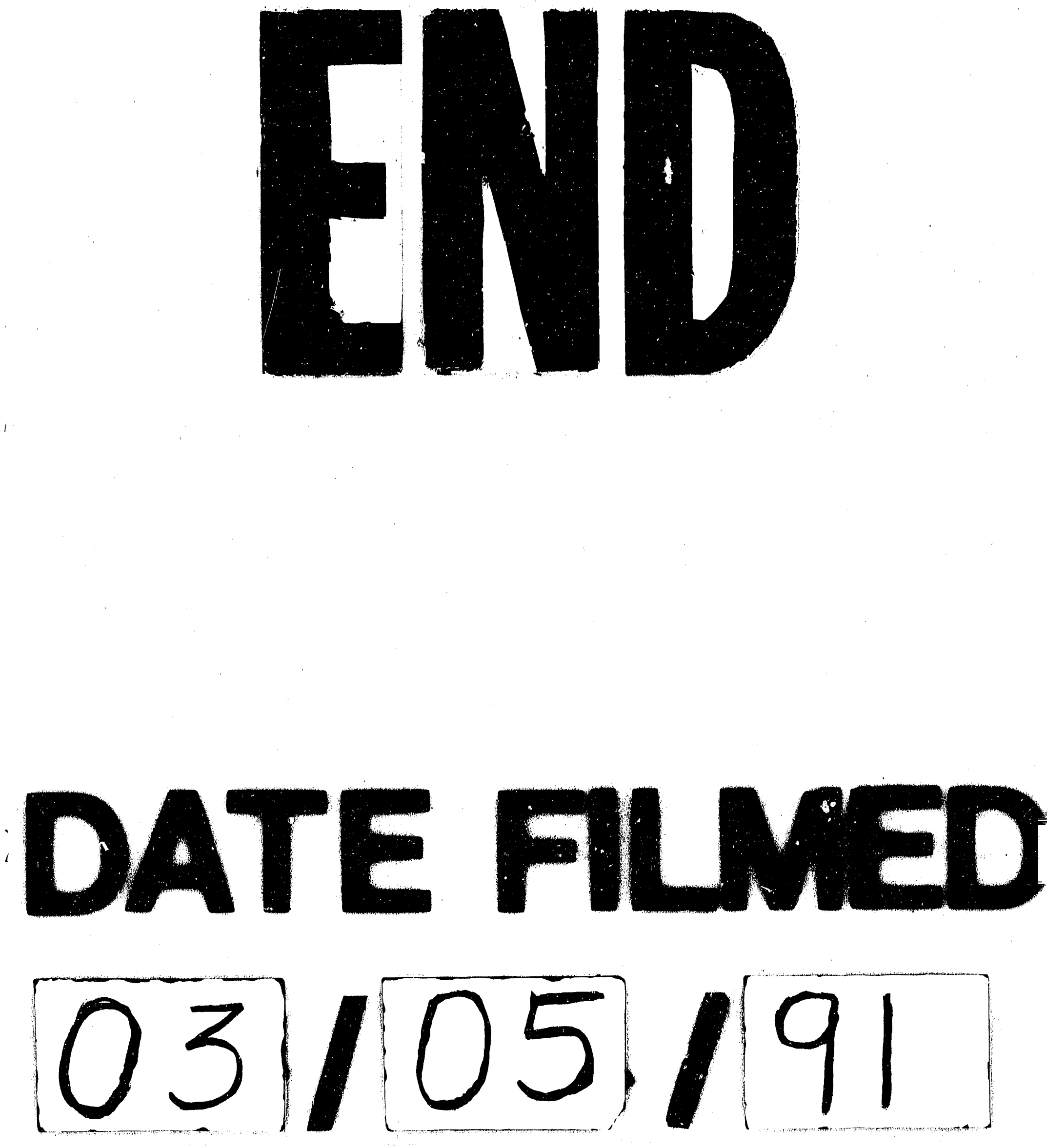
